Illinois State University

ISU ReD: Research and eData

Theses and Dissertations

$4-5-2018$

\title{
The Role of Dogs in Prehistoric Illinois: A Study of Dog Paleopathology at the Range Site in the American Bottom
}

Allison L. Huber

Illinois State University, ahuber50@gmail.com

Follow this and additional works at: https://ir.library.illinoisstate.edu/etd

Part of the History of Art, Architecture, and Archaeology Commons

\section{Recommended Citation}

Huber, Allison L., "The Role of Dogs in Prehistoric Illinois: A Study of Dog Paleopathology at the Range Site in the American Bottom" (2018). Theses and Dissertations. 864.

https://ir.library.illinoisstate.edu/etd/864

This Thesis is brought to you for free and open access by ISU ReD: Research and eData. It has been accepted for inclusion in Theses and Dissertations by an authorized administrator of ISU ReD: Research and eData. For more information, please contact ISUReD@ilstu.edu. 


\title{
THE ROLE OF DOGS IN PREHISTORIC ILLINOIS: A STUDY OF DOG
}

PALEOPATHOLOGY AT THE RANGE SITE IN THE

AMERICAN BOTTOM

\begin{abstract}
ALLISON L. HUBER
141 Pages

Archaeological investigations at the Range site (11S47) in the American Bottom region of Illinois resulted in the recovery of over 3,300 domestic dog (Canis familiaris) remains. Fiftytwo dog burials associated with the Late Woodland Patrick phase (A.D. 650-900) and Terminal Late Woodland Period (A.D. 900-1050) were identified in the assemblage. The well-preserved nature of these remains allowed for the examination and interpretation of pathology and trauma, providing insight into the role and treatment of dogs at the site. The data obtained from the Range assemblage indicate the most common pathologies present are antemortem tooth absence, periodontal disease, cranial trauma, rib fractures, and vertebral trauma. Based on archaeological investigations and ethnohistoric accounts, the Range dogs likely served primarily as beasts of burden and although they likely endured harsh treatment, there is also evidence that sick or crippled dogs were well cared for. The patterns observed at Range compare favorably with other sites in the American Bottom region that have canid remains.
\end{abstract}

KEYWORDS: Canis familiaris; Domestic Dog; Paleopathology; The Range Site; Illinois 
THE ROLE OF DOGS IN PREHISTORIC ILLINOIS: A STUDY OF DOG

PALEOPATHOLOGY AT THE RANGE SITE IN THE

AMERICAN BOTTOM

ALLISON L. HUBER

A Thesis Submitted in Partial

Fulfillment of the Requirements

for the Degree of

MASTER OF SCIENCE

Department of Sociology and Anthropology

ILLINOIS STATE UNIVERSITY

2018 
(C) 2018 Allison L. Huber 
THE ROLE OF DOGS IN PREHISTORIC ILLINOIS: A STUDY OF DOG PALEOPATHOLOGY AT THE RANGE SITE IN THE AMERICAN BOTTOM

\author{
ALLISON L. HUBER
}

COMMITTEE MEMBERS:

Abigail Stone, Chair

James Skibo

Steven Kuehn 


\section{ACKNOWLEDGMENTS}

I would first like to thank Dr. Abby Stone, my committee chair and advisor, for all of her support and guidance throughout this process. Her thought-provoking questions challenged and motivated me to not just earn my Master's degree, but also end up with research and writing of which I was legitimately proud. I would also like to thank the other members of my committee, Dr. Jim Skibo for his suggestions, and Steven Kuehn for encouragement, advice, and patience throughout the analysis and writing process.

I would also like to thank Dr. Thomas Emerson and the Illinois State Archaeological Survey for allowing me to analyze the Range site faunal assemblage. I also thank Laura Kozuch, Mary Hynes, Kris Hedman, and Jolene Kuehn for their assistance with the curation, imagery, and photography aspects of this project.

Finally, I would like to give special thanks to my family for their unfailing support, encouragement, and counsel throughout my academic career. I thank my little brother, Steven, for always having a hug for me when life felt overwhelming and I thank my boyfriend, Andy Schuessler, who never stopped telling me that I could do this.

A. L. H. 


\section{CONTENTS}

Page

ACKNOWLEDGMENTS

TABLES $\quad$ ix

FIGURES

CHAPTER I: INTRODUCTION 1

CHAPTER II: IMPORTANCE OF DOGS IN NATIVE AMERICAN SOCIETY 5

$\begin{array}{ll}\text { Past Research } & 7\end{array}$

CHAPTER III: THE AMERICAN BOTTOM REGION AND THE RANGE SITE (11S47) 10

$\begin{array}{ll}\text { The Floodplain } & 10\end{array}$

$\begin{array}{ll}\text { Colluvial Veneers and Alluvial Fans } & 12\end{array}$

$\begin{array}{ll}\text { The Uplands } & 12\end{array}$

The Woodland Period in the American Bottom 13

The Early Woodland Period (cal. 900 B.C.—150 B.C.) 13

The Middle Woodland Period (cal. 150 B.C.-A.D. 400) 14

The Late Woodland Period (cal. A.D. 400-900) 14

The Patrick phase (cal. A.D. 650-900) 15

The Sponemann phase (cal. A.D. 650-900) 16

The Terminal Late Woodland period (cal. A.D. 900-1050) 17

$\begin{array}{ll}\text { The Dohack phase (ca. A.D. 900-950) } & 18\end{array}$

$\begin{array}{ll}\text { The Range phase (cal. A.D. 950-975) } & 18\end{array}$

The George Reeves phase (ca. A.D. 975-1010) 19

$\begin{array}{ll}\text { The Lindeman phase (ca. A.D. 1010-1050) } & 19\end{array}$ 
$\begin{array}{ll}\text { The Range Site (11S47) } & 20\end{array}$

$\begin{array}{ll}\text { Site Description and Locale } & 20\end{array}$

History of Excavations at Range $\quad 21$

$\begin{array}{ll}\text { Analytical approach and methodology } & 22\end{array}$

The Late Woodland Occupation of the Range Site 22

Late Woodland Patrick phase occupation at the Range site 23

$\begin{array}{ll}\text { Patrick phase canid remains } & 24\end{array}$

The Terminal Late Woodland occupation at the Range site 26

$\begin{array}{ll}\text { Dohack phase canid remains } & 26\end{array}$

$\begin{array}{ll}\text { Range phase canid remains } & 28\end{array}$

$\begin{array}{ll}\text { George Reeves phase canid remains } & 28\end{array}$

$\begin{array}{ll}\text { Lindeman phase canid remains } & 28\end{array}$

CHAPTER IV: DOG PALEOPATHOLOGY 30

$\begin{array}{ll}\text { Dental Paleopathology } & 30\end{array}$

$\begin{array}{ll}\text { Skeletal Paleopathology } & 31\end{array}$

CHAPTER V: METHODOLOGY 35

Dog Classification 36

$\begin{array}{ll}\text { Burial Context } & 37\end{array}$

$\begin{array}{ll}\text { Age Distributions } & 38\end{array}$

$\begin{array}{ll}\text { Sex Distributions } & 39\end{array}$

$\begin{array}{lr}\text { Basioccipital Form } & 40\end{array}$

Table Test/Humerus Roll

$\begin{array}{ll}\text { Sagittal Crest } & 42\end{array}$ 
Mandibular-Condyloid Ridge $\quad 42$

$\begin{array}{ll}\text { Superior Nuchal Line } & 42\end{array}$

$\begin{array}{ll}\text { Discriminant Analysis } & 42\end{array}$

$\begin{array}{ll}\text { Dental Paleopathology } & 43\end{array}$

Antermortem Tooth Fracture $\quad 44$

$\begin{array}{ll}\text { Periodontal Disease } & 44\end{array}$

$\begin{array}{ll}\text { Abscess } & 45\end{array}$

$\begin{array}{ll}\text { Antemortem Tooth Absence } & 45\end{array}$

$\begin{array}{ll}\text { Skeletal Paleopathology } & 47\end{array}$

$\begin{array}{ll}\text { Cranial Trauma } & 48\end{array}$

$\begin{array}{ll}\text { Vertebral Trauma } & 48\end{array}$

Scapular, Pelvic, and Appendicular Trauma $\quad 49$

CHAPTER VI: DESCRIPTION OF DOG BURIALS 53

Late Woodland-Patrick Phase 53

Dog F\#431-1 (Adult, Male) 53

Dog F\#441-1 (Adult, Indet.) 55

Dog F\#441-2 (Pup, Indet.) 56

Dog F\#441-3 (Adult, Male) $\quad 56$

Dog F\#798-1 (Adult, Indet.) 56

Dog F\#2036-1 (Adult, Indet.) 57

Dog F\#2631-1 (Adult, Indet.) 57

Dog F\#2813-1 (Pup, Indet.) 58

Dog F\#2820-1 (Pup, Indet.) 58 
Dog F\#2900-1 (Adult, Indet.) 58

Dog F\#3765-1 (Adult, Male) 58

Dog F\#3765-2a-d (Pup, Indet.)

Dog F\#3768-1 (Pup, Indet.) $\quad 60$

Dog F\#4449-1 (Adult, Indet.) 60

Dog F\#4819-1 (Adult, Likely Male) $\quad 60$

Dog F\#4852-1 (Adult, Indet.) 63

Dog F\#5010-1 (Adult, Indet.) 63

Dog F\#5027-1 (Young Adult, Indet.) 63

Dog F\#5100-1 (Pup, Indet.) 64

Dog F\#5128-1 (Adult, Indet.) 64

Dog F\#5263-1 (Adult, Female) 64

Dog F\#5586-1 (Older Adult, Male) 65

Terminal Late Woodland_-Dohack Phase $\quad 65$

Dog F\#2368-1 (Young Adult, Likely Male) 65

Dog F\#2915-1 (Older Adult, Male) 66

Dog F\#3370-1 (Adult, Indet.) 67

$\begin{array}{ll}\text { Dog F\#3625-1 (Adult, Indet.) } & 68\end{array}$

Dog F\#3867-1 (Young Adult, Indet.) 68

Dog F\#3867-2 (Young Adult, Indet.) 68

Dog F\#4246-1 (Adult, Male) $\quad 69$

Dog F\#4887-1 (Pup, Indet.) 69

Dog F\#5197-1 (Young Adult, Female) 69 
$\begin{array}{ll}\text { Dog F\#5314-1 (Adult, Indet.) } & 70\end{array}$

Dog F\#5328-1 (Older Adult, Possibly Male) $\quad 70$

Dog F\#5385-1 (Adult, Male) $\quad 71$

Terminal Late Woodland-Range Phase $\quad 72$

Dog F\#156-1 (Pup, Indet.) $\quad 72$

$\begin{array}{ll}\text { Dog F\#387-1 (Adult, Likely Male) } & 72\end{array}$

Dog F\#904-1 (Adult, Indet.) $\quad 72$

$\begin{array}{ll}\text { Dog F\#3093-1 (Adult, Male) } & 73\end{array}$

$\begin{array}{ll}\text { Dog F\#4011-1 (Pup, Indet.) } & 73\end{array}$

Terminal Late Woodland-George Reeves Phase 73

$\begin{array}{ll}\text { Dog F\#1769-1 (Adult, Indet.) } & 73\end{array}$

Dog F\#2340-1 (Pup, Indet.) 73

Dog F\#2541-1 (Pup, Indet.)

Dog F\#5047-1 (Pup, Indet.) 74

$\begin{array}{ll}\text { Dog F\#5047-2 (Adult, Male) } & 74\end{array}$

$\begin{array}{ll}\text { Dog F\#5047-3 (Pup, Male) } & 75\end{array}$

Dog F\#5159-1 (Pup, Indet.) 76

Terminal Late Woodland_Lindeman Phase $\quad 76$

Dog F\#1919-1 (Pup, Indet.)

Dog F\#2335-1 (Pup, Indet.) 76

$\begin{array}{ll}\text { Dog F\#2978-1 (Adult, Indet.) } & 78\end{array}$

$\begin{array}{ll}\text { CHAPTER VII: RESULTS } & 79\end{array}$

$\begin{array}{ll}\text { Dog Classification } & 79\end{array}$ 
Age Distribution

$\begin{array}{ll}\text { Sex Distribution } & 80\end{array}$

$\begin{array}{ll}\text { Dental Paleopathology } & 81\end{array}$

$\begin{array}{ll}\text { Periodontal Disease } & 81\end{array}$

Antemortem Tooth Absence $\quad 83$

$\begin{array}{ll}\text { Antemortem Tooth Fracture } & 83\end{array}$

$\begin{array}{ll}\text { Abscess } & 84\end{array}$

$\begin{array}{ll}\text { Skeletal Paleopathology } & 84\end{array}$

$\begin{array}{ll}\text { Cranial Trauma } & 85\end{array}$

$\begin{array}{ll}\text { Vertebral Trauma } & 86\end{array}$

$\begin{array}{ll}\text { Spinous process anomalies } & 86\end{array}$

$\begin{array}{ll}\text { Osteophytes and ankylosis spondylitis } & 87\end{array}$

$\begin{array}{ll}\text { Fractures of the transverse processes and centrum } & 87\end{array}$

$\begin{array}{lr}\text { Rib Trauma } & 88\end{array}$

$\begin{array}{ll}\text { Scapular and Pelvic Trauma } & 89\end{array}$

$\begin{array}{ll}\text { Appendicular Trauma } & 90\end{array}$

$\begin{array}{ll}\text { Cut Marks } & 91\end{array}$

Isolated Remains $\quad 91$

CHAPTER VIII: DISCUSSION 93

Intra-site Comparisons $\quad 93$

Distribution and Location Patterns $\quad 93$

$\begin{array}{ll}\text { Burial Types } & 94\end{array}$ 
$\begin{array}{ll}\text { Age Distributions } & 95\end{array}$

$\begin{array}{ll}\text { Sex Distributions } & 95\end{array}$

$\begin{array}{ll}\text { Dental Pathology } & 96\end{array}$

$\begin{array}{ll}\text { Skeletal Pathology } & 98\end{array}$

$\begin{array}{ll}\text { Inter-site Comparisons } & 101\end{array}$

$\begin{array}{ll}\text { CHAPTER VIIII: CONCLUSION } & 108\end{array}$

$\begin{array}{ll}\text { REFERENCES } & 110\end{array}$

APPENDIX A: CANID AGE DETERMINATION CHART 125

APPENDIX B: CANID MEASUREMENTS (HAAG 1948) 126 


\section{TABLES}

Table

Page

1. Dog Burial Categories $\quad 37$

2. Dog Burial Classification for the Range Assemblage 79

3. Age Distribution of the Range Assemblage $\quad 80$

4. Sex Distribution of the Range Assemblage 81

5. Dental Pathology Observed in the Range Assemblage 82

6. Summary of Skeletal Trauma Observed in the Range Assemblage 84

7. Cranial Trauma Observed in the Range Assemblage 86

8. Vertebral Trauma Observed in the Range Assemblage 88

9. Inter-Site Comparison of Vertebral Trauma 104

10. Inter-Site Comparison of Cranial and Rib Trauma 105

11. Inter-Site Comparison of Dental Pathology 107 


\section{FIGURES}

Figure $\quad$ Page

1. Map of the American Bottom Region 11

2. Patrick Phase Occupation Areas 25

3. Dohack and Range Phase Occupation Areas 27

4. George Reeves and Lindeman Phase Occupation Areas 29

5. Dog F\#2915-1, Extensive Alveolar Reabsorption in the Left Mandible After Loss of First and Second Premolars $\quad 31$

6. Dog F\#2915-1, Bent Spinous Processes Observable on the Thoracic Vertebrae 32

7. Dog F\#5010-1, Ankylosis Spondylitis Observable on the Thirteenth Thoracic, and First and Second Lumbar Vertebrae 33

8. Dog F\#431-1, Large Depression Fracture on Rostrum 35

9. Basioccipital Types Used for Sex Determination Based on Studies $\begin{array}{ll}\text { Conducted by The and Trouth (1976) } & 41\end{array}$

10. Canid Mandible from the Janey B. Goode Site (F.2716) with Periodontal Disease 46

11. An Abscess Forming at the Root of the Right M1 of a Canid Mandible from the Janey B. Goode Site (F.1433)

12. Grooving and Eburnation Observable on Canid Vertebrae from the Janey B. Goode Site (F.7633)

13. Dog F\#2335-1, Infection and Atrophy of the Left Femoral Neck and Fovea Capitis

14. Dog F\#2915-1, a Healed Fracture of the Left Fibula and Fusion of the Tibia and Fibula 
15. Pinpoint Porosity Observable on a Canid Tibia from the Janey B Goode Site (F.4339)

16. Dog F\#431-1, Anterior View of Rostrum Showing Deviation to the Left of the Midline

17. Dog F\#798-1, Close-Up of Atlas with Cut Marks on the Ventral Surface

18. Dog F\#4819-1, Uneven Wear on the Left Side of the Dental Arcade and Malocclusion of the Right Jaw 


\section{CHAPTER I: INTRODUCTION}

For thousands of years, domestic dogs (Canis familiaris) have sustained a unique and complex relationship with humans, figuring prominently in both spiritual and prosaic realms of prehistoric society. Dogs served a variety of roles in Native American communities, which often included both practical and spiritual functions such as hunting, load hauling, guarding, supplementing the diet, providing clothing, and serving as spirit guardians and companions in the afterlife (e.g., Hudson 1976; Kerber 1997; Schwartz 1997; Strong 1985). Based on archaeological investigations and ethnohistoric accounts, it is evident that this unparalleled human-dog relationship sets the species apart from any other animal, domestic or otherwise (e.g., Byrd et al. 2013; Kerber 1997; Kuehn 2014a, 2014b).

The recovery of dog remains from archaeological sites and development of new analytical techniques (e.g., DNA analysis, isotope analysis) have spurred an increased interest in dog research for analysts worldwide. Historically, dog research has focused primarily on the process of dog domestication, morphological differences between wild and domestic canids, and burial treatment of canine companions (e.g., Cantwell 1980; Haag 1948; Morey 1986; Olsen 1974, 1985). While this type of research provides insight on treatment at death, it does not tell us much about dogs' lives. Often, dog paleopathology studies are cursory at best, with little detailed analysis because of time and funding constraints, inexperience of the analysts, and other factors. This is detrimental to our understanding of the daily lives of dogs in the past as this type of analysis provides significant insight on the changing roles and treatment of dogs over time (Kuehn 2014a, 2014b). Although it is not always possible to directly associate observed paleopathology with specific activities or causes, some skeletal anomalies can be reasonably 
identified based on previous archaeological investigations and ethnohistoric sources (e.g., Arnold 1979; Baker and Brothwell 1980; Bartosiewicz and Gál 2008; Binois et al. 2013; Crellin 1994; Groot 2008; MacKinnon 2010; Park 1987; Snyder 1995; Teegen 2005; Warren 2004).

In the Midwest region of North America, some dog paleopathologial data are available but limited, with no statewide or regional synthesis despite a relatively large number of recovered dog assemblages. This is partly because of the small sample size at any given site and less than ideal preservation, but more significantly the result of incomplete analysis of pathology and trauma observed on skeletal remains. Analysis, and in some cases reanalysis, of the betterpreserved dog remains is an ongoing effort that is beneficial to our understanding of daily life for late prehistoric dogs in this region (e.g., Baker and Brothwell 1980; Bartelle et al. 2010; Kuehn 2014a; Warren 2004).

One Midwest site with a particularly large quantity of canid remains is the Range site (11S47). Archaeological excavations at this site, located in the American Bottom region, resulted in the identification of $52 \mathrm{dog}$ burials associated with the Late Woodland Patrick phase (A.D. 650-900) and the Terminal Late Woodland (A.D. 900-1050) (Kelly 1987, 1990a, 1990b, 2007a, 2007b). Because of time and funding constraints, two-thirds of the Range faunal assemblage was left unanalyzed, leaving the possibility of additional dog remains not identified in the field. Additionally, analysis of the dog burials was limited to determination of age, sex, and general size of individuals. Little to no analysis of pathology and trauma was conducted, leaving numerous questions unanswered. In this thesis, I analyzed the dog remains from this site, looking specifically for evidence of pathology and trauma. In addition to expanding upon the limited initial reports, this research provides significant insight into the life, death, and post-death 
treatment of domestic dogs at the Range site as well as in the broader American Bottom and Midwest regions. Three research questions guided this project:

1. What interpretations can be made about the role of dogs in Native American society based on examination of mortuary treatment and pathology from the Range site?

2. Based on the new interpretative data obtained from the Range analysis, is there evidence of temporal changes in the role and treatment of dogs at the site?

3. Can knowledge derived from this study be applied to other sites with dog remains in the American Bottom and beyond?

4. Can reanalysis of old assemblages using modern analytical techniques generate new insights into the treatment of dogs throughout prehistory?

The dog remains identified in the initial Range site faunal analysis were reanalyzed at the Illinois State Archaeological Survey's bioarchaeology lab under the supervision of Steven Kuehn. Additionally, canid remains not recognized in the original analyses were analyzed. All remains were analyzed by the author following standard zooarchaeological methods (e.g., Reitz and Wing 2008) as well as additional analytical criteria necessary for a thorough analysis of dog paleopathology and burial treatment (e.g., Baker and Brothwell 1980; Kuehn 2014b; Warren 2004). These methodologies are elaborated upon later in this thesis. For each individual dog, the following information was collected from each element present: side, portion, cultural modifications (e.g., burning, cut marks), age, sex, and evidence of pathology or trauma (e.g., fractures, skeletal abnormalities, infection). Data from each individual were quantified by 
calculating Minimum Number of Individuals (MNI) and Number of Identified Specimens (NISP).

For this research, social zooarchaeology provided the theoretical framework necessary for this discussion. Unlike traditional zooarchaeological approaches that emphasize subsistence patterns, exploitation of resources, and environmental reconstruction, social zooarchaeology views the human-animal relationship in more holistic terms, giving due significance to cultural and social elements that influence these inter-species interactions (Russell 2012).

The application of social zooarchaeology as a theoretical construct is particularly important in studies of dog paleopathology because of the dynamic bond between humans and dogs. Dogs not only contributed physically and spiritually in Native American communities, but also served as companion animals. In prehistoric North America, no other species was a part of daily life in the same manner as dogs. Acknowledgement and consideration of this social bond in conjunction with paleopathology will aid in a better understanding of the daily activities and interactions between humans and dogs.

Analysis of the pathology and trauma observed on the dog remains from the Range site provides significant insight on the daily lives, treatment, and societal roles of domestic dogs in the late prehistoric American Bottom. The results demonstrate that the Range dogs were likely pack animals and endured harsh treatment, similar to the canid remains recovered from contemporaneous sites in the American Bottom region, but were also socially significant as indicated by the burial treatment some dogs were afforded. Some temporal differences between the LW and TLW dogs are observable, although interpretations are limited due to the relatively short time frame and small sample size. 


\section{CHAPTER II: IMPORTANCE OF DOGS IN NATIVE AMERICAN SOCIETY}

For thousands of years, dogs have coexisted with humans. The unique relationship between dogs and humans goes beyond companionship, with dogs figuring prominently in both the physical and spiritual realms of Native American society. Ethnohistoric accounts illustrate the diversity of functions dogs have served in prehistoric North America. Dogs often assisted in the tracking and hunting of large game such as musk oxen, caribou, moose, seal, deer, elk, and bear, as well as smaller prey like raccoon, muskrat, waterfowl, rabbit, and beaver (e.g., Howard 1965; Gayton 1946:183; Rasmussen 1931; Schwartz 1997:31-39). Groups in the Arctic often trained dogs to locate seal breathing holes, a task that would be nearly impossible without a canid's keen sense of smell (e.g., Arima 1984; Dumas 1984; Schwartz 1997:31). In many societies, dogs were often used for hauling meat, firewood, and other supplies, either by carrying packs on their backs or pulling sleds and travois (e.g., Park 1987; Schwartz 1997; Snyder 1995:198-199).

Dogs also served spiritual roles in many Native American cultures. They are present in many myths and creation stories such as in the case of the Cheyenne, Hidatsa, Shawnee, Penobscot, and numerous other tribes (e.g., Brightman 1993:135; Dorsey 1905; Howard 1965;

Schwartz 1997:19-21; Seger 1934:153; Speck 1925). Dogs are often considered guardians of the dead, leading human spirits to the afterlife. The significance of dogs in Native American society is evident, in part, in burial treatment. Although some canid remains are recovered from archaeological middens or refuse pits, many are quite obviously intentionally interred in shallow pits. Occasionally these remains are buried with grave goods or accompany a human burial, 
perhaps indicating a ritual or sacrificial death (e.g., Lewis and Lewis 1961; McMillan 1970;

Morey 1992; Schwartz 1997:103).

Evidence of such burial treatment is observable at a number of sites in the Midwest and Southeast regions. At the Archaic site of Koster (6400 B.C.) in the Illinois River Valley, at least three dogs were interred in shallow pits and placed on their sides (Morey and Wiant 1992). The lack of modification (e.g., cut marks, burning) and the burial of one dog with a grinding stone and clam shell placed near its cranium suggest a meaningful and intentional internment of these individuals. Similarly, the Archaic period Eva site, located on the banks of the Tennessee River, appears to contain a number of deliberately buried dogs (Lewis and Lewis 1961). Of the 18 dog burials, four were interred in association with human burials and 14 were buried alone in shallow pits. Two of the dog burials were particularly distinctive. One individual was placed beneath the skull of a 30-to-35-year-old human male, along with a projectile point, a turtle shell rattle, a snake vertebra necklace, several awls, and an antler tine. The second individual was not associated with a human burial but was interred with two splinter bone awls and a large stone pick. Based on the burial contexts of these two dogs, Lewis and Lewis (1961) suggest these individuals were highly valued hunting companions in life.

In the Green River Valley of Kentucky, many of the shell-mound sites (e.g., Eva Stratum II, Carlston Annis, Ward, Read, Indian Knoll, Baker, Jimtown Hill, Jackson Bluff, etc.) contain dozens of canid burials (e.g., Claassen 2008; Crothers 2005; Warren 2004; Webb 1950, 1974). Approximately 15 percent of these dogs are buried with humans, often with other grave goods such as turtle shell, red ochre, and shell beads (Claassen 2008). The majority of the dogs found at these sites, however, are interred in their own graves. While not directly associated with human graves, these dog burials are often located at the edges of human burials and appear to be 
positioned intentionally (i.e., facing a particular direction or located on a particular side of the human burial or shell heap).

A final example is the extensive canid assemblage recovered from the Janey B. Goode site in the American Bottom (Kuehn 2014b). Over 100 individual dogs are represented at the site including 55 complete or nearly complete burials, 25 crania, and three articulated limbs. Many of these dogs exhibit evidence of pathologies suggesting they contributed in the daily physical duties in the community. Of particular interest are the three articulated limbs. One dog is represented by an articulated right forelimb. No butchery marks are present on these remains. The left forepaw of another individual was recovered from a pit feature along with the complete skeleton of an adult female dog. Neither of these individuals exhibits evidence of butchery. The third feature contained both forelimbs of a dog; cut marks are observable on the right radius and left ulna. Some, if not all of these articulated forelimbs, may reflect the ceremonial or ritual removal of the forepaws for inclusion in pits, as noted by various researchers (e.g., Byrd et al. 2013; Kerber 1997:85-86; Prahl 1967:18; Valera and Costa 2013).

While this discussion is not exhaustive, it does provide some insight into the burial treatment afforded to select dogs. The varied placement of canid remains (i.e., in structures, in pits in front of structures, in pits behind structures, in refuse pits/middens, etc.), even within the same site, attests to the wide-ranging statuses dogs played in Native American societies.

\section{Past Research}

Historically, dog research has focused primarily on the evolutionary process of dog domestication (e.g., Morey 1992, 1994, 2006; Schwartz 1997:8; Templeton 1989; Wayne 1993). In the past century, researchers such as Allen (1920), Benecke (1987), Lawrence and Reed 
(1983), and Wayne (1993), as well as others, have identified some of the key morphological characteristics that distinguish domestic dogs from their wild relatives. Early Old World peoples were likely selecting for puppy-like behavior rather than morphology, but as has been noted in other domesticated animals, juvenile morphology and behavior often go hand-in-hand (e.g., Schwartz 1997:10). Submissive, playful, and docile dogs would likely have been the only ones tolerated in human society. In general, dogs are smaller than their wolf counterparts and exhibit a shorter rostrum, steeper forehead, and wider cranium in proportion to the length. Additionally, the sagittal crest is more rounded and projects less posteriorly, the tympanic bulla is smaller and more compressed, and the coronoid process of the mandible is "turned-back". These morphological differences are the result of neoteny, or the retention of juvenile characteristics into adulthood.

Based on cranial and long bone measurements, Allen (1920:457-458) described the "typical" types of Indian dogs found in prehistoric North America. According to him, the two main types of dogs found in the Midwest are the smaller Indian dog and the larger or common Indian dog. He also notes the possible presence of a third breed, the short-nosed dog. These types of dogs were characterized as medium-sized (approximately 40-45 pounds), similar to a modern terrier or beagle, with a sharp sagittal crest, high forehead, and long limb bones in proportion to body size. The first mandibular premolars were often absent. For the purposes of this research, description of the "typical" dog is kept vague given the potential for morphological variation and overlap between dog types.

While this type of research provides insight on how dogs became domesticated and the emergence of various breeds, it does not contribute to our understanding of the daily activities and roles of the domestic dog in prehistoric societies. Although not often incorporated into dog 
burial research, analysis of paleopathology can provide significant insight on the changing roles and treatment of dogs over time (Kuehn 2014a, 2014b; Warren 2004). A handful of researchers, such as Warren and Kuehn, have analyzed the pathology and trauma observed on canid remains from prehistoric archaeological sites in the Midwest, but that type of data are still not frequently collected. And, when it is collected and reported, it usually does not consist of anything more than description with no meaningful interpretation. 
CHAPTER III: THE AMERICAN BOTTOM REGION AND THE RANGE SITE (11S47)

The American Bottom region of the Midwest is well known for its strategic location at the confluence of the Illinois, Missouri, and Mississippi rivers (e.g., McElrath 1988; White et al. 1984:15) (Figure 1). The uplands bordering the floodplain, the colluvial veneers and alluvial fans to the east of the floodplain, and the Mississippi River floodplain itself provided prehistoric peoples with a diverse array of environmental resources making the region ideal for settlement.

\section{The Floodplain}

The Mississippi River floodplain is undoubtedly the most important geomorphic zone in the region, both geographically and in regards to prehistoric occupation (White et al. 1984:17). The floodplain lies between the Illinois and Missouri bluffs and extends from Alton, Illinois, down to the mouth of the Kaskaskia River in Chester, Illinois. Prehistorically, portions of the floodplain saw seasonal fluctuations in water levels, an important factor affecting type, quantity, and abundance of aquatic resources available. Other topographic features of this zone include sloughs, terraces, swales, ridges, and meander scars. This research will focus on the north-central portion of the American Bottom, particularly the Prairie Lake meander scar where the Range site is located. 


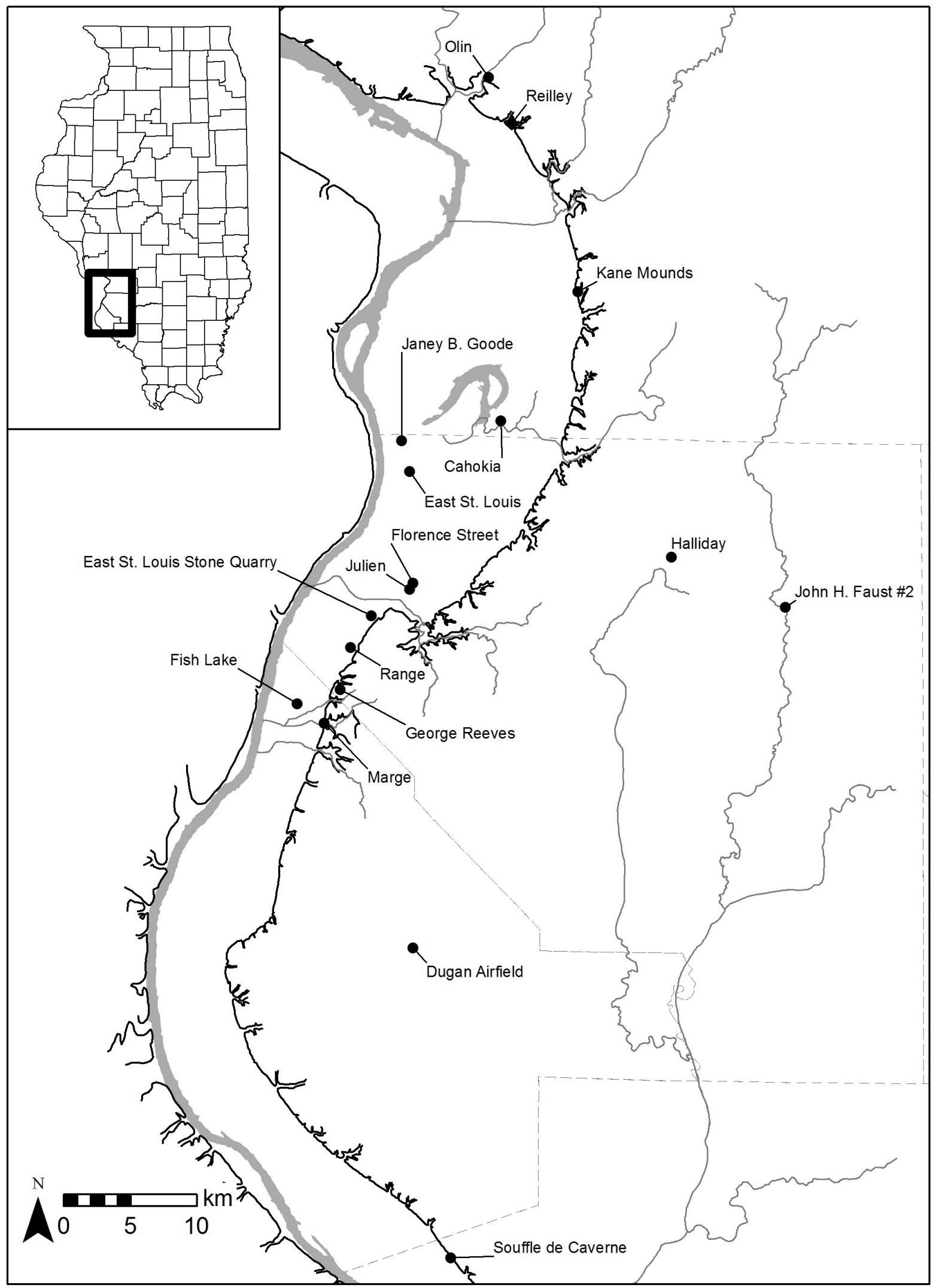

Figure 1. Map of the American Bottom region (from Kuehn 2016). 


\section{Colluvial Veneers and Alluvial Fans}

The colluvial veneers and alluvial fans are located at the foot of the bluffs, on the eastern (Illinois) side of the floodplain (White et al. 1984:16). The colluvial veneers in the American Bottom are made up of upland loesses and glacial till that are redeposited as a result of talus creep, debris slide, and debris fall (Peregrine and Ember 2001:258). In upland areas dissected by series of streams, well-drained alluvial fan deposits can overlay the colluvial veneers, forming alluvial fans at the mouths of streams. These colluvial veneers and alluvial fans are ideal for plant growth, particularly oak, elm, ash, mayapple, blood root, spring beauty, jack-in-the-pulpit, wild ginger, and a variety of other species.

\section{The Uplands}

The bluffs adjacent to the floodplain rise approximately $24 \mathrm{~m}$ above the floodplain surface and are made primarily of Mississippian age limestone (Salem, St. Louis, and Ste. Genevieve formations), with smaller portions consisting of soft Pennsylvania age coals, shales, and sandstones (White et al. 1984:16). The main topographic features of the uplands are sinkholes and a series of short streams that redeposit upland loesses in the floodplain forming alluvial fans. Prairie, forest, and forest edge habitats provide a variety of dietary resources, including white-tailed deer, raccoon, wolf, fox, black bear, bobcat, squirrel, striped skunk, opossum, cottontail rabbit, woodchuck, weasel, rodents, turkey, raptors, prairie chicken, northern bobwhite, and box turtle. 


\section{The Woodland Period in the American Bottom}

In the Midwest region of North America, the Woodland Period (1,000 B.C. $-1,000$ A.D.) is divided into Early, Middle, Late, and Terminal Late Woodland components. These sub-periods are differentiated by changes in social, ritual, economic, settlement, and subsistence behavior. This section will summarize the cultural history of the Woodland Period in the American Bottom region, focusing particularly on the Late Woodland period Patrick phase and Terminal Late Woodland period since these are the components of the Range site investigated in this study.

\section{The Early Woodland Period (cal. 900 B.C.—150 B.C.)}

At the beginning of the Early Woodland period, population densities were low with small, temporary communities, similar to preceding Archaic settlement patterns. Towards the end of the period, however, population sizes began to increase resulting in a slightly more sedentary lifestyle (Buikstra et al. 1986; Fortier 2001). The introduction of pottery during this period may be one possible catalyst of this population growth, as it would allow people to collect, process, and cook food in previously impossible ways (Fiedel 2001). These early vessels were characteristically thick-bodied and included types such as Marion Thick, Black Sand Incised, and Morton Incised (Bluhm 1950; Griffin 1952). Utilization of the environmental resources in the region resulted in a diverse diet that included terrestrial and aquatic species, nuts (e.g., hickory, acorn, hazelnut), and native crops (e.g., squash, bottle gourd, sumpweed, sunflower, and chenopod) (Fritz 1993; Lewis 1986). 


\section{The Middle Woodland Period (cal. 150 B.C.—A.D. 400)}

The transition from the Early to Middle Woodland period is marked by the construction of mounds, trade of exotic materials, and elaborate ceremonial activities in some parts of the Midwest (e.g., Fortier 2001). Despite archaeological evidence of this in nearby regions (e.g., the Illinois River Valley) (Fortier 2001), no large mound-village complexes are evident in the American Bottom during the Middle Woodland period. Settlements were small, consisting of only nuclear or extended family members, and are often interpreted as aggregation or seasonal campsites. At the beginning of the period, the majority of occupation sites were located in the Mississippi River floodplain with expansion into the uplands occurring later in the period (Fortier et al. 2006). The abandonment of floodplain occupations may have coincided with varying water levels that would have made the lower areas uninhabitable (McElrath and Fortier 2000). Most sites were concentrated around major waterways such as the Mississippi and Illinois rivers where the inhabitants would have access to a variety of terrestrial and aquatic resources (Holt 2000; Milner 2004). Subsistence behavior was very similar to the preceding period, consisting primarily of aquatic species, tubers, and a variety of nuts; however, the Middle Woodland diet was also supplemented by domesticated starchy cultigens (e.g., chenopod, erect knotweed, little barley, maygrass, sunflower, and sumpweed) (Fortier et al. 2006; Fritz 1993; Milner 2004).

\section{The Late Woodland Period (cal. A.D. 400-900)}

The Late Woodland period was a time of technological innovation and increasing social complexity (Emerson et al. 2000; Fortier et al. 2006; Green 1987, 1993). For the first time, societies were associated with specific regions in the American Bottom, occupying just about 
every area of the floodplain and surrounding uplands (Fortier and Jackson 2000). At the beginning of the period, subsistence strategies continued to focus on utilization of local resources. Later, maize becomes an important dietary staple; however, the paucity of archaeological evidence of maize during the formation of large communities suggests that this was not one of the primary catalysts of social change and complexity (Fortier et al. 2006; Koldehoff and Galloy 2006; Simon and Parker 2006). Previously, the Late Woodland period was divided into three sequential phases: Rosewood (A.D. 300-450), Mund (A.D. 450-650), and Patrick (A.D. 650-900) (Fortier et al. 1984; Kelly et al. 1984); however, more recent assessments of the Late Woodland sequence indicate the two earlier phases were actually two distinct cultural units with differing types of projectile points, ceramics, and settlement patterns (Fortier et al. 2006:190). Much more is known about the final phase of the Late Woodland period.

The Patrick phase (cal. A.D. 650-900). The Patrick phase is thought of as, "the archetypical American Bottom Late Woodland manifestation," (Fortier et al. 2006:190) as it was during this phase that populations increased drastically and societies flourished. During this 250year range, occupations targeted the American Bottom uplands as well as the previously occupied floodplain. Facilities were more complex than their predecessors, including features such as keyhole structures, large community structures, rectilinear family structures, limestonelined pits, and earth ovens (Fortier and Jackson 2000; Fortier et al. 2006). Keyhole structures were particularly unique to the Patrick phase occupations at sites in the American Bottom (e.g., Fortier 2014; Fortier and Jackson 2000; Kelly et al. 1987; McElrath 1988:12). Additionally, settlement forms during the Patrick phase were often more diverse with multi-structure clusters, extractive camps, isolated domestic clusters, and linear arrangements of pits and structures (e.g., 
Kelly et al. 1987; Fortier et al. 1984). Despite the larger size of these settlements, Koldehoff and Galloy (2006) argue that these may represent multiple short-term occupations, on account of the slash and burn horticultural patterns of societies during this phase. Fortier (2014:45-46) proposes two possibilities: (1) keyhole structures were used year-round, as there is no archaeological evidence to suggest otherwise, or (2) if keyhole ramps did serve as heat ducts, the structures were only used during the cold months and spent the warm months outside in temporary structures that left no archaeological footprint.

Significant changes were also seen in terms of material goods: the bow and arrow replaced the atlatl, new pipe forms were designed, gaming disks (discoidals) were produced, and larger bowls and storage vessels were utilized (Fortier and Jackson 2000; Fortier et al. 2006). The new technologies and styles observed in societies during the Patrick phase indicate evolving lifestyles and set the stage for even more dynamic changes in the following period.

The Sponemann phase (cal. A.D. 650-900). The Sponemann phase was originally thought to follow the Patrick phase chronologically based on the distinct ceramic assemblage and the presence of maize; however, reevaluation of the defining attributes of the phase and alleged presence of maize concluded that the Sponemann phase is separate, but coeval, to the Patrick phase (Fortier 2015:141-142). The earlier reports of maize at Sponemann phase sites identified these assemblages as Terminal Late Woodland (formally Emergent Mississippian) given the absence of maize in Patrick phase contexts (Fortier et al. 1991). It was recently determined that the presence of maize in these contexts was the result of contamination from adjacent Mississippian Period features (Fortier 2015:141; Simon 2017). Based on radiocarbon dates and material culture, researchers concur that the Sponemann culture is the result of intermingling 
between nonlocal Fall Creek and local Patrick communities. The main distinguishing feature of this phase is the presence of both Patrick ceramic traits (e.g., S-twisted cordmarking, grit/grog temper, globular jars cordmarked to the lip, and interior lip impressions) and non-Patrick ceramic traits (e.g., chert temper, upper rim castellation, and higher frequencies of Z-twisted cordmarking and exterior lip impressions). Although there are Sponemann phase features at Range, none produced canid remains.

\section{The Terminal Late Woodland period (cal. A.D. 900-1050)}

Fortier and colleagues (2006:191) consider the Terminal Late Woodland period the most dynamic period in the American Bottom sequence because of the substantial cultural heterogeneity and rapid change as evidenced by the diversity of ceramic, floral, faunal, and lithic assemblages, as well as settlement patterns. Additionally, the development of various sociopolitical landscapes set the stage for the emergence of Mississippian communities, such as Cahokia.

Previously, this period was referred to as the "Emergent Mississippian" period; however, more recent research suggests that Terminal Late Woodland is a more appropriate term (Fortier et al. 2006; Fortier and McElrath 2002). Although the archaeological record indicates the presence of a variety of discrete cultures present in the American Bottom at this time, there are some common features observed across societies including increased trade, ritualism and ceremonialism, community nucleation, and some evidence of village-level political control (e.g., Fortier and Jackson 2000; Fortier and McElrath 2002). As Terminal Late Woodland peoples continue to cultivate native plants they also begin to incorporate maize into their diet at a rapidly increasing rate. The production of maize varies from community to community, but by the end of 
the period, maize serves as a dietary staple (Hedman 2006; Hedman and Emerson 2015; Simon and Parker 2006; Simon et al. 2016). The Terminal Late Woodland period (ca. A.D. 900-1050) is divided into four phases (from earliest to latest): Dohack, Range, George Reeves, and Lindeman.

The Dohack phase (ca. A.D. 900-950). The Dohack phase is the first in the Terminal Late Woodland sequence. This phase is distinguished from the preceding Patrick phase by an increase in limestone tempered ceramics and a significant decrease in cordwrapped stick dowel impressed vessels (Fortier et al. 2006; Fortier and McElrath 2002; Kelly et al. 1990:21). Lithic assemblages are similar to Patrick phase assemblages, including small stemmed and triangular projectile points, pipes, and clay and stone discoidals. Structures continue to be small and rectangular in shape with individual posts along the basin floors and walls, but there is a decrease in the number of earth ovens and in the ratio of pits to structures. Additionally, a significant increase in maize consumption is suggested by the presence of maize in a greater percentage (5060 percent) of Dohack phase pits compared to Patrick phase pits ( $<5$ percent) with maize (Kelly et al. 1987, 1990).

The Range phase (cal. A.D. 950-975). The Range phase succeeds the Dohack phase. In addition to the jars, bowls, and pinch pots present in Patrick and Dohack ceramic assemblages, stumpware was a new inclusion to the ceramic assemblage during the Range phase (Fortier et al. 2006; Fortier and McElrath 2002; Kelly et al. 1990:305-306). Continuation of techniques such as limestone tempering and cordmarking is typical of most vessels. Small rectilinear structures predominate and preceding subsistence patterns persist. 
The George Reeves phase (ca. A.D. 975-1010). The next phase in the sequence is the George Reeves phase. This phase is marked by the incorporation of hooded bottles into the ceramic assemblage (Fortier et al. 2006; Fortier and McElrath 2002; Kelly et al. 2007:17-20). Cordmarking continues to be the predominant surface treatment, although an increase in plain surface and red-filmed vessels is evident in George Reeves ceramic assemblages. Additionally, shell-tempered vessels are present during this phase, suggesting an increase in extraregional trade from sources in southeast Missouri. The lithic assemblage is similar to the preceding phases, but with significantly higher percentages of Burlington chert tools. Feature types and structures, as well as subsistence patterns, mirror those of the Dohack and Range phases.

The Lindeman phase (ca. A.D. 1010-1050). Like the preceding phase, the Lindeman phase ceramic assemblage consists of jars, bowls, hooded bottles, stumpware, and pinch pots, as well as the new addition of globular seed jars (Fortier et al. 2006; Fortier and McElrath 2002; Kelly et al. 2007:235-238). Shell, grog, and grit tempered vessels derived from sources in southeast Missouri, and the confluence of the Ohio and Mississippi rivers, reflect a continuation of exchange patterns initiated earlier in the Terminal Late Woodland period. A much higher frequency of vessels with red-filmed or plain surfaces is notable during this phase. Much of the lithic assemblage (e.g., small-stemmed and triangular projectile points, clay and stone discoidals) persisted, along with an increase in the prevalence of spindle whorls, perforated ceramic sherds, and Burlington chert tools. In general, the Lindeman phase reflects a greater diversity of feature types, which is especially evident in smaller features located within the larger structures. Subsistence patterns indicate a continued reliance on local, wild resources with some consumption of maize. 


\section{The Range Site (11S47)}

Cahokia has received much attention in both past and present research, as researchers attempt to unravel the complex social, ritual, and political aspects that led to the rise and fall of the great city (e.g., Hedman 2006; Hedman and Emerson 2015; Holley 1989; Holley et al. 1993; Iseminger 2010; Milner et al. 1984; Muller 1997; Pauketat 1994, 1998, 2012). Archaeological investigations at sites in the areas surrounding Cahokia aimed to address some of these variables (Emerson 1984; Emerson and Jackson 1984; Emerson et al. 1983; Fortier et al. 1984; Galloy 2003; Harn 1980). During the late 1970s and early 80s, the Illinois State Archaeological Survey (formally Illinois Transportation Archaeological Research Program (ITARP) and Resource Investigation Program (RIP)) excavated dozens of prehistoric sites in the American Bottom in association with the FAI-270 alignment project. The sites excavated as a result of this project were of varying size, temporal affiliation, and environment and thus vastly expanded upon previous knowledge of prehistoric societies in the region. Investigations at the Range site were particularly significant as it was one of the largest and most intensely occupied sites in the FAI270 project (Kelly et al. 1987:8-10).

\section{Site Description and Locale}

The Range site is located in St. Clair County, Illinois, approximately $0.5 \mathrm{~km}$ east of the town of Dupo, and covers an area of roughly 10 ha (Kelly et al. 1987:10-11) (see Figure 3.1). The site is situated on the point bar ridge of the Prairie Lake meander scar. Prehistorically, Prairie Lake, a large oxbow lake, bordered the site to the north and east and was a major hydrographic feature; seasonal flooding and springs from limestone bluffs kept the lake 
replenished even during drier years. These bluffs form part of the Dupo-Waterloo Anticline. Approximately $400 \mathrm{~m}$ east of the site is a small valley in these bluffs, which gave early inhabitants relatively easy access to the uplands. The site is also in close proximity to Fish Lake and the Mississippi River, which are roughly $2 \mathrm{~km}$ and $5 \mathrm{~km}$ away, respectively.

In addition to being the largest site excavated in the FAI-270 project area, the Range site was also one of the most intensively occupied. Evidence of Late Archaic occupations extends across the entire site, offering new insight into settlement and subsistence behavior in the American Bottom during this period. The site was most intensively utilized from the Late Woodland period through the Mississippian period. This unique sequence of well-defined occupations at a single site contributes significantly to eastern North American archaeology (Kelly et al. 1987:1). This thesis research will focus on the Late Woodland Patrick phase and Terminal Late Woodland occupations of the Range site, as these are the components associated with dog burials. These occupations will be discussed in more detail later in this chapter.

\section{History of Excavations at Range}

The Range site was first recorded in 1961 by Alan Harn, who was assisting the Illinois Archaeological Survey (IAS) with a survey of the American Bottom for a National Science Foundation grant (Kelly et al. 1987:10-11). He and others surface collected and mapped the site, but no more work was done until 1975 when the Illinois Department of Transportation (IDOT)'s proposed FAI-270 alignment initiated further investigation. Preliminary surveying (e.g., controlled surface collection, proton magnetometer survey, fluxgate magnetometer survey, phosphate samples collection, test excavations) was conducted over the next several years by various institutions (e.g., Loyola University, Illinois State Archaeological Survey (ISAS), 
University of Illinois). The University of Illinois at Urbana-Champaign (UIUC) assumed responsibility for Range and approval to begin a full-scale excavation was obtained in 1977 due to significant evidence of prehistoric occupations at the site. Fieldwork, under the supervision of

John E. Kelly, began in the spring of 1978 and continued intermittently through the fall of 1981. By the end, more than $46,000 \mathrm{~m}^{2}$ had been uncovered and approximately 5,500 features had been excavated (Kelly et al. 2007:1-15).

Analytical approach and methodology. Throughout the analysis of the various material assemblages from the Range site, the smallest analytical unit used in regard to context is the feature (Kelly et al. 1987:23-24). Determination of the component affiliation of each feature took into account a combination of attributes including ceramics (or lack there of), lithics, stratigraphy, feature boundaries, feature types, feature association, and feature superpositioning. Occupation areas were defined based on the overall patterning and distribution of mapped features, particularly structures.

Initially, all features were excavated in the portion of the site north of the field road. However, a sampling strategy was employed during later excavations to reduce the amount of material recovered and expedite investigations. Dog burials were identified either in the field or during laboratory analysis and will be described in greater detail later.

\section{The Late Woodland Occupation of the Range Site}

The Late Woodland occupation of the site was restricted primarily to a small area at the northern end and a large area in the central portion of the site along a ridge crest and adjacent slope (Kelly et al. 1987:131-436). The majority of the 1,872 Late Woodland features represented 
a Patrick phase occupation, though a small Rosewood phase (early Late Woodland) component may also have been present. The Patrick phase occupations were especially significant for two reasons: the spatial patterning of features, particularly structures, allowed for interpretations of settlement and social structure, and the faunal and floral material collected from these occupations provided information about subsistence behavior and, most importantly, the role of agricultural products in the diet.

\section{Late Woodland Patrick phase occupation at the Range site. Identification of Patrick} phase features was based on ceramics (e.g., cordmarked, grog-tempered, grit-tempered, limestone-tempered), superpositioning and spatial association of features, and similarity in types of fills (Kelly et al. 1987:136-137). Features covered an area measuring approximately $725 \mathrm{~m}$ in length and were distributed over the entire portion of the site investigated. Nine Patrick phase occupation areas were identified and are numbered beginning with P-1 in the northern portion of the site and proceeding sequentially to P-9 in the southernmost portion of the site (Figure 2). Boundaries of the occupation areas were based primarily on the spatial patterning of various structures, though these divisions were sometimes subtle.

Due to the large quantity of cultural material recovered from these occupation zones and time constraints, only a portion of the various artifact assemblages (e.g., ceramics, lithics, faunal, floral, ceramics) was analyzed. This research project focuses solely on the dog remains recovered from the site. The faunal remains from Occupation Areas P-1 and P-2, as well as 120 features in the northern two-thirds of Occupation Area P-3 were analyzed (Kelly et al. 1987:142143). The remainder of the faunal material was put into storage with the intent for analysis in the future. 
Patrick phase canid remains. Lucretia Kelly's original analysis identified 18 Patrick phase dog burials located in Occupation Areas P-3 through P-8 (L. Kelly 1987:361-365). These individuals were analyzed by L. Kelly (1987: 361-365) following standard zooarchaeological methods, which include basic determinations of age (e.g., juvenile, adult, mature adult) and sex (e.g., male, female, probable male, probable female, indeterminate). For the majority of dog burials, little additional data were obtained. The four individuals from Features 431 and 441 in Occupation Area P-3 were described in slightly more detail, and included burial context, position of internment, and cranial and long bone measurements, when possible. Some paleopathological aspects of these four skeletons were briefly described (e.g., tooth eruption and wear, antemortem tooth absence, healed rib fractures), however, no interpretations were derived from this data. Presumably, time and funding constraints inhibited a more in-depth analysis of these dog remains. Kelly notes that the 18 dog skeletons recovered were identified either in the field or during lab processing, which 


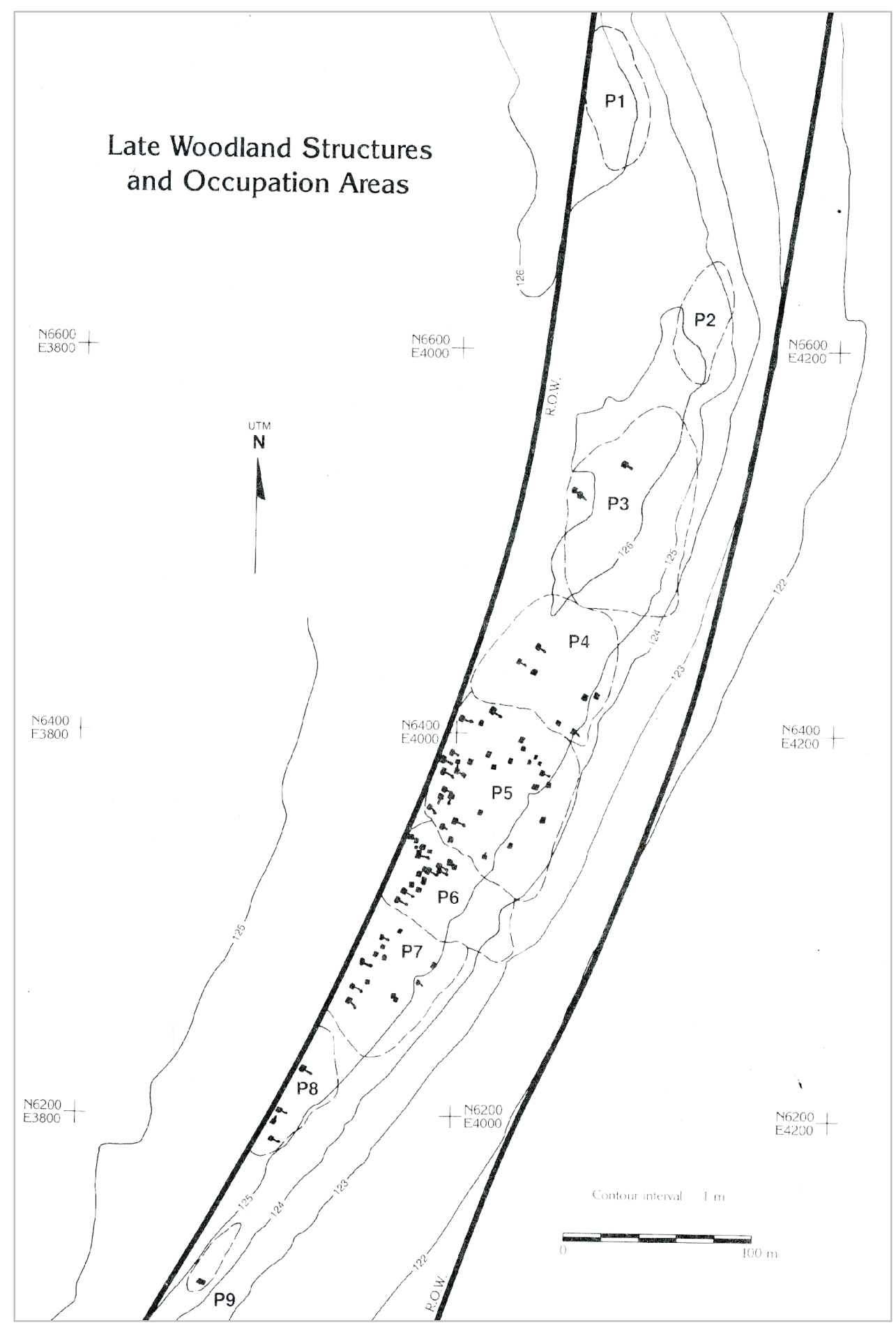

Figure 2. Patrick phase occupation areas (from Kelly et al. 1987).

suggested that there may have been additional dog remains in the unanalyzed faunal assemblages (L. Kelly 1987:365). 
The Terminal Late Woodland occupation at the Range site. Although not as extensive as the Late Woodland period occupation, the Terminal Late Woodland occupation of the Range site covered approximately 2.6 ha and is concentrated in the central portion of the site (Kelly et al. 2007:13). Canid remains were recovered from all four Terminal Late Woodland occupation phases (e.g., Dohack, Range, George Reeves, Lindeman).

Dohack phase canid remains. The Dohack phase occupation was restricted to the southern portion of the central region and was divided into six occupation areas (D-1 through D6), beginning with D-1 in the north and extending down to D-6 in the south (Figure 3). Three complete and five partial dog skeletons were associated with this phase. Only one individual, from Feature 2915, was described in any detail: this dog was a mature adult with worn teeth, absence of the first and second premolars, six thoracic vertebrae with spinous process deviations, and partially healed fractures of the proximal left ulna and three left ribs (L. Kelly 1990a:239241). 


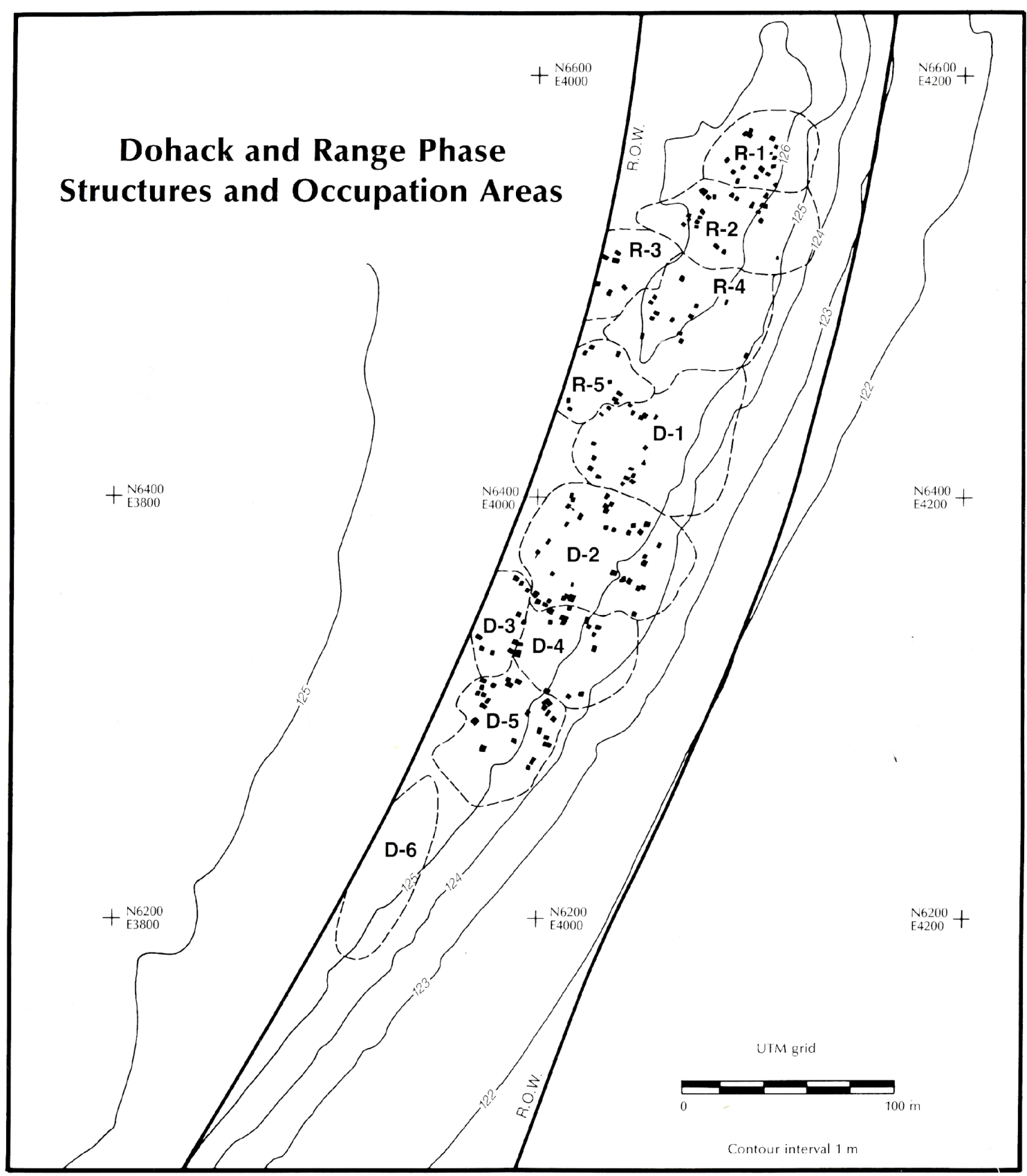

Figure 3. Dohack and Range phase occupation areas (from Kelly et al. 1990). 
Range phase canid remains. The Range phase occupation areas (R-1 through $\mathrm{R}-5)$ were delineated similar to the preceding phase, beginning with R-1 in the north and ending with R-5 in the south (Figure 3). Five partial dog skeletons were recovered, including four pups and one adult (L. Kelly 1990b: 488-495). Due to limited skeletal portions, little analysis was possible.

George Reeves phase canid remains. The George Reeves phase occupation was concentrated in the central portion of the site and divided into three occupation areas (G-1 through G-3) (Figure 4). Four dogs were associated with this phase, though only one individual (from Feature 1769) was complete enough to warrant identification as a dog burial (L. Kelly 2007b: 180).

Lindeman phase canid remains. The Lindeman phase component of the Range site was limited to approximately 1 ha in the northern portion of the central region, and coincided with the George Reeves phase G-2 Occupation Area (Figure 4). Structure distribution patterns and frequent superpositioning of features suggested a single, large community. Pit Feature 1919 contained the only dog burial associated with this phase. This individual was identified as a pup due to lack of epiphyseal fusion and general bone porosity (L. Kelly 2007b: 427). Field notes indicate that the pup's head was positioned toward the north and the body was extended. 


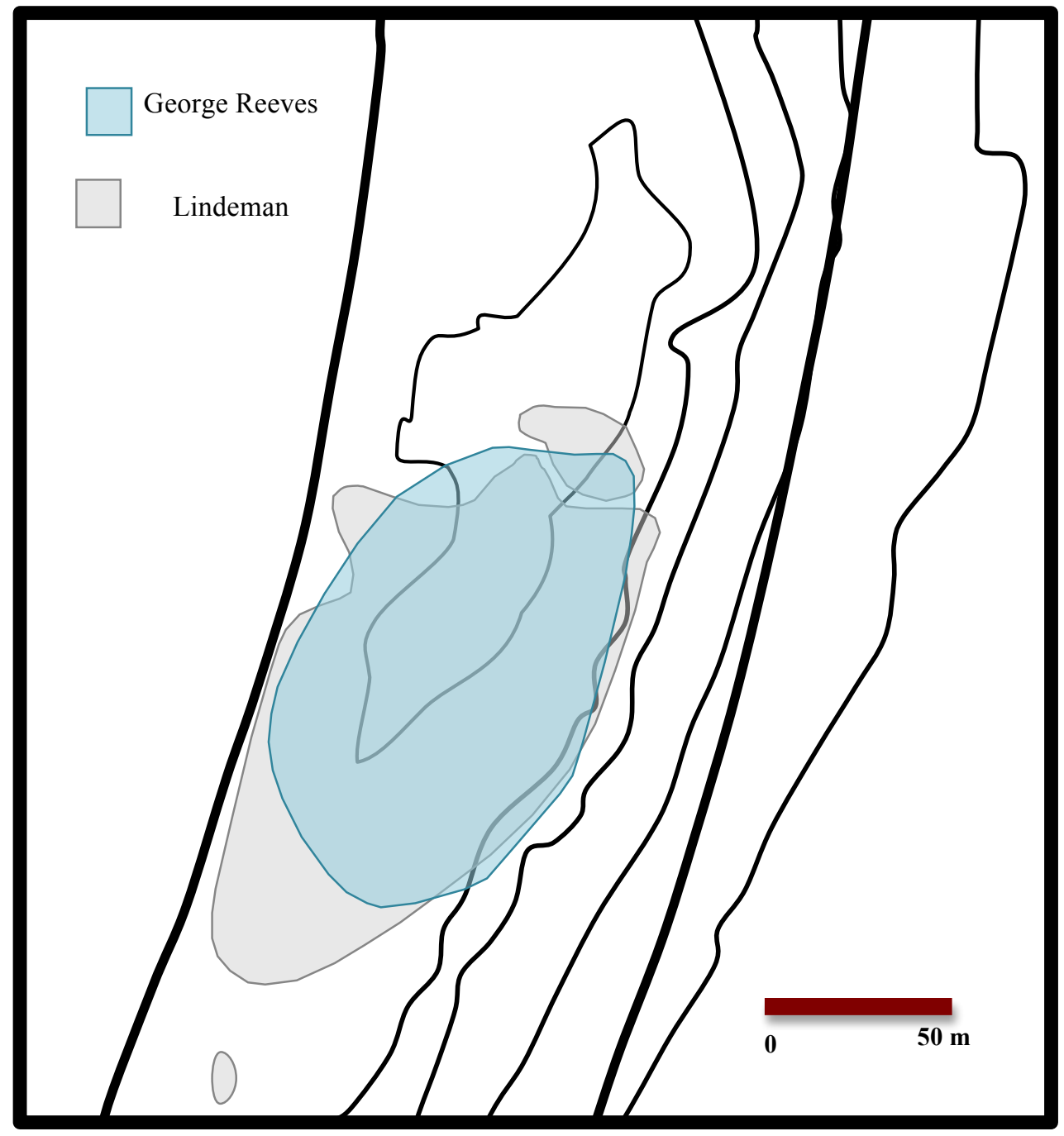

Figure 4. George Reeves and Lindeman phase occupation areas (based on Kelly et al. 2007). 


\section{CHAPTER IV: DOG PALEOPATHOLOGY}

Paleopathology is the analysis of pathology and trauma evidence observed on skeletal remains (Baker and Brothwell 1980; Warren 2004). Bone pathologies include bacterial, viral, and fungal infections and diseases, and vary in degree of severity, location, and duration. Trauma refers to skeletal damage or modification following unintentional or abusive injury, or from a long-term or repetitive physical activity. These conditions are not mutually exclusive, however, and the resulting skeletal evidence often overlaps. For example, a fracture resulting from injury can become infected resulting in additional tissue remodeling. Similarly, bone weakened by malnutrition or inflammation from infection is more prone to injury (e.g., Groot 2008). Although skeletal evidence of pathology and trauma cannot always be associated with specific causes or activities, this type of analysis can provide insight on the societal roles and treatment of dogs in prehistoric communities (e.g., Baker and Brothwell 1980; Bartelle et al. 2010; Bartosiewicz and Gál 2008; Groot 2008; Kuehn 2014b; MacKinnon 2010; Siegel 1976).

\section{Dental Paleopathology}

One of the most commonly observed dental pathologies on dog remains is antemortem tooth absence, which includes both tooth loss during life with associated bone remodeling, and unerupted teeth (Kuehn 2014b:105; Warren 2004) (Figure 5). A number of factors can result in tooth absence, including periodontal disease, trauma, agenesis, feeding behaviors, and even intentional tooth removal (e.g., Baker and Brothwell 1980; Losey et al. 2014; Warren 2004). Agenesis, the congenital absence of a tooth, is commonly noted in the premolars (both maxillary and mandibular) in prehistoric North American dogs (e.g., Allen 1920; Colton 1970). However, 
if complete alveolar reabsorption occurs, it can be difficult to ascertain whether a tooth was lost or never erupted in the first place. Although periodontal disease or infection often plays a secondary role in antemortem tooth loss, several dog paleopathology studies in North America (Kuehn 2014b; Losey et al. 2014) have identified trauma (e.g., bite wounds from fights with other dogs, disciplinary strikes or kicks, encounters with large game or prey) as the primary cause of tooth loss and fracture among domestic dogs.

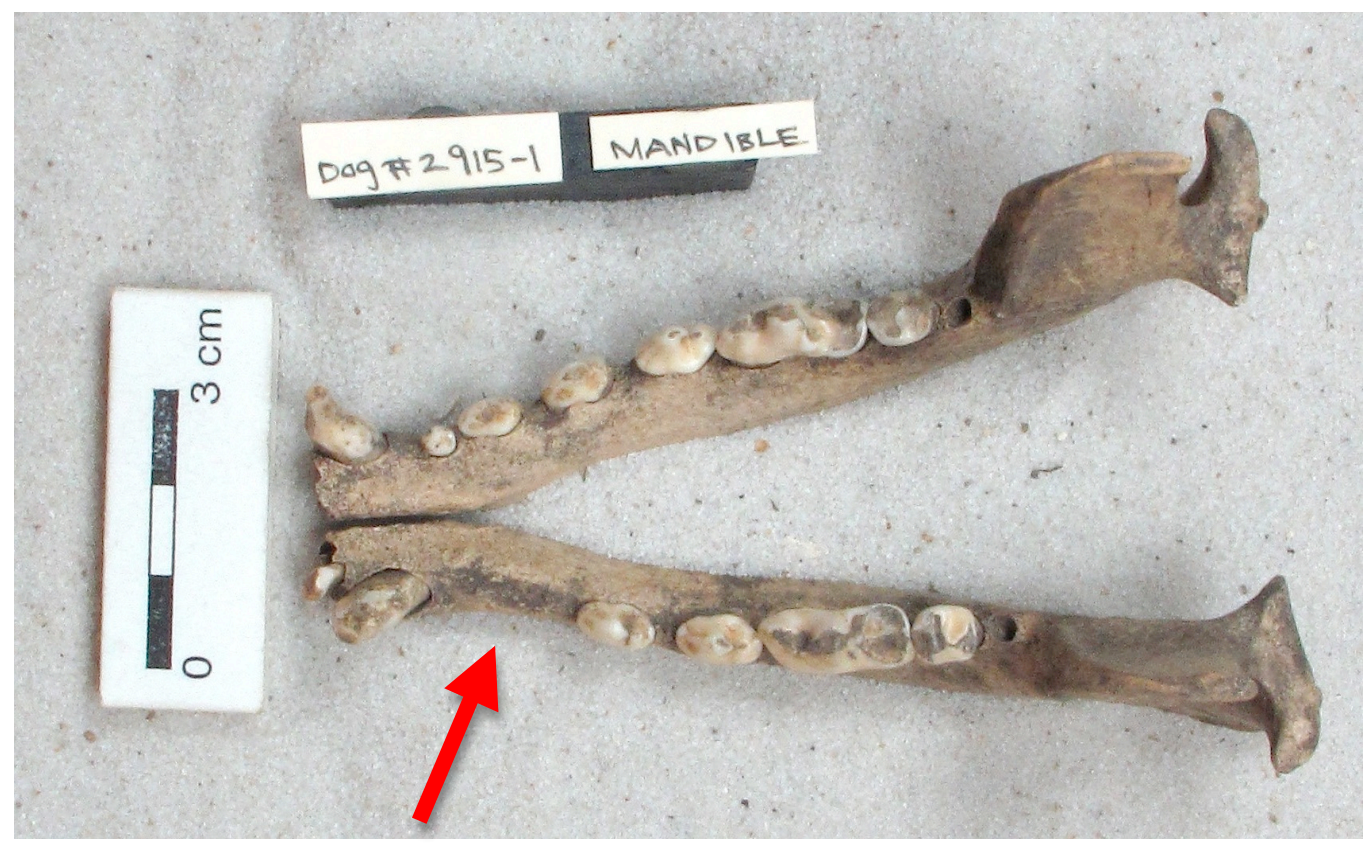

Figure 5. Dog F\#2915-1, extensive alveolar reabsorption in the left mandible after loss of the first and second premolars.

\section{Skeletal Paleopathology}

The most common locations of skeletal pathologies and trauma observed on dog remains include the vertebral column, skull, and ribs. Vertebral spinous process anomalies are deviated spinous processes of the lower cervical, thoracic, and lumbar vertebrae. These deviations are evidenced by warping or bowing of the spinous process away from the midline of the body, compression or "mushrooming" of the dorsal end (tip), actual fracture of the spinous process, or 
a combination of these deviations (Figure 6).

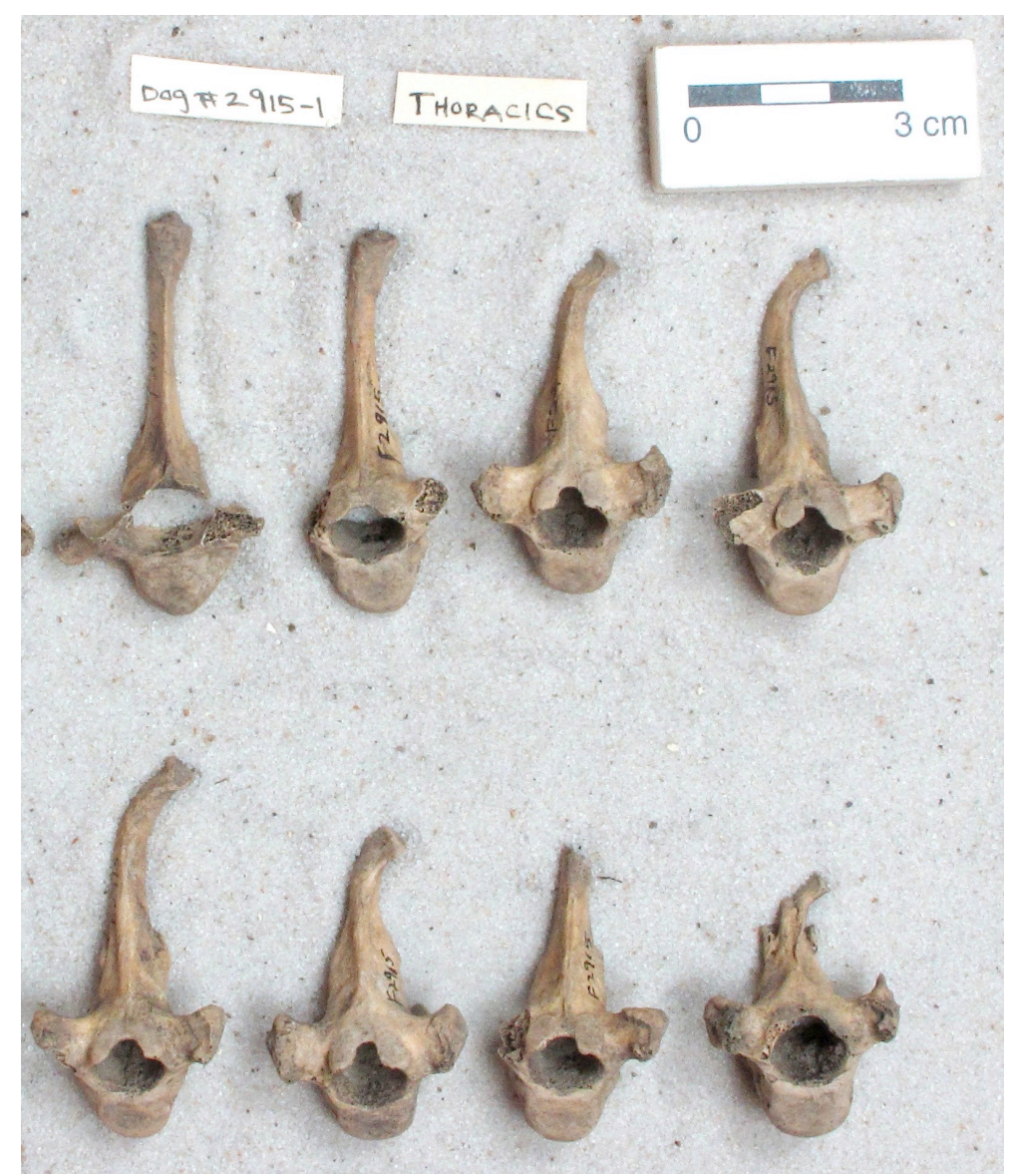

Figure 6. Dog F\#2915-1, bent spinous processes observable on the thoracic vertebrae (view of cranial surface).

Although spinous process anomalies can be caused by genetic or developmental abnormalities, severe deviations are often interpreted as the result of trauma from occupational stress, resulting from activities such as pack or load hauling (Warren 2004:91-93). A number of ethnographic accounts describe using domestic dogs to pull travois, sleds, or sledges, or hauling packs (e.g., Crellin 1994; Schwartz 1997; Park 1987; Warren 2004). In the American Bottom, it is possible that dogs were used to transport foodstuffs or firewood, a much needed resource (e.g., Lopinot and Woods 1993; Warren 2004). 
Osteophytes (also referred to as vertebral lipping) are another skeletal indicator of repetitive physical activity like load hauling, although other factors such as age, disease, and genetics may also play a role (e.g., Arnold 1979; Crellin 1994; Darwent and Gilliland 2001; Kuehn 2014b:114; Morey and Aaris-Sørensen 2002:50; Snyder 1995; Warren 2004). Osteophytes are densely sclerotic bone spurs that develop on the margins of articular surfaces, particularly on the vertebrae, as a result of degenerative vertebral margin osteophytosis (Baker and Brothwell 1980:227; von den Driesch 1976; Warren 2004:139-140). In severe cases, osteophytes may eventually bridge the intervertebral spaces, leading to ankylosis spondylitis (Figure 7) (Warren 2004).

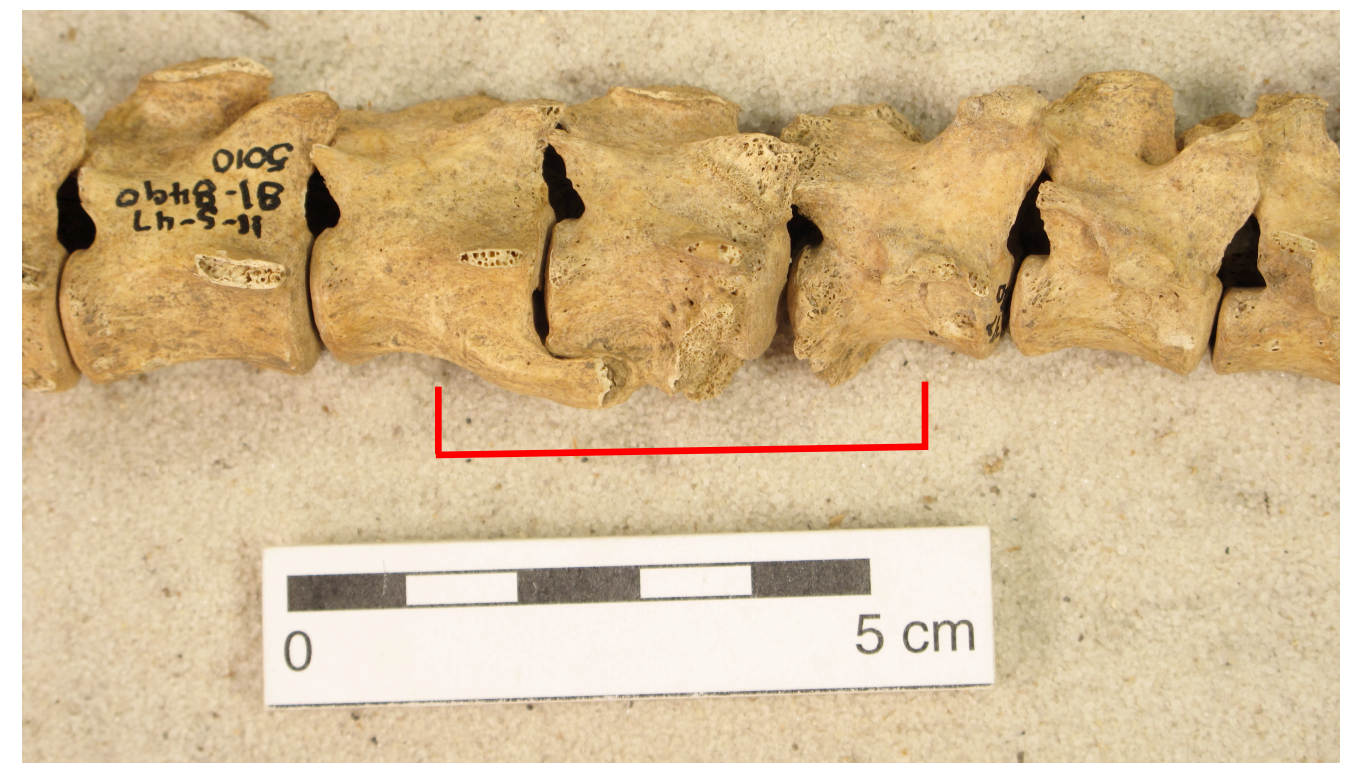

Figure 7. Dog F\#5010-1, ankylosis spondylitis observable on the thirteenth thoracic, and first and second lumbar vertebrae.

Evidence of cranial trauma is prevalent in archaeological assemblages. Impact or depression fractures are typically observed on the frontal or parietal bones near the eye orbit, and on the rostrum (e.g., Binois et al. 2013; Kuehn 2014b:110; Losey et al. 2014; Park 1987; Warren 
2004). Most of these fractures show some degree of healing indicating the injury was not fatal. Small wounds, especially when observed on the rostrum, are often interpreted as tooth punctures from dog fights, which were likely a common occurrence (e.g., Freuchen 1935:162-163; Losey et al. 2014; Park 1987:188). Larger depression fractures have been attributed to disciplinary and sometimes abusive actions (e.g., Baker and Brothwell 1980; Binois et al. 2013:41-45; Kuehn 2014b; Park 1987; Warren 2004) (Figure 8). For example, an ethnographic account by Jenness $(1922: 240)$ reports that:

...It is not often that the Eskimos strike their dogs, apart from an occasional blow to drive them out of the house, but whenever they do strike, they strike hard. Inveterate fighters and trouble-breeders naturally receive the most punishment, and I have seen dogs almost mutilated with a stick...Instances of cruelty do occasionally occur, but the majority of the natives are kind and indulgent masters to their dogs, and reciprocate the affection that their dogs obviously feel for them.

Fractures of other post-cranial elements, especially the ribs, also suggest blows, strikes, or kicks. These may be caused by disciplinary action or abuse, but may also be the result of interspecies conflict, accidents, and encounters with large prey (e.g., Arnold 1979; Bartosiewicz and Gál 2008; Binois et al. 2013; Crellin 1994; Groot 2008; Kuehn 2014b; MacKinnon 2010; Park 1987; Snyder 1995; Teegen 2005; Warren 2004). 


\section{CHAPTER V: METHODOLOGY}

Two researchers, Warren (2004) and Kuehn (2014b), have incorporated paleopathology into their analyses of dog burials from archaeological sites in the Midwest and Southeast regions. In their respective research, evidence of pathology and trauma was divided into two groups: dental or periodontal (e.g., antemortem tooth fracture, periodontal disease, abscess, antemortem tooth absence) and skeletal or non-dental (e.g., vertebral spinous process anomalies, osteophytes, active or healed periostitis, fractures).

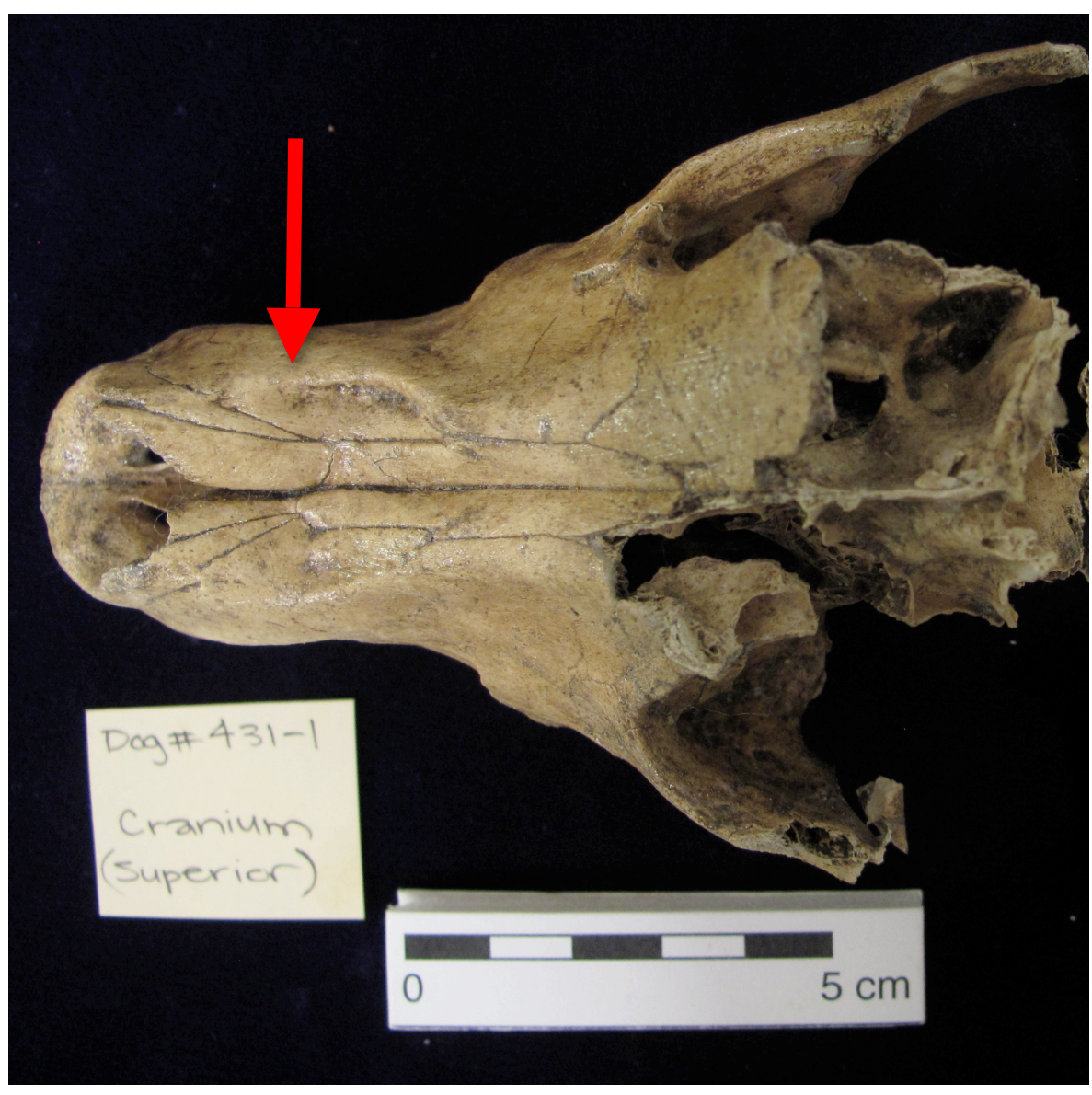

Figure 8. Dog F\#431-1, large depression fracture on rostrum. 


\section{Dog Classification}

For this research, dog remains are divided into four categories based on the elements and portions present: Burial, Head, Articulated Limb, and Isolate (Table 1). Other researchers (e.g., Grant 1984; Kuehn 2014b; Morris 2011; Pluskowski 2012) have used similar classifications, although no typology is universally accepted. Burial dogs are complete or mostly complete skeletons that were intentionally placed in a subsurface pit, structure, or similar feature. The term burial does not necessarily mean that the dog was interred in a discrete or specially prepared pit used solely for burial. Most pits almost certainly served multiple purposes (storage, refuse disposal, cooking, burial) so this term refers simply to a complete or partial dog carcass that was intentionally placed in a subsurface feature. The Burial category is further divided into burials with heads (code B1); burials without heads (B2), which lack any cranial elements or teeth; and probable burials (B3), which are distinguished by poor preservation and/or limited elements

present. The Head category consists of dogs represented only by cranial elements with or without the hyoid, atlas, or axis. The Articulated Limb category consists of articulated limb and paw bones that are removed from the rest of the body and specifically placed in a pit feature. Isolates are single elements that are not considered burials. In most cases, these remains could be either dog or coyote so they are identified as Canis sp. rather than specifically Canis familiaris. Occasionally multiple isolates are recovered from the same feature, but because they cannot be definitively identified as coming from a single individual, they are analyzed separately. 
Table 1

Dog Burial Categories

Dog Category Code

\section{Burial}

Burial with head

B1

Burial without head

B2

Burial, probable

B3

Head

Cranium only

H1

Cranium and mandible

$\mathrm{H} 2$

Cranium and vertebra/hyoid

H3

Articulated Limb

\section{Burial Context}

Feature types have been condensed into four general categories: pit, small-sized structure, large-sized structure, and keyhole structure. Pit features reflect a wide range of functions, particularly those associated with food preparation and storage. Similarly, structures may have been used for a variety of purposes especially those associated with domestic activities. Keyhole structures are described as having a main room, ramp, and end pit (Binford et al. 1970; Fortier et al. 1984). At the Range site, this type of feature is interpreted as functioning primarily sleeping quarters (Kelly et al. 1987:168). The ramps are thought to be long entryways, possibly for the 
purpose of regulating heat within the structure. It should be noted that these types of features likely served multiple functions over the course of site occupation.

\section{Age Distributions}

Accurately estimating age at death is imperative to valuable interpretations of faunal assemblages. Because some morphological markers of sex are developmental, sex determination is contingent on knowledge of the individual's age. Additionally, pathological risks may differ depending on the individual's age, making it necessary to determine age prior to analysis of pathology present.

Dogs were classified as juvenile/pup or adult. These categories are based on tooth eruption times (based on the tooth eruption table compiled by Arnall (1961, Table 2), who combined the studies done by Bourdelle and Bressou (1953), Miller (1949), and Nickel et al. (1960), and skeletal maturity chronology (Pfeil and DeCamp 2009). For this research, I combined these references into a single chart (see Appendix A) for consistency, as there can be considerable variation between breeds. I believe this chart illustrates the "average" dog well and provides a reasonable base for data collection and interpretation. The terms pup and juvenile are used interchangeably. Pups are described as having unerupted, erupting, or fully erupted deciduous teeth and/or partially erupted permanent teeth, and unfused or fusing epiphyses of the postcranial elements. Prior to complete dental and skeletal maturity (i.e., adulthood), pups can be more specifically aged based on which teeth have erupted and/or which elements are fused or unfused. Although timing can vary depending on the individual and size, it is generally accepted that permanent dentition is fully erupted by approximately 10 months of age and skeletal maturity is reached between 12 and 18 months of age (e.g., Warren 2004). 
Once an individual is considered an adult, it becomes more difficult to assign a specific age. Until it is approximately two years old, the dog is considered a young adult. This age category is distinguishable from other categories by complete skeletal and dental maturity with little to no wear visible on the occlusal surface of the teeth. Adult and older adult individuals exhibited slight to moderate and significant occlusal wear, respectively. Occlusal wear is not necessarily an accurate way to age dogs. A number of other factors such as diet, activity, pathology, and trauma can accelerate tooth wear. When possible, other skeletal features such as overall size and bone texture were taken into consideration. The adult age subcategories (i.e., young adult, mature or indeterminate adult, older adult) were noted during analysis; however, for the purposes of this discussion, dogs will be categorized generally as either "juvenile/pup" or "adult".

\section{Sex Distributions}

Sex determination is reliant on prior estimation of age. With the exception of bacula, skeletal indicators of sex are developmental and are therefore not reliable until the dog has reached skeletal maturity. For this reason, sexing will be limited to adult individuals. The only exception is when a juvenile baculum is present.

If a baculum is present, the individual is male. In the absence of a baculum, examination of various quantitative and non-metric traits is used to determine sex (e.g., Ruscillo 2006; Shigehara et al. 1997; The and Trouth 1976). Male individuals typically exhibit more developed muscles, which result in more pronounced surface markings (i.e., bony ridges, processes, and crests) where the muscles attach to the outer layer of the periosteum (Scott 1957; The and Trouth 1976). 


\section{Basioccipital Form}

In male individuals, the well-developed rectus capitis ventralis major and minor muscles form a narrow, raised triangular area around the tuberculum pharyngicum between the occipital condyles and sphenobasilar junction (Figure 9). Studies conducted by The and Trouth (1976) classified this triangular area into three types:

Type I: The general shape of the region is a narrow triangle with a very acute vertex angle. The two sides (nearly) meet each other and are never further than $1 \mathrm{~mm}$ apart. This type is considered male.

Type II: The base of the region is broad so that a real triangle does not form. The two sides do not meet in the median line, remaining at least $3 \mathrm{~mm}$ apart. This type is considered female.

Type III: The general shape of the region is triangular, although the sides remain 1-3 mm apart in distance. This category is for the individuals that cannot be reasonably classified as either Type I or Type II. Thus, sex is indeterminate for this type. 


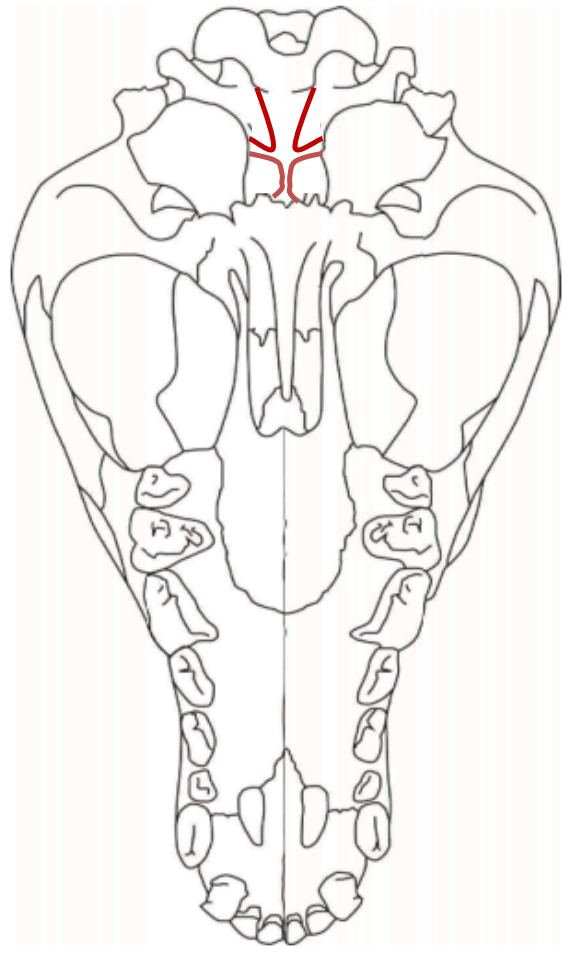

Type I

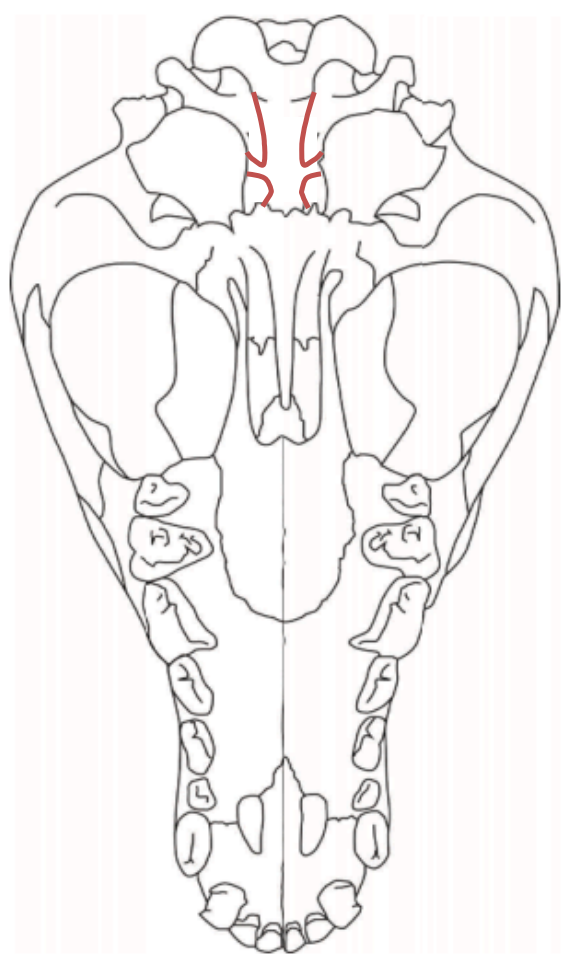

Type II

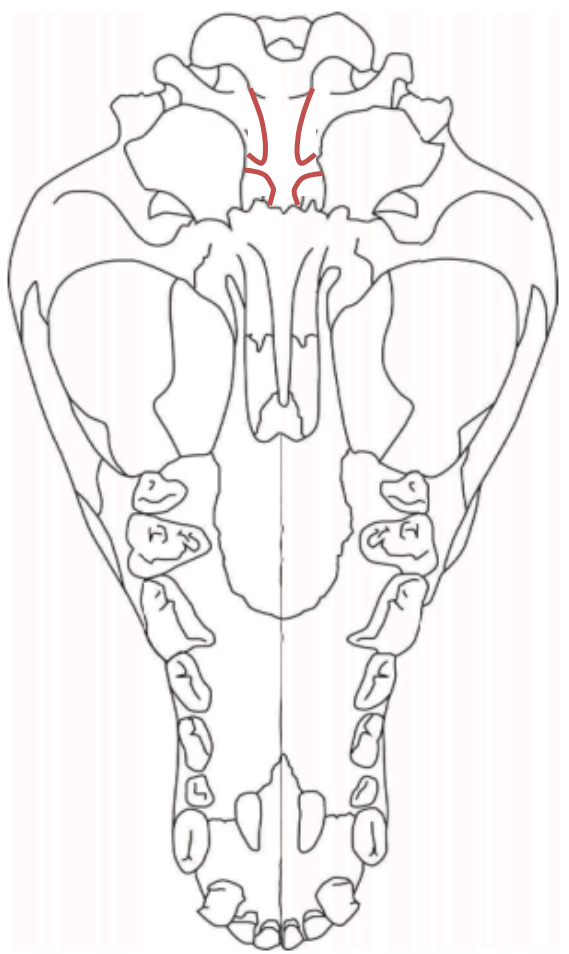

Type III

Figure 9. Basioccipital types used for sex determination based on studies conducted by The and Trouth (1976).

\section{Table Test/Humerus Roll}

For this test, a complete humerus is held from the proximal end and laid on its anteroventral surface on a level table (Ruscillo 2006). The humerus will either stay on it anteroventral surface or roll on its medial side. If the humerus rolls over, it is male; if not, it is female. The humerus rolls in male individuals because of the more pronounced deltoid muscle attachment. This test was conducted five times for each element in order to minimize any human error (extraneous movement, etc.) and the most commonly observed sex is recorded. If pathology is present, results may be less accurate. This test results in either a male or female determination; there is no indeterminate classification unless the bone is incomplete, juvenile, or pathological. 


\section{Sagittal Crest}

If the left and right temporal lines meet just behind the bregma and form a wellpronounced sagittal crest, the dog is male (Hasebe 1952; Shigahara et al. 1997). In females, the two lines do not meet and the sagittal crest is relatively smooth in comparison.

\section{Mandibular-Condyloid Ridge}

The condyloid ridge forms the inferior margin of the masseter fossa of the mandible. In males, the more developed masseter muscle attachment creates a distinct ridge between the masseter fossa and inferior edge of the mandible (Shigehara et al. 1997). In females, this muscle attachment is smoother. In hard to tell situations, a fingernail can be run down the lateral side of the masseter muscle attachment; in males, the fingernail will catch on the acutely angled ridge.

\section{Superior Nuchal Line}

In males, the superior nuchal line in the occipital region is not straight whereas in females, it is straight (Shigehara et al. 1997). This occurs because of the well-developed temporal muscles present in males.

\section{Discriminant Analysis}

Sex can also be determined using discriminant functions derived from select determinant factors with high coefficients of difference (Shigahara et al. 1997). Shigahara et al. (1997) derived nine discriminant functions; only the function using elements from the entire skeleton was utilized for this research as this function has the lowest probability of error ( 7 percent). The equation is as follows: 


$$
\mathrm{Y}=(\mathrm{A})-0.0423(\mathrm{~B})+0.0767(\mathrm{C})-5.89
$$

In this function, (A) is the bucco-lingual diameter of the mandibular canine, $(\mathrm{B})$ is the subpubic angle, and (C) is the maximum breadth of the atlas. When the appropriate measurements are substituted into the equation and the resulting discriminant value $(\mathrm{Y})$ is positive, the individual is determined to be male. If the discriminant value is negative, the individual is female. Unfortunately, discriminant analysis was not very useful for this research as all three measurements could not be obtained in the majority of individuals. It should also be noted that the discriminant functions discussed in Shigehara et al. (1997) were derived based on two specific breeds (the modern shiba and Jomon period dogs) and may result in differing accuracy rates when applied to other breeds.

If the sex is not clearly male or female or when skeletal remains are fragmentary or absent, the sex was categorized as indeterminate. If the sex is not definitive but is skewed in favor of one sex or the other, the sex was considered likely male or likely female.

\section{Dental Paleopathology}

Only dogs with permanent dentition were included in this discussion of dental pathologies and trauma since these are rarely observed on juvenile individuals. Pathologies observed on the Range dogs include tooth fracture, periodontal disease, periodontal abscess, and antemortem tooth absence. A detailed discussion of the analytical methods employed for each pathology is presented below. Examinations were conducted using a 10x power hand lens. Detailed descriptions and schematic illustrations were documented when applicable. Pathology frequencies do increase with age and heavier occlusal wear does make teeth more susceptible to fracture and other damage; however, due to the relatively small sample of dogs with permanent 
dentition and the potential overlap of age subcategories (i.e., young adult, mature adult, and older adult), this aspect was not included in this discussion.

\section{Antermortem Tooth Fracture}

The location and type of fracture were recorded. In order to eliminate possible postmortem damage, only fractures with worn margins are discussed here. Fractures can occur at the crown, the root(s), or both. Coronal fractures are subdivided into five categories: chips, transverse fractures, slab fractures, vertical fractures, and non-specific fractures (Warren 2004). The only type of fracture observed in this assemblage is the slab fracture, which is described as oblique.

\section{Periodontal Disease}

Periodontal disease is inflammation of the tissues surrounding the teeth (i.e., gingiva, cement, periodontal membrane, alveolar bone) as a result of bacteria in dental plaque (Page and Schroeder 1981, 1982) (Figure 10). In more advanced cases the alveolar bone becomes increasingly compromised resulting in "periodontal pockets" around the teeth. The destruction of the alveolar bone can occur horizontally in which the roots of multiple teeth are exposed at once, or vertically in which single roots are exposed. Occasionally, intrabony pockets (periodontal abscesses) form around the roots of one or multiple adjacent teeth. For this analysis, periodontal disease is categorized as either present or absent. 


\begin{abstract}
Abscess
Abscesses can develop as a result of periodontal disease or around teeth that have suffered trauma (fractures) (Figure 11). It can affect a single tooth or multiple teeth and can result in antemortem tooth loss. When present, the location of the abscess was recorded.
\end{abstract}

\title{
Antemortem Tooth Absence
}

A tooth was considered absent during life if all its root sockets display some degree of alveolar remodeling, or if smooth bone is present suggesting agenesis (see Figure 5). If a tooth is lost early enough before death, complete alveolar resorption can be difficult to distinguish from an unerupted or undeveloped tooth. Therefore, the term "antemortem tooth absence" is used in place of "antemortem tooth loss". The probable cause of tooth loss (e.g., agenesis, fracture, abscess) was noted when it could be reliably ascertained. 


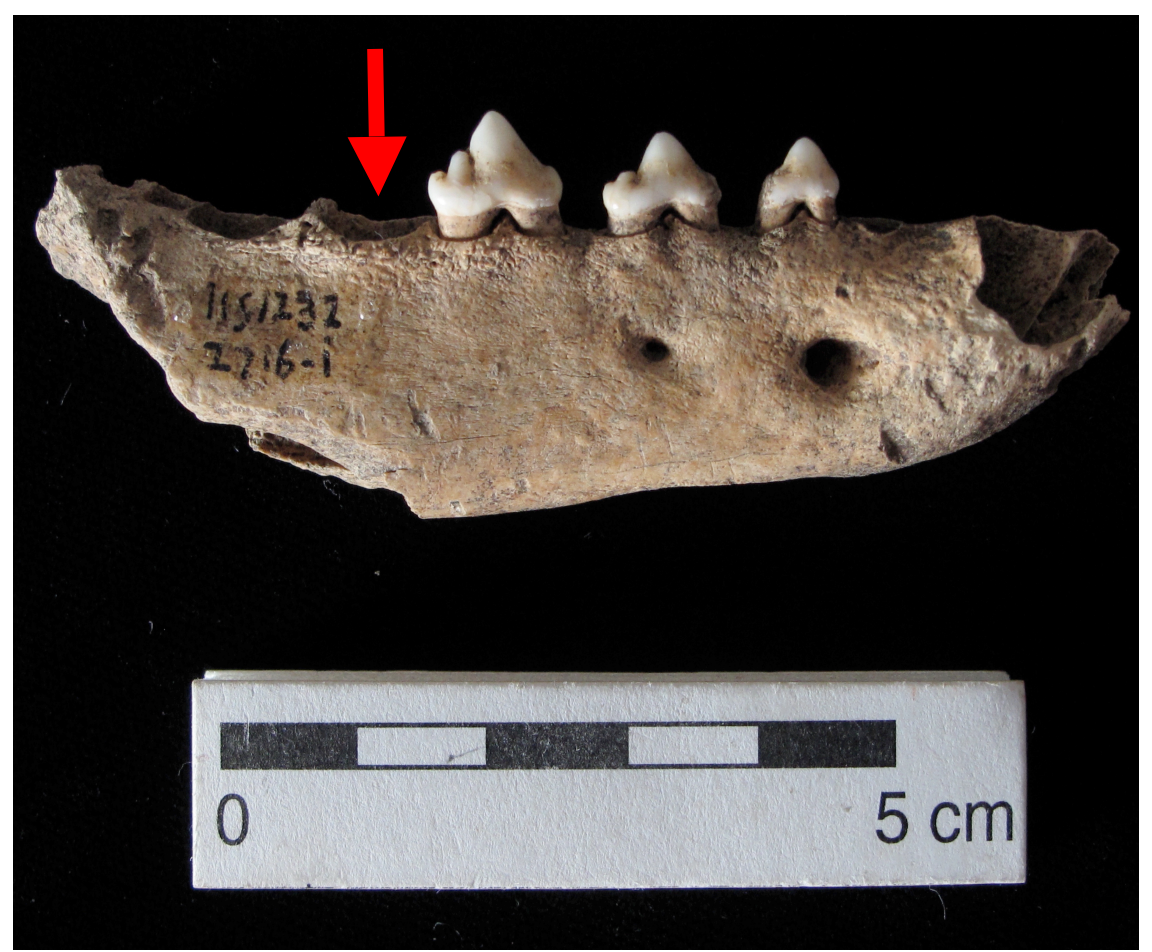

Figure 10. Canid mandible from the Janey B. Goode site (F.2716) with periodontal disease. Arrow points to area where the disease is the most extensive (Image courtesy of the Illinois State Archaeological Survey).

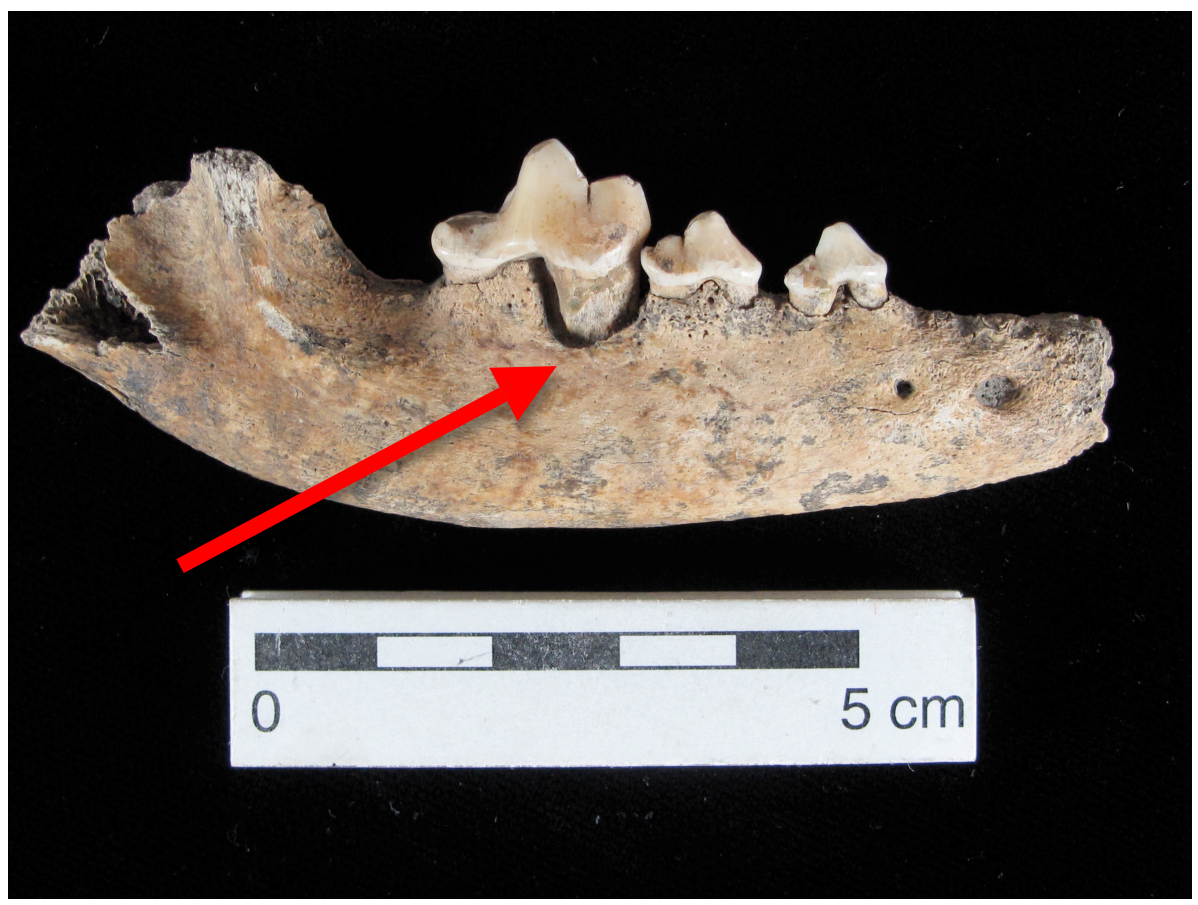

Figure 11. An abscess forming at the root of the right M1 of a canid mandible from the Janey B. Goode site (F.1433) (Image courtesy of the Illinois State Archaeological Survey). 


\section{Skeletal Paleopathology}

All elements in the assemblage were examined for evidence of pathology and trauma using a 10x power hand lens. Only fractures exhibiting some degree of healing indicating antemortem trauma was recorded in order to minimize the inclusion of post-depositional breakage and taphonomy. When possible, degree of severity and degree of healing were recorded in addition to the location of the pathology or trauma.

Grouped elements (cranial bones, ribs, sternebrae, carpals, tarsals, metacarpals, and metatarsals) were considered units comprising a single location. Phalanges were grouped as proximal/middle or terminal. Vertebrae were considered both individually and as regional groups (cervical, thoracic, or lumbar). Some vertebrae (all cervical vertebrae, thoracic vertebrae 1, 2,

and $10-13$, and the $7^{\text {th }}$ lumbar vertebra) have diagnostic traits allowing them to be specifically identified in insolation. Other vertebrae may be specifically identifiable if the spinal column is complete or nearly complete. Incomplete vertebrae or those found in isolation may only be identifiable to the regional level. With the exception of phalanges, elements and grouped elements were analyzed separately by side (left or right). Elements such as the mandible, pubis, ilium, and ischium were analyzed by side as individual elements. For this discussion, percentages of cranial trauma are limited to the portion of the population with heads. For discussion of vertebral, scapular/pelvic, and appendicular trauma, percentages are limited to the portion of the population with postcranial elements, including Articulated Limbs. 


\section{Cranial Trauma}

Cranial trauma refers to any pathology or trauma affecting the cranium, maxilla, or mandible. Depression fractures are circular or ovular in shape and typically exceed $10 \mathrm{~mm}$ in diameter (see Figure 8). Depression fractures are typically found on the rostrum or near the orbitals. Puncture or bite marks are similarly shaped but generally measure $10 \mathrm{~mm}$ or less in diameter. These smaller fractures are most commonly observable on the rostrum although they can also be found on the frontal bones. Fractures (non-depression) can occur on thinner parts of the cranium such as the nasal bones and zygomatic processes. Active or healed pathology is also noted when observable. When pathology or trauma is present, the location is documented as well as any secondary conditions (i.e., deformity, malocclusion, etc.) caused by the cranial trauma.

\section{Vertebral Trauma}

Vertebral trauma consists of spinous process anomalies, endplate trauma, osteophytes, and ankylosis spondylitis. Spinous process anomalies, or deviated spinous processes, typically occur on the lower cervical, thoracic, and lumbar vertebrae (see Figure 6). Deviations include bending or warping of the spinous process away from the midline of the body (left or right), fracture of the spinous process, or abnormal compression. These types of abnormalities were often accompanied by irregular bony growth. Although minor deviation can occur as a result of genetic or developmental factors, trauma is generally the accepted cause of more severe cases (Warren 2004:91-93). A combination of congenital and traumatic factors is also possible (e.g., Baker and Brothwell 1980; D. Morey in Darwent and Gilliland 2001). For this analysis, spinous process anomalies were categorized by type (side of deviation, compression, fracture) and location. Vertebral endplate trauma consists of compression fractures of either the cranial or 
caudal centrum epiphyses. This pathology is categorized as either present or absent; when present, the vertebra and surface (cranial or caudal) affected are noted.

Osteophytes, or vertebral lipping, are densely sclerotic bony spurs that develop as a result of vertebral margin osteophytosis (Warren 2004:139-140). Osteophytic growth typically develops on the ventral and lateral margins of the centrum, although it can also be occur on other postcranial elements along the margins of the articular surfaces. This pathology often forms as the result of osteoarthritis. Osteophytes are categorized as either present or absent; osteophytes are considered present if irregular bony protrusions along the margins of the vertebral body can be macroscopically observable. Eventually, these bony growths may bridge the intervertebral spaces, leading to ankylosis spondylitis (Warren 2004:141) (see Figure 7). For this analysis, ankylosis spondylitis is recorded as either present or absent; categorization as present indicates heavy and distinct fusion of elements as the result of bony growth. Although this pathology most often affects the lower vertebrae, it is not restricted to the spine. For both osteophytes and ankylosis spondylitis, the location of the pathology is noted when present. Porosity, grooving, and eburnation should also be noted when present (Figure 12).

\section{Scapular, Pelvic, and Appendicular Trauma}

When present, the location and a detailed description of the trauma were documented. Some of the more common pathologies observed include active and healed infection, fracture, abnormal bony growth (osteophytes, fusion of two elements), porosity, and eburnation (Figure 13-15). Secondary conditions associated with the initial trauma were also documented (e.g., infection or fusion of elements as the result of a fracture, etc.). 


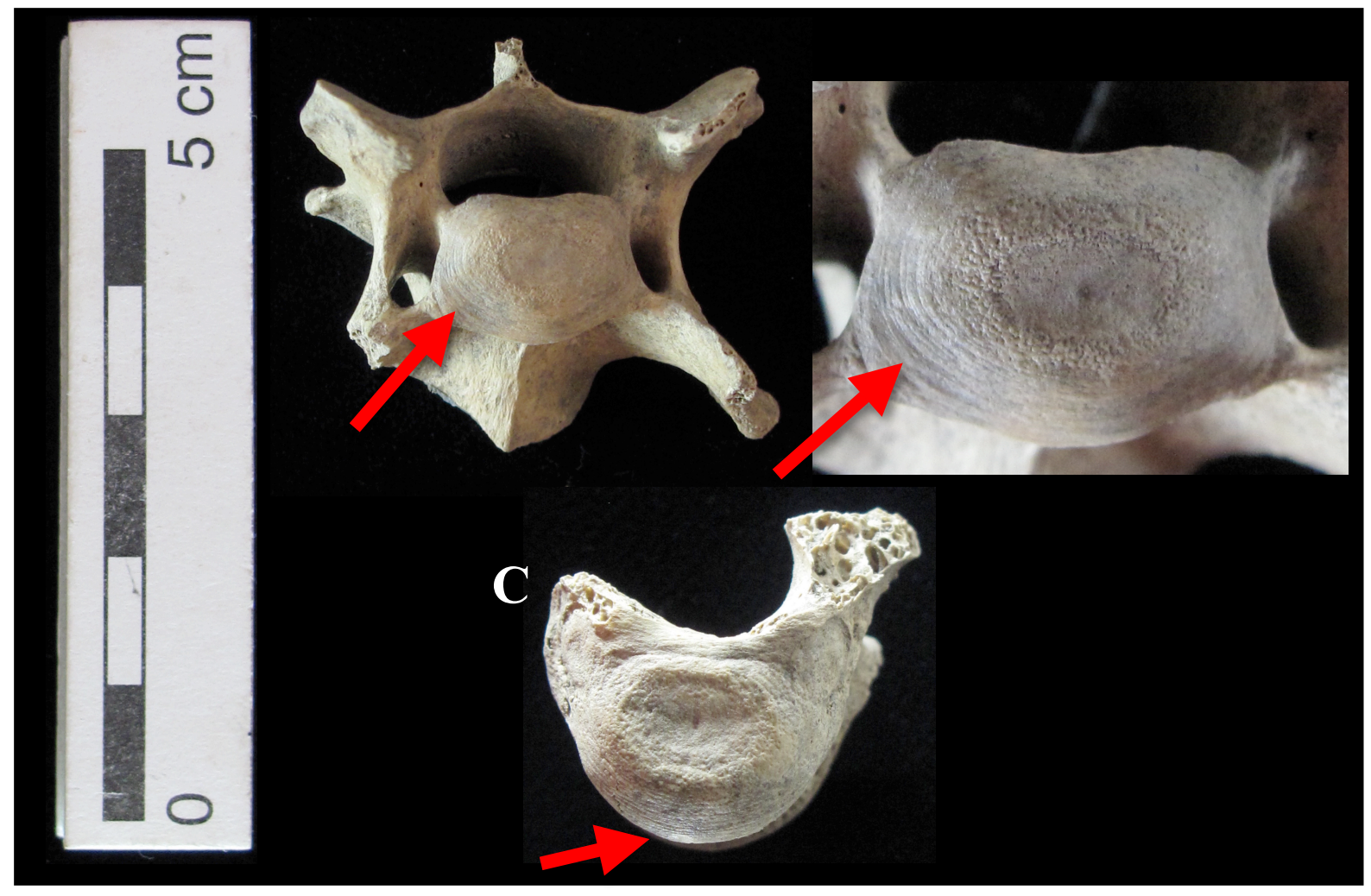

Figure 12. Grooving and eburnation observable on canid vertebrae from the Janey B. Goode site (F.7633): (A) shows grooving on the centrum of a cervical vertebra; (B) shows a close-up of the grooving; (C) shows eburnation on the centrum of a thoracic vertebra (Images courtesy of the Illinois State Archaeological Survey). 


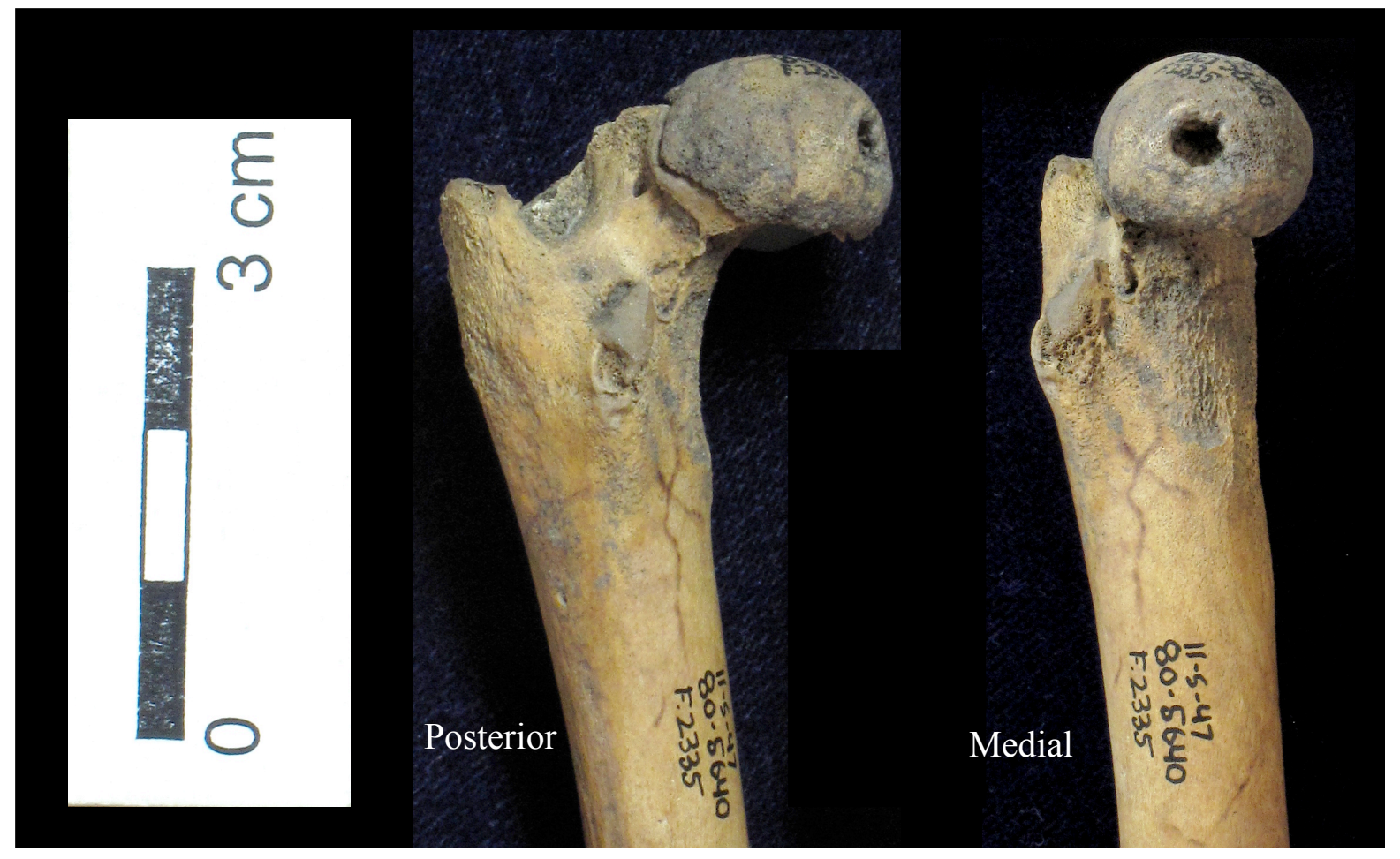

Figure 13. Dog F\#2335-1, infection and atrophy of the left femoral neck (A) and fovea capitis (B).

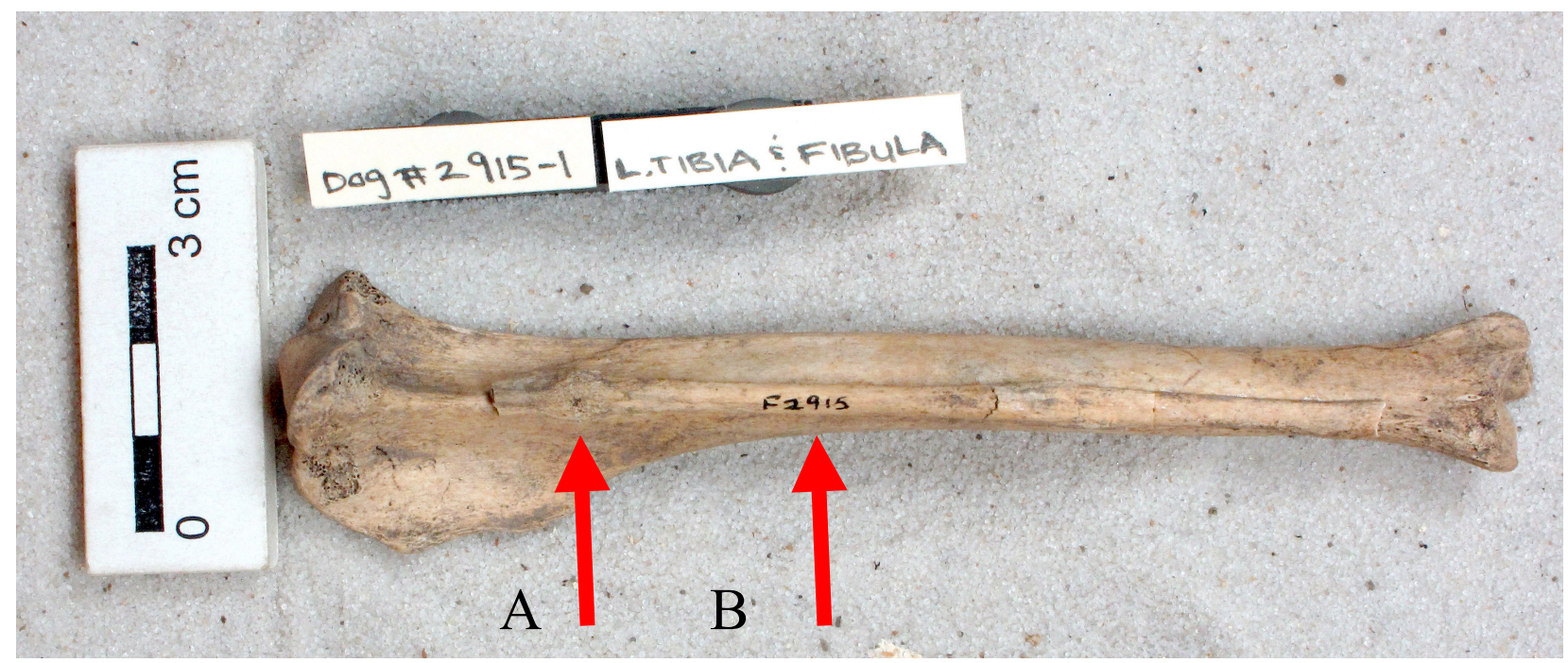

Figure 14. Dog F\#2915-1, a healed fracture of the left fibula (A) and fusion of the tibia and fibula (B). 


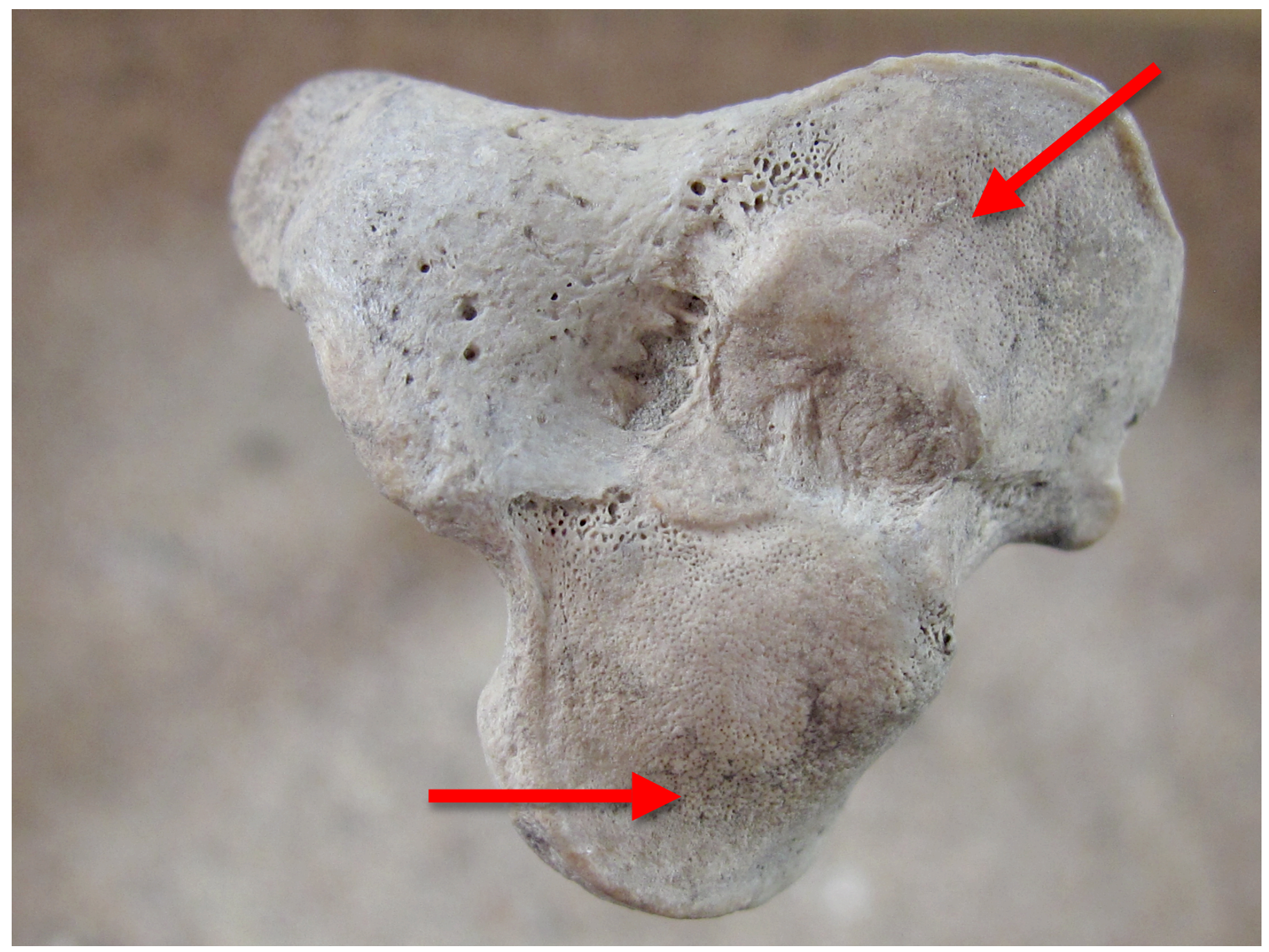

Figure 15. Pinpoint porosity observable on a canid tibia from the Janey B. Goode site (F.4339) (Image courtesy of the Illinois State Archaeological Survey). 


\section{CHAPTER VI: DESCRIPTION OF DOG BURIALS}

For this research, each of the 52 dog burials recovered from the Range site were analyzed to determine age, sex, burial context, and pathologies and trauma. A detailed discussion of the analytical techniques utilized for this research are outlined in the previous chapter. Broader trends and conclusions based on data collected from examination of the assemblage will be discussed in subsequent chapters.

\section{Late Woodland-Patrick Phase}

\section{Dog F\#431-1 (Adult, Male)}

Dog F\#431-1 was recovered from the floor of a medium-sized circular pit. The body was found on its right side in a flexed position facing north-northwest. The skeleton was complete and in relatively good condition. Little additional faunal material was recovered from this feature. All elements present were completely fused indicating that this individual was an adult. The presence of robust muscle attachments and significant wear on the articular surfaces of the majority of bones suggested this dog was possibly an older adult or endured repetitive physical activity. Sex was determined to be male based on the presence of a baculum and non-metric observations.

A large, partially healed depression fracture was present on the rostrum causing significant compression and malocclusion (see Figure 7). When viewed anteriorly, the rostrum deviated to the left of the midline (Figure 16). Abnormally heavy wear was present on the maxillary first premolars, and first and second molars. The left fourth premolar was fractured 
antemortem, as was evident by the rounding of the broken edges. The mandibular teeth show similar evidence of malocclusion. Significant wear was present on the first, second, and third molars as well as on the labial (anterior) surfaces of the incisors and canines. In an aligned jaw, the typical wear pattern is heaviest on the lingual (posterior) surfaces of these teeth, again illustrating the significant malocclusion of this dog. The lower right first premolar was lost antemortem and the alveola was almost completely remodeled. Periodontal disease was evident around the majority of teeth. Another much smaller (2.6 $\mathrm{mm}$ in dia.) depression fracture was present on the left maxilla, also with evidence of healing. Postcranially, osteophytic growth was observed on the proximal articular surface of the left femur and acetabulum of the left pelvis. Five ribs, all from the right side, had healed fractures. Two of the thoracic vertebrae and five of

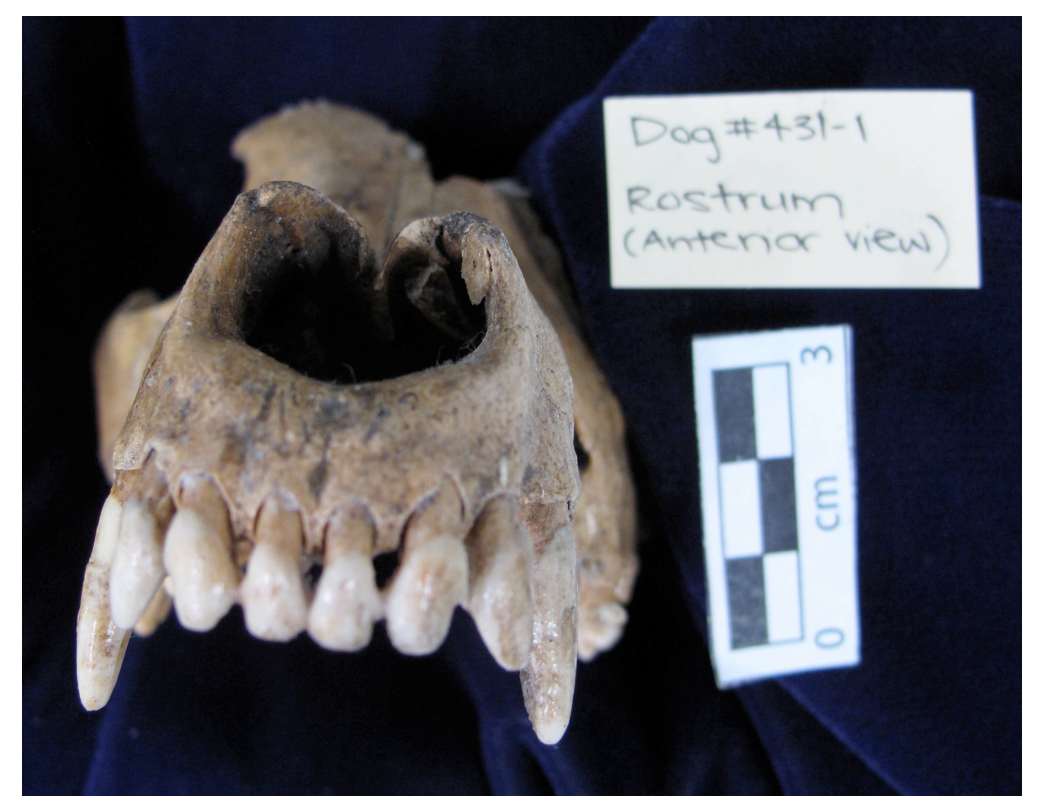

Figure 16. Dog F\#431-1, anterior view of rostrum showing deviation to the left of the midline.

the lumbar vertebrae exhibited spinous process anomalies. 


\section{Dog F\#441-1 (Adult, Indet.)}

In a large-sized circular pit, two adult dogs and one pup were recovered from the lower $30 \mathrm{~cm}$ of the southwestern half. Dog \#441-1 was one of the adult dogs and was found in a flexed position facing south with the head seemingly twisted 180 degrees from normal. This skeleton was complete and in good condition. Although the initial analysis indicated the presence of a baculum (L. Kelly 1987:361), this element was not found during the reanalysis. The final sex determination was indeterminate due to discrepancies between non-metric cranial observations and the humeri roll results.

All teeth were present with the exception of the lower right first premolar, which was lost antemortem as evidenced by the partially remodeled alveola. Most elements exhibited pinpoint porosity and marginal lipping of articular surfaces. The right fibula was fractured mid-shaft, but healed malaligned. Significant periostitis was present along the entire length of the left scapular spine, possibly the result of fracture. Small areas of spongy bone growth (possibly active periostitis) were present on the distal left humerus and right pelvis. Several of the ribs displayed significant osteophytic growth on the proximal ends indicating partial fusion to the sternum and one rib had a healed fracture. The majority of the thoracic vertebrae had both healed and active periostitis on the spinous processes and zygopophyses. Partially healed compression fractures were present on the cranial surface of the third lumbar, and the caudal surfaces of the seventh thoracic centrum and sacrum. The second and third lumbar vertebrae were partially fused indicating ankylosis. Additionally, several of the thoracic and lumbar vertebrae displayed spinous process deviations. 


\section{Dog F\#441-2 (Pup, Indet.)}

Dog F\#441-2 was also recovered from this large-sized circular pit although the position of this individual could not be determined. The skeleton was almost complete and in fair condition. Based on tooth eruption, the pup was between 2-5 months old. Due to the age, no sex could be determined. No evidence of pathology or trauma was observed.

\section{Dog F\#441-3 (Adult, Male)}

The other adult dog in Feature 441 was extended on his right side. The skeleton was complete and in good condition. Based on cranial non-metric observations and the humerus roll, this dog was male. All elements showed significant muscle attachment robusticity, marginal lipping, and pinpoint porosity suggesting advanced age and/or physical labor. The maxillary fourth premolars, first molars, second molars, and incisors were heavily worn. Additionally, the right canine was fractured antemortem and then heavily worn. Similarly, the mandibular first, second, and third molars, as well as canines and incisors were heavily worn. Both lower third premolars were lost antemortem as evidenced by the completely filled alveoli. Two of the lower right ribs had healed fractures with extensive remodeling. The fifth, sixth, seventh, and eighth thoracic and third and fourth lumbar vertebrae exhibited spinous process deviations.

\section{Dog F\#798-1 (Adult, Indet.)}

Dog F\#798-1 was recovered from a large-sized square pit and was represented by the cranium, atlas, and portions of the left forelimb. Based on epiphyseal fusion, this dog was an adult, but small in stature. Sex was indeterminate. Cut marks were present on the ventral side of the atlas (Figure 17). No other pathology or trauma was observed. 

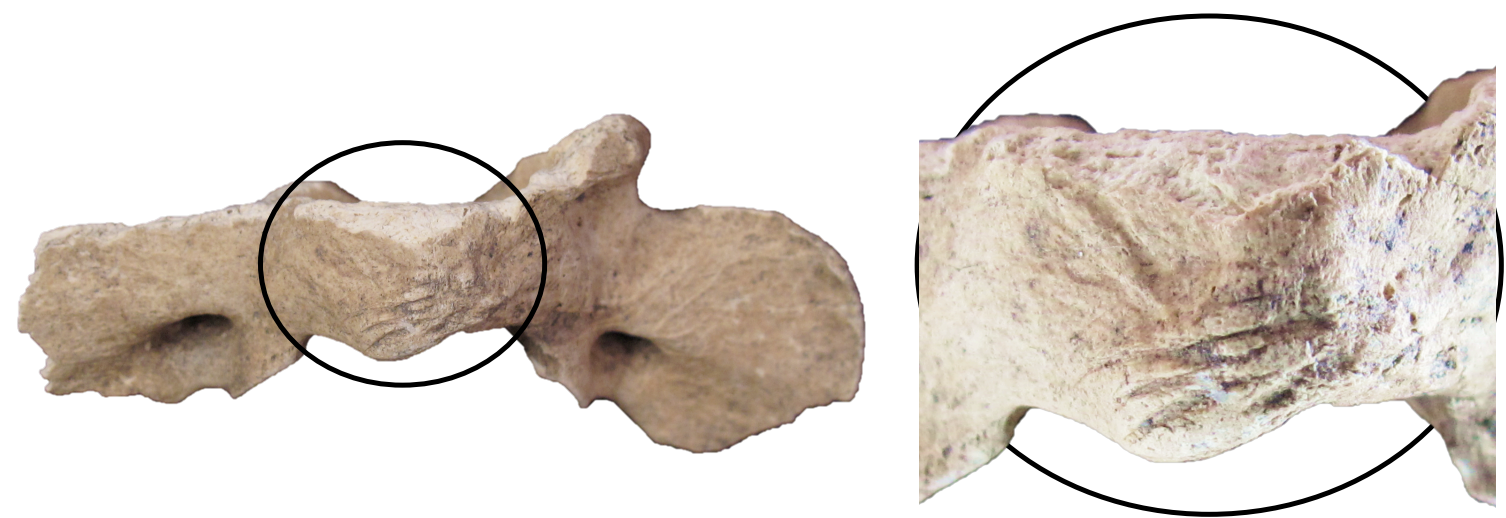

Figure 17. Dog F\#798-1, close-up of atlas with cut marks on the ventral surface.

\section{Dog F\#2036-1 (Adult, Indet.)}

Dog F\#2036-1 was recovered from the floor of a medium, circular pit and was represented by the skull and atlas. This individual was an adult based on tooth eruption and wear. No sex could be determined because of fragmentation. No pathology or trauma was observed on the remains. Excavators noted a concentration of limestone near this individual (Feature notes F.2335).

\section{Dog F\#2631-1 (Adult, Indet.)}

Dog F\#2631-1 was recovered from the ramp floor of a keyhole structure. Only poorly preserved cranial and mandibular fragments were present. None of the teeth were present, but based on relative size this dog was likely an adult. Sex could not be determined due to the fragmented condition. No pathology or trauma was observed. 


\section{Dog F\#2813-1 (Pup, Indet.)}

The skull and limbs of Dog F\#2813-1 were found in a medium-sized oval pit. Based on tooth eruption and lack of epiphyseal fusion, this dog was between 2-5 months old. Sex is indeterminate because of juvenility. No pathology or trauma was observed.

\section{Dog F\#2820-1 (Pup, Indet.)}

Dog F\#2820-1 was also found on the ramp floor of a keyhole structure in a tightly flexed position. The skeleton was complete with the exception of the thoracic vertebrae, majority of the cervical vertebrae, left forelimb, and the paws. Based on tooth eruption and epiphyseal fusion, this dog was between 4-6 months old. Due to age, no sex can be determined. No pathology or trauma was present.

\section{Dog F\#2900-1 (Adult, Indet.)}

Dog F\#2900-1 was recovered from the fill of a medium-sized oval pit. This individual was represented by the mandibles and both forelimbs. Based on tooth wear and long bone fusion, this was an adult dog. Lack of sex determining elements prohibits determination of sex. Remains exhibited extensive taphonomy and fragmentation. The right mandibular first premolar was lost antemortem as evidenced by bony remodeling. Periodontal disease was present on both mandibles. No other pathology or trauma was observable.

\section{Dog F\#3765-1 (Adult, Male)}

Feature 3765 was a large-sized oval pit and contained the remains of one adult dog and four pups. Dog F\#3765-1 was an adult and skeletally complete. The original analysis identified 
this individual as female (L. Kelly 1987:365), likely based on the presence of four pups in the pelvic region. However, based on cranial non-metric observations and the humerus roll test, my final determination was male, although a baculum was not recovered.

In general, all elements exhibited extensive porosity, cortical thinning, and marginal lipping. Significant pitting and bony growth were present on the cranium, particularly on the parietals and along the sagittal crest. Although this could be indicative of infection, it was more likely that the rough surface texture was the result of advanced age or post-burial taphonomy. The right maxillary first premolar was unerupted and there was moderate periodontal disease surrounding the majority of teeth. The maxillary first and second incisors were broken antemortem and heavy wear after breakage suggested this individual had an overbite. The mandibular incisors were similarly more heavily worn in comparison to the other teeth.

Several elements, including the right distal humerus, right proximal radius, left and right pelves, left and right femora, and atlas had some areas of active and/or healed infection. The small area of infection on the left femur shaft was particularly distinct in that it appeared flaky and superficial. The majority of vertebrae exhibited marginal lipping, porosity/cortical thinning, eburnation, and grooving. Osteophytic growth was present on the fifth, sixth, and seventh cervical vertebrae, and fifth lumbar vertebra in addition to the previously listed pathologies, which met the criteria for osteoarthritis.

\section{Dog F\#3765-2a-d (Pup, Indet.)}

A minimum of four pups was recovered from the pelvic region of the Dog F\#3765-1. As mentioned above, the original report noted the position of the pups in the pelvic region of Dog F\#3765-1 and suggested all five individuals may have died during birth (L. Kelly 1987). 
However, in addition to determining the sex of Dog \#3765-1 as male, tooth eruption indicated that all four pups were at least one month old. The skeletons of these pups were nearly complete, although elements could not be distinguished by individual pup. No pathology or trauma was noted.

\section{Dog F\#3768-1 (Pup, Indet.)}

Dog F\#3768-1 was recovered from a large-sized oval pit. The majority of the skeleton was present with the exception of the paws. Based on epiphyseal fusion and tooth eruption, this individual was 2-5 months old. Sex could not be determined because of skeletal immaturity. No pathology or trauma was observed.

\section{Dog F\#4449-1 (Adult, Indet.)}

Dog F\#4449-1 was recovered from the fill of a large-sized circular pit. The only elements present were the right mandible and maxilla. These remains were very fragmented. Based on tooth eruption and wear, this individual was an adult. No sex could be determined due to the poor condition of the remains. No pathology or trauma was observed.

\section{Dog F\#4819-1 (Adult, Likely Male)}

Dog F\#4819-1 was recovered from the floor of a keyhole structure. The body was in a tightly flexed position and was complete. All elements were completely fused indicating this dog was an adult. Based on the right humerus and mandibular condyloid ridge, this individual was likely male. 
The first and second molars in both the mandible and maxilla were worn almost down to the root (Figure 18). The left mandibular canine was worn to a nub and likely rubbed on the maxillary incisors instead of the left maxillary canine (which had very little wear). This suggested the maxilla was shifted to the left of the midline causing significant malocclusion. Furthermore, the right maxillary and mandibular canines were beveled and heavily worn indicating abnormal rubbing against one another. The maxillary and mandibular first premolars were absent, likely as a result of the abnormally short diastema. Little more can be said regarding additional pathology or trauma because of fragmentation of the skull. The majority of postcranial remains exhibited robust muscle attachments and degeneration of articular surfaces suggesting hard work or advanced age. 

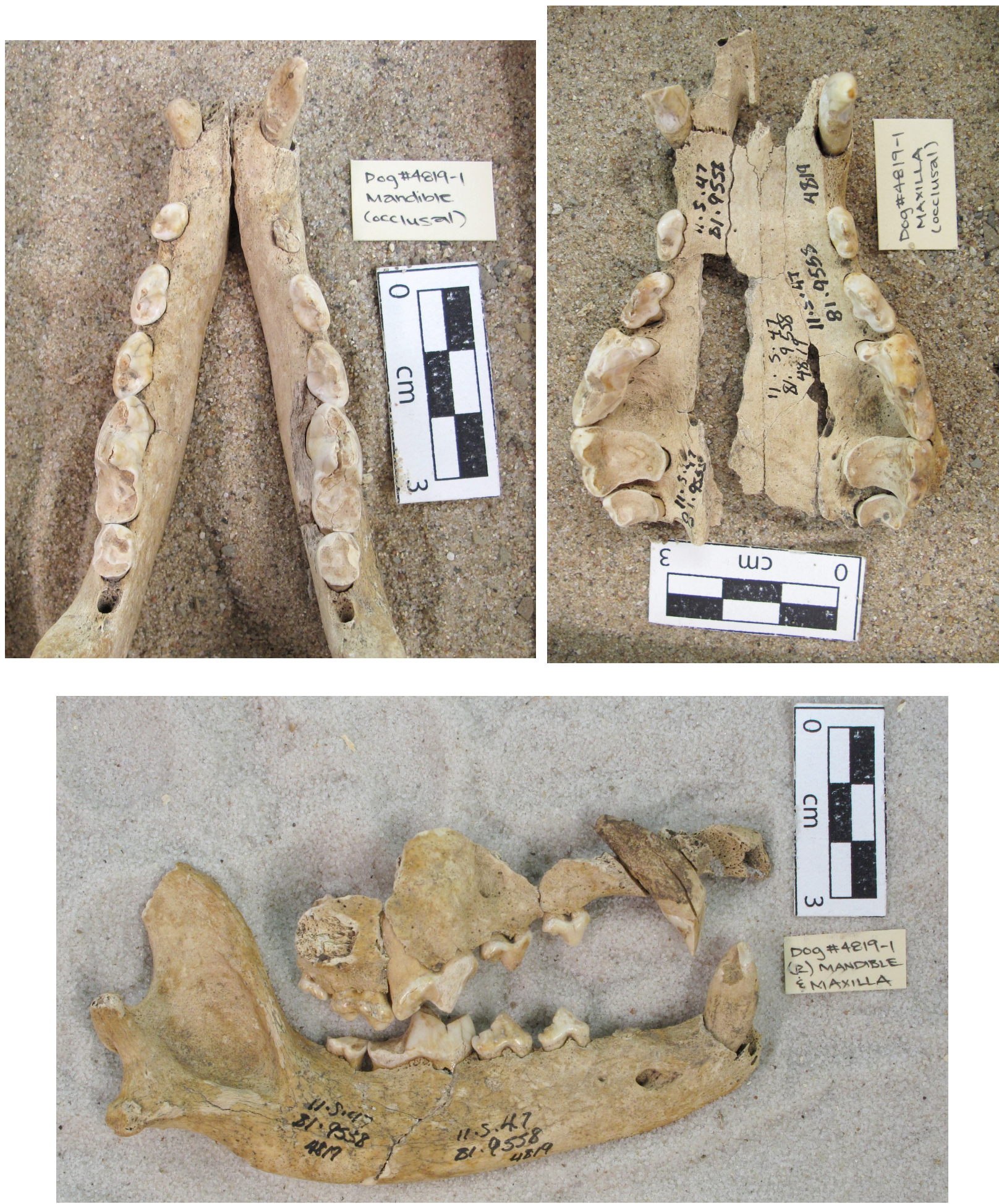

Figure 18. Dog F\#4819-1, uneven wear on the left side of the dental arcade (shown in top images) and malocclusion of the right jaw (shown in bottom image). 


\section{Dog F\#4852-1 (Adult, Indet.)}

Dog F\#4852-1 was recovered from a pit feature and was represented by the skull, atlas, and axis. This individual was an adult, but sex cannot be determined due to the fragmentary condition. Both mandibular first premolars were absent and the area surrounding these teeth exhibited significant infection. Additionally, there was significant periodontal disease surrounding the fourth premolars and molars.

\section{Dog F\#5010-1 (Adult, Indet.)}

Dog F\#5010-1 was recovered from a pit feature and was represented by the elements of the upper body, with the exception of the skull. Based on epiphyseal fusion, this dog was an adult. Sex was indeterminate. In general, muscle attachments appear gracile. Only the lower portion of the vertebral spine (T7-L4) are present and all displayed spinous process anomalies. The eleventh thoracic vertebra had a healed fracture of the spinous process. The anterior articular surface of the centrum of the second lumbar vertebra had a compression fracture that occurred antemortem as was evidenced by partial healing. The thirteenth thoracic vertebra and first and second lumbar vertebrae were fused indicating ankylosis spondylitis (see Figure 7). Additionally, two ribs showed significant osteophytic growth at the proximal ends.

\section{Dog F\#5027-1 (Young Adult, Indet.)}

Dog F\#5027-1 was recovered from a pit feature identified on the floor of Feature 4907, a small rectilinear structure. This individual lay in a curled position. The elements present included the skull, forelimbs, and vertebrae. Based on tooth wear and epiphyseal fusion, this individual 
was considered a young adult. Sex was indeterminate due to poor condition of the bones. No pathology or trauma was observable.

\section{Dog F\#5100-1 (Pup, Indet.)}

Dog F\#5100-1 was recovered from a large-sized pit. Elements present included cranium, mandible, long bones from forelimbs and hindlimbs, pelvis, rib, and a single vertebra fragment. Based on tooth eruption and epiphyseal fusion, this individual was 4-6 months of age. Sex was indeterminate due to the juvenile nature of the remains. No pathology or trauma was observed.

\section{Dog F\#5128-1 (Adult, Indet.)}

Dog F\#5128-1 was recovered from the floor of a small-sized rectangular structure and was represented by an articulated left forelimb, including the humerus, radius, ulna, carpals, metacarpals, phalanges, and sesmoids. Based on epiphyseal fusion, this animal was an adult. Elements were poorly preserved inhibiting extensive examination and determination of sex. The only observable pathology was porosity/cortical thinning on articular surfaces.

\section{Dog F\#5263-1 (Adult, Female)}

Dog F\#5263-1 was recovered from a pit with expanded sides. Only portions of the cranium were present. Based on non-metric cranial observations, this individual was a female. All of the teeth were erupted and displayed moderate to heavy wear indicating she was an adult.

Both of the first premolars were absent and some bony remodeling was present; however, it was not clear whether these teeth were lost antemortem or never erupted. A bony inclusion was present on the root of the left canine and extensive periodontal disease and thinning of the 
alveolar bone was observed. Additionally, there was some bony remodeling on the right zygomatic process.

\section{Dog F\#5586-1 (Older Adult, Male)}

Dog F\#5586-1 was recovered from a pit feature. The skeleton was complete, but in poor condition. This dog was an adult and presence of osteophytic growth on the majority of elements suggested he was likely an older adult. A baculum was present indicating this individual was a male.

The left maxillary second incisor and possibly the first incisor were lost antemortem based on significant alveolar resportion. The left maxillary third incisor was worn almost to the root and beveled. There were several small areas of active periostitis on the rostrum. The left fibula was fractured mid-shaft and had begun to heal malaligned. The right fibula was also fractured mid-shaft and, although there was significant bony growth indicating partial healing, the two pieces of bone never rejoined. The left pisiform and cuneiform were fused.

\section{Terminal Late Woodland—Dohack Phase}

\section{Dog F\#2368-1 (Young Adult, Likely Male)}

Dog F\#2368-1 was recovered in an extended position from a vertical-sided pit. This individual was complete with the exception of the hind limbs, although several of the left metatarsi were present. This dog was a young adult based on epiphyseal fusion and tooth eruption; several of the thoracic vertebrae centrum epiphyses were unfused, but this element is one of the last to fuse so it was still likely that this individual was a young adult as opposed to a 
juvenile. Based on the humerus roll and non-metric cranial and mandibular observations, this dog was likely a male. L. Kelly (1990b:494) determined this individual fell into Colton's smalldog category. No pathology or trauma was noted with the exception of slight porosity on the articular surfaces of the majority of elements.

\section{Dog F\#2915-1 (Older Adult, Male)}

Dog F\#2915-1 was recovered in an extended position from a pit with restricted sides. This dog was complete and in fair condition. Based on the humerus and non-metric cranial and mandibular observations, this individual was male. The presence of age-related bony growth and wear on articular surfaces suggested he may be an older adult. L. Kelly (1990b) noted this dog fell into the small-dog category (Colton 1970) based on cranial and post-cranial measurements. The maxillary first premolars and the left maxillary second molar were lost antemortem (see Figure 5). There was significant wear on the first and second molars and unequal wear on the maxillary canines resulting in heavier wear on the right canine. There was evidence of multiple depression fractures on the rostrum and frontal bones of the skull. Two of these were small $(<5$ $\mathrm{mm}$ in diameter) and two were large. One large depression fracture was located on the nasal bones and, although some healing had occured, the bones did not rejoin. The surrounding area exhibited significant bony growth and active and healed infection. This injury may have been the cause of the malocclusion observed. The second large depression fracture was located on the left frontal just behind the orbit. This fracture was completely healed and slightly deformed. The left mandibular first and second premolars were lost antemortem and the left mandibular canine was well worn and rounded over. An abscess had begun to form by the root of the right mandibular third premolar. Both mandibles exhibited extensive periodontal disease. 
A large abscess was present just below the ulnar notch of the left ulna. It was not clear whether this infection was secondary to a fracture or if it was osteomyelitis. There were a couple of small areas of bony growth at the distal end of the right femur. The greater trochanter of this femur was deformed. The left fibula had a healed fracture on the proximal mid-shaft surrounded by a ring of bony growth (see Figure 14). The left tibia and fibula were fused mid-shaft, just below this fracture. The right tibia and fibula were fused at the distal end. The left pelvis had multiple areas of infection both on the ilium and ischium. The right ilium was fractured with evidence of healed and active periostitis. Two left ribs and three right ribs had healed fractures, and the majority of ribs had bony growth on the proximal articular surfaces, especially on the last four or five ribs. Eight of the thoracic vertebrae, five of the lumbar vertebrae, and the sacrum had fractured neural processes, one of which did not rejoin when it healed. The majority of thoracic vertebrae exhibited left deviations, with some bending and twisting observed on three specimens (see Figure 6). Two of the lumbar vertebrae also had left deviations and were followed by two with right deviations.

\section{Dog F\#3370-1 (Adult, Indet.)}

Dog F\#3370-1 was recovered from a large-sized single-post structure. The only elements present were the skull and first two cervical vertebrae. This individual was an adult based on tooth eruption and wear. No sex could be determined due to fragmentation. Both mandibular first premolars were lost antemortem and exhibited alveolar remodeling. Cut marks were present along the ventral edge of both mandibles. These cut marks were consistent with skinning marks (Binford 1981). No other pathology or trauma was observed. 


\section{Dog F\#3625-1 (Adult, Indet.)}

Dog F\#3625-1 was recovered from a large, single-post structure. This individual was nearly complete. Based on tooth eruption and wear this dog was an adult, although sex was indeterminate. The right maxillary and mandibular first premolars were absent. No other pathology or trauma was present.

\section{Dog F\#3867-1 (Young Adult, Indet.)}

Dog F\#3867-1 was recovered from the floor of a small rectilinear structure along with the cranium of another dog (Dog F\#3867-2). This individual was represented by the cranium and mandible, both of which were in poor condition. Based on tooth eruption and occlusal wear, this individual was a young adult. No sex could be determined because of the fragmented condition of the remains. L. Kelly (1990b:494) determined this individual fell into Colton's small-dog category. No other pathology or trauma was observed.

\section{Dog F\#3867-2 (Young Adult, Indet.)}

Dog F\#3867-2 was recovered from the floor of a small rectilinear structure along with Dog F\#3867-1. The only element recovered was the cranium, which was highly fragmented. Based on tooth eruption and wear, this individual was a young adult, similar to Dog F\#3867-1. Because of poor condition, no sex could be determined. L. Kelly (1990b:494) determined this individual fell into Colton's small-dog category. No pathology or trauma was observed. 


\section{Dog F\#4246-1 (Adult, Male)}

Dog F\#4246-1 was recovered from the floor of a house structure and was positioned on its back facing northeast. The skeleton was complete and in fair condition with a moderate amount of taphonomy. This individual was an adult and male, based on non-metric cranial and mandibular observations. L. Kelly (1990b:494) determined this individual fell into Colton's small-dog category.

Some periodontal disease was present in both the maxilla and mandibles and there were small pits on the left maxillary second premolar and second molar, which may or may not have been pathological. Additionally, the left maxillary first premolar and both mandibular first premolars were absent. No other pathology or trauma was observed.

\section{Dog F\#4887-1 (Pup, Indet.)}

Dog F\#4887-1 was recovered from the fill of a single-post house structure. This individual was represented by the forelimbs, hindlimbs, ribs, and a single vertebra fragment. This dog was classified as a pup since some of the elements were unfused. It was difficult to be more specific given the absence of certain skeletal elements/portions and teeth; however, this individual was likely close to one year old based on the general size of the elements. No sex could be determined due to juvenility. No pathology or trauma was observable on the remains.

\section{Dog F\#5197-1 (Young Adult, Female)}

Dog F\#5197-1 was recovered from a pit with expanded sides. The only element present was the cranium. Little occlusal wear was present suggesting this individual was a young adult. Based on non-metric cranial observations, this dog was a female. L. Kelly (1990b:494) 
determined this individual fell into Colton's small-dog category. The only pathology noted was slight periodontal disease.

\section{Dog F\#5314-1 (Adult, Indet.)}

Dog F\#5314-1 was recovered from the fill of a house structure. Only the maxillae and mandibles were recovered. Although these elements were not articulated in the feature, the analyst deemed they represented a single individual. Based on the heavy occlusal wear observed, this individual was an adult, possibly of an advanced age. Due to the fragmented state of these remains, no sex could be determined. L. Kelly (1990b:494) determined this individual fell into Colton's small-dog category.

The left maxillary second premolar was lost antemortem as evidenced by alveolar remodeling. Degeneration of the alveoli surrounding the left maxillary third incisor and canine was present. Additionally, the left maxillary second incisor was fractured antemortem. The left maxillary first incisor may also have fractured antemortem, although this was difficult to ascertain due to the heavy degree of wear on this tooth. The left mandibular first premolar was lost antemortem as indicated by alveolar remodeling. Slight periodontal disease was noted around the mandibular premolars and molars. Two small areas of possible infection are observed on the medial surface of the right mandible.

\section{Dog F\#5328-1 (Older Adult, Possibly Male)}

Dog F\#5328-1 was recovered from a vertical-sided pit feature. The only element present was a portion of the cranium and right maxilla. The only tooth present was the right maxillary fourth premolar, which was heavily worn suggesting an older adult individual. Because of the 
fragmented condition, non-metric observations are limited so this individual was considered possibly male. L. Kelly (1990b:494) determined this individual fell into Colton's small-dog category.

Some periodontal disease was observed around the maxillary alveoli. A healed depression fracture was present on the right frontal and orbital. The bony remodeling associated with the healing of this fracture resulted in deformity of this portion of the cranium.

\section{Dog F\#5385-1 (Adult, Male)}

Dog F\#5385-1 was recovered from an expanded-sided pit feature. The cranium was the only element present. Moderate tooth wear suggested the individual was an adult. Based on nonmetric cranial observations, this individual was male. L. Kelly (1990b:494) determined this individual fell into Colton's small-dog category.

Both of the maxillary second premolars were lost antemortem as evidenced by alveolar remodeling. The right maxillary first molar was also lost antemortem, which was likely due to an abscess at the root. The right maxillary fourth premolar was fractured antemortem. Two small, healed depression fractures were present on the left frontal and orbital. These fractures were the likely cause of deformation of the parietals and asymmetry of the maxilla. This may also have made the right fourth premolar more susceptible to fracturing. 


\section{Terminal Late Woodland-Range Phase}

\section{Dog F\#156-1 (Pup, Indet.)}

Dog F\#156-1 was recovered from the fill of a central storage pit. This individual was complete with the exception of the vertebrae, paws, and portions of the forelimbs and pelvis. Based on tooth eruption and long bone epiphyseal fusion, this dog was 2-4 months old. Due to the young nature of these remains, no sex could be determined. No pathology or trauma was observable on the remains.

\section{Dog F\#387-1 (Adult, Likely Male)}

Dog F\#387-1 was recovered from the floor of vertical-sided storage pit. The only element present was the cranium. The moderate amount of tooth wear suggested this individual was an adult. Based on cranial non-metric observations, the sex was likely male. Although no measurements were possible because of the lacquer/glue used by previous analysts, L. Kelly (1990b:494) noted this individual fell into Colton's small dog category. No pathology or trauma was present.

\section{Dog F\#904-1 (Adult, Indet.)}

Dog F\#904-1 was recovered from a small, oval pit and was represented by the mandibles, hind paws, and portions of the left hind leg and pelvis. This individual was an adult based on tooth wear and epiphyseal fusion. No sex could be determined due to fragmentation. No pathology or trauma was present excepting porosity and cortical thinning observed on the majority of elements. 


\section{Dog F\#3093-1 (Adult, Male)}

Dog F\#3093-1 was recovered from the fill of a medium-sized square pit. The only element present was the cranium. Fusion of the cranial sutures indicated an adult individual and non-metric observations suggest this was a male. No pathology or trauma was observed.

\section{Dog F\#4011-1 (Pup, Indet.)}

Dog F\#4011-1 was recovered from a large-sized circular pit and was represented by the cranium and right mandible. The skull was very fragmented. All teeth present were deciduous indicating this individual was 2-5 months old. Sex was indeterminate given the young age. No pathology or trauma was observed.

\section{Terminal Late Woodland-George Reeves Phase}

\section{Dog F\#1769-1 (Adult, Indet.)}

Dog F\#1769-1 was recovered from a large, single-post structure and was represented by a complete left hind paw and single cervical vertebra. Complete epiphyseal fusion of the elements suggested this individual was an adult. However, no sex could be determined. No pathology or trauma was observed on the remains.

\section{Dog F\#2340-1 (Pup, Indet.)}

Dog F\#2340-1 was recovered from the fill of a medium-sized square pit. This individual was represented by the long bones of both forelimbs and the right hindlimb, and some ribs. None 
of these elements were fused indicating this dog was less than five months of age. Due to the juvenility of the remains, no sex could be determined. No pathology or trauma was observed on these remains.

\section{Dog F\#2541-1 (Pup, Indet.)}

Dog F\#2541-1 was recovered from the fill of a large-sized pit. Elements present included cranium, long bones of the forelimbs and hindlimbs, pelvis, and rib. All elements were unfused indicating this dog was less than five months old. No sex could be determined because of the age. No pathology or trauma was observed on the remains.

\section{Dog F\#5047-1 (Pup, Indet.)}

Dog F\#5047-1 was recovered in a flexed position from the floor of a square refuse pit along with two other dogs (Dog F\#5047-2 and Dog F\#5047-3). This skeleton was complete and in good condition. Based on tooth eruption this individual was 1-2 months old. Sex could not be determined due to juvenility. The dogs found in this feature were noted in the feature notes;

however, they do not appear to have been analyzed by L. Kelly (2007a). No pathology or trauma was observed on the remains.

\section{Dog F\#5047-2 (Adult, Male)}

Dog F\#5047-2 was also recovered in a flexed position from the floor of the square refuse pit along with Dog F\#5047-1 and Dog F\#5047-3. This complete individual was fully articulated and in good condition. Moderate tooth wear, robust muscle attachments, and age-related wear 
indicated this individual was an adult, possibly an older adult. Based on non-metric cranial observations and the humerus this dog was male.

Both mandibular first premolars, and the left third premolar were lost antemortem as evidenced by complete alveolar reabsorption. Extensive periodontal disease was present around the mandibular and maxillary dentition. A possible healed depression fracture was observed where the nasal and frontal bones join. Although this could simply be age-related, the distinct outline and bony remodeling suggested a healed fracture.

Both radii exhibited healed fractures mid-shaft. The left radius rejoined during the healing process; the shaft wass slightly curved as a result. The right radius fracture did not properly rejoin and displayed evidence of both healed and healing infection. The resulting deformity was matched on the right ulna, which also exhibited a healed, non-union fracture. Robust muscle attachments, porosity, and eburnation were present on all elements. Both active and healed infection was observed on the majority of the thoracic and lumbar vertebrae. Multiple neural spine fractures were present as well as deviations from the midline. Additionally, several thoracic vertebrae (T6-T10) had deformed centrums that seemed to bulge on the left side. The lack of pathology on the corresponding ribs suggested the vertebral deformity was likely due to infection rather than trauma.

\section{Dog F\#5047-3 (Pup, Male)}

Dog F\#5047-3 was also recovered in a flexed position from the floor of the square refuse pit along with Dog F\#5047-1 and Dog F\#5047-2. This individual wass complete and in good condition. Based on tooth eruption, this pup was 3-5 months old. Although this individual was 
juvenile, the presence of a baculum indicated he is male. The only pathology observed was bony growth from infection along the spine of the left scapula.

\section{Dog F\#5159-1 (Pup, Indet.)}

Dog F\#5159-1 was recovered from a large-sized rectangular pit. Elements present included the skull, forelimbs, hindlimbs, pelvis, ribs, and a metapodial. Based on tooth eruption and epiphyseal fusion, this individual was $2-5$ months old. No sex could be determined due to juvenility. No pathology or trauma was observed.

\section{Terminal Late Woodland—Lindeman Phase}

\section{Dog F\#1919-1 (Pup, Indet.)}

Dog F\#1919-1 was recovered from a pit feature in an extended position, facing north. This complete skeleton was fully articulated at the base of Zone B2 of the pit. Based on tooth eruption and epiphyseal fusion, this dog was 6-7 months old. Due to juvenility, no sex could be determined. No pathology or trauma was observed.

\section{Dog F\#2335-1 (Pup, Indet.)}

Dog F\#2335-1 was recovered from a pit feature and represented a complete individual. Observations of tooth eruption and epiphyseal fusion suggested this dog was 6-8 months old. Because of the fragmented condition of the skull and unfused postcranial elements, no sex could be determined. 
A healed hairline fracture with slight bony remodeling was observed on the anterior end of the right nasal bone. A small depression ( $\sim 5.5 \mathrm{~mm}$ in diameter) was present on the left frontal, although there was no evidence that this represented a healed fracture. Active infection was observable on the majority of the rostrum as well as around the maxillary teeth, particularly the canines and fourth premolars. The rostrum appeared abnormally short and very compressed (possibly congenital). This may explain the slight inward rotation of the right maxillary first premolar. Similarly, the inward rotation of both mandibular fourth premolars was likely the result of crowding. Both mandibular first premolars were absent; there appeared to not be enough room between the canines and second premolars. Bony growth along the anterior edge of the ascending rami suggested either active infection or possibly extreme masticatory stress at a young age. This bony growth was particularly significant on the right mandible where it covered the majority of the ramus and posterior portion of the element.

The greater tubercle of the left humerus was split and exhibited active infection and bony remodeling. Active infection was also observable on the proximal and distal portions of the left femur. In comparison with the right femur, the neck of the left femur appeared narrower suggesting atrophy of the bony tissue. Additionally, the fovea capitis of the left femur was abnormally large ( $\sim 4 \mathrm{~mm}$ in diameter) and irregularly shaped (see Figure 13$)$. The acetabula of the left and right pelvis exhibited both healed and active infection. Significant infection and atrophy was also present on one of the phalanges. Two of the lumbar vertebrae exhibited healed transverse process fractures. 


\section{Dog F\#2978-1 (Adult, Indet.)}

Dog F\#2978-1 was recovered from the floor of a single-post structure. Elements present included femur, tibia, pelvis, astragalus, patella, cervical vertebra, and caudal vertebra. Based on epiphyseal fusion, this individual was an adult. Sex was indeterminate due to lack of skeletal indicators of sex. Porosity/cortical thinning was observed on the proximal and distal ends of the long bones. Some bony growth was noted on the proximal end of the left tibia. Additionally, one caudal centrum was collapsed. No other pathology or trauma was present. 


\section{CHAPTER VII: RESULTS}

\section{Dog Classification}

Thirty-five of the 52 individuals are categorized as Burials, representing 67.3 percent (Table 2). The majority of these are classified as Burials with heads. LW and TLW Burials with heads account for 17 and 12 individuals, respectively. Burials without heads and probable Burials represent six individuals, of which four are associated with the TLW. Five LW and ten TLW dogs are classified as Heads. The majority of the LW Heads are crania with mandibles and vertebra/hyoids. Heads consisting of crania only constitute the majority of the TLW Heads. A single Articulated Limb is associated with each period.

Table 2

Dog Burial Classification for the Range Assemblage

\begin{tabular}{|c|c|c|c|c|c|c|c|}
\hline \multirow[t]{2}{*}{ Dog Category } & \multirow[t]{2}{*}{ Code } & \multicolumn{2}{|c|}{$\begin{array}{c}\text { Late } \\
\text { Woodland }\end{array}$} & \multicolumn{2}{|c|}{$\begin{array}{l}\text { Terminal Late } \\
\text { Woodland }\end{array}$} & \multicolumn{2}{|c|}{ Total } \\
\hline & & $\#$ & $\%$ & \# & $\%$ & \# & $\%$ \\
\hline Burial with head & B1 & 17 & 68.0 & 12 & 44.4 & 29 & 55.8 \\
\hline Burial without head & $\mathrm{B} 2$ & 1 & 4.0 & 3 & 11.1 & 4 & 7.7 \\
\hline Burial, probable & B3 & 1 & 4.0 & 1 & 4.0 & 2 & 3.8 \\
\hline Cranium only & H1 & 1 & 4.0 & 6 & 22.2 & 7 & 13.5 \\
\hline Cranium and mandible & $\mathrm{H} 2$ & 2 & 8.0 & 3 & 11.1 & 5 & 9.6 \\
\hline $\begin{array}{l}\text { Cranium and } \\
\text { vertebra/hyoid }\end{array}$ & $\mathrm{H} 3$ & 2 & 8.0 & 1 & 4.0 & 3 & 5.8 \\
\hline Articulated Limb & Art & 1 & 4.0 & 1 & 4.0 & 2 & 3.8 \\
\hline
\end{tabular}

\section{Burial Context}

Twenty-one of the $25 \mathrm{LW}$ dogs were recovered from pit features. One individual was recovered from small-sized structures and three from keyhole structures. None are associated with large-sized structures. Eighteen of the 27 TLW dogs were found in pit features, with two 
and seven individuals recovered from small-sized and large-sized structures, respectively. None were recovered from keyhole structures.

\section{Age Distribution}

Of the 52 dogs recognized at Range, 33 individuals or 63.5 percent were classified as adults (Table 3). Adult individuals ranged in age from young adult to older adult, with mature or indeterminate adults accounting for 73 percent of the adult population. The remaining 19 individuals are categorized as juveniles, of which 16 are estimated to be less than 6 months of age. Comparison between the LW and TLW dogs reveals nearly identical ratios of adults to juveniles $(3: 2)$.

Table 3 Age Distribution of the Range Assemblage

\begin{tabular}{rccc}
\hline & Adult & Juvenile & Total \\
\hline Late Woodland & $16(64.0 \%)$ & $9(36.0 \%)$ & 25 \\
Terminal Late Woodland & $17(63.0 \%)$ & $10(37.0 \%)$ & 27 \\
\hline Total & $\mathbf{3 3 ( 6 3 . 5 \% )}$ & $\mathbf{1 9 ( 3 6 . 5 \% )}$ & $\mathbf{5 2}$ \\
\hline
\end{tabular}

\section{Sex Distribution}

In addition to the 33 adult dogs, one juvenile dog is sexable based on the presence of a baculum (Table 4). This individual was recovered from a George Reeves phase feature. Sex could be determined for 16 individuals, with 36 categorized as indeterminate. Of the $25 \mathrm{LW}$ dogs, males $(\mathrm{MNI}=5)$ and females $(\mathrm{MNI}=1)$ account for 20 and 4 percent, respectively. TLW males $(\mathrm{MNI}=9)$ and females $(\mathrm{MNI}=1)$ represent 33.3 and 3.7 percent respectively. 
Table 4

Sex Distribution of the Range Assemblage

\begin{tabular}{rccccc}
\hline & Male & Female & $\begin{array}{c}\text { Indet. } \\
\text { Adult }\end{array}$ & $\begin{array}{c}\text { Indet. } \\
\text { Juvenile }\end{array}$ & Total \\
\hline Late Woodland & $5(20.0 \%)$ & $1(4.0 \%)$ & $10(40.0 \%)$ & $9(36.0 \%)$ & 25 \\
Terminal Late Woodland & $9(33.3 \%)$ & $1(3.7 \%)$ & $8(29.6 \%)$ & $9(33.3 \%)$ & 27 \\
\hline Total & $\mathbf{1 4}(\mathbf{2 6 . 9} \%)$ & $\mathbf{2 ( 3 . 8 \% )}$ & $\mathbf{1 8 ( 3 4 . 6 \% )}$ & $\mathbf{1 8 ( 3 4 . 6 \% )}$ & $\mathbf{5 2}$ \\
\hline
\end{tabular}

\section{Dental Paleopathology}

Of the 30 dogs with permanent dentition, 19 (63.3 percent) exhibit dental pathology or trauma, including ten LW and nine TLW individuals (Table 5). Periodontal disease and antemortem tooth absence were the most commonly observed pathologies.

\section{Periodontal Disease}

Periodontal disease was observed in 64.3 percent $(\mathrm{N}=9)$ of the $\mathrm{LW}$ and 37.5 percent $(\mathrm{N}$ $=6$ ) of the TLW dogs. This pathology was most commonly observed around the premolars and molars, with slightly higher frequencies in the mandible. Disease affecting the canine and incisor alveoli was minimal.

One TLW individual of particular interest is Dog F\#2335-1. Although this dog does have fully erupted permanent dentition, the majority of postcranial elements are unfused indicating an age between six and eight months. In addition to the extensive periodontal disease surrounding most of the maxillary and mandibular teeth, active infection covers the majority of the rostrum. The dental arcade of this dog is very compressed; none of the maxillary or mandibular first 
premolars erupted and the mandibular fourth premolars are rotated inward due to overcrowding. The morphological abnormalities observed may have made this individual more susceptible to infection.

Table 5

Dental Pathology Observed in the Range Assemblage

\begin{tabular}{|c|c|c|c|c|c|}
\hline Dog F\# & $\begin{array}{c}\text { Tooth } \\
\text { Fracture } \\
\end{array}$ & $\begin{array}{c}\text { Periodontal } \\
\text { Disease }\end{array}$ & Abscess & $\begin{array}{c}\text { Antemortem } \\
\text { Tooth } \\
\text { Absence } \\
\end{array}$ & \\
\hline $2915-1$ & -- & $\mathrm{X}$ & $X$ & $\mathrm{X}$ & \\
\hline $3370-1$ & -- & -- & -- & $X$ & \\
\hline $3625-1$ & -- & -- & -- & $X$ & \\
\hline $4246-1$ & -- & $X$ & -- & $\mathrm{X}$ & \\
\hline $5197-1$ & -- & $\mathrm{X}$ & -- & & \\
\hline 5314-1 & $\mathrm{X}$ & $\mathrm{X}$ & -- & $\mathrm{X}$ & \\
\hline $5385-1$ & $X$ & -- & $X$ & $X$ & \\
\hline $5047-2$ & -- & $\mathrm{X}$ & -- & $\mathrm{X}$ & \\
\hline $2335-1$ & -- & $\mathrm{X}$ & -- & $\mathrm{X}$ & \\
\hline 2036-1 & -- & $\mathrm{X}$ & -- & & \\
\hline 2900-1 & -- & $X$ & -- & $X$ & \\
\hline $431-1$ & $\mathrm{X}$ & $\mathrm{X}$ & -- & $\mathrm{X}$ & \\
\hline $441-1$ & -- & $X$ & -- & $X$ & \\
\hline $441-3$ & $\mathrm{X}$ & -- & -- & $\mathrm{X}$ & \\
\hline $4819-1$ & -- & $X$ & -- & $\mathrm{X}$ & \\
\hline $4852-1$ & -- & $\mathrm{X}$ & -- & $\mathrm{X}$ & \\
\hline $5263-1$ & -- & $X$ & -- & $\mathrm{X}$ & \\
\hline $5586-1$ & -- & $X$ & -- & $\mathrm{X}$ & \\
\hline \multirow[t]{2}{*}{$3765-1$} & $X$ & $X$ & -- & $X$ & \\
\hline & & & & & $\begin{array}{c}\text { Total \# of } \\
\text { dogs with } \\
\text { dental } \\
\text { pathology }\end{array}$ \\
\hline Total LW & $3(21.4 \%)$ & $9(64.3 \%)$ & 0 & $9(64.3 \%)$ & $10(71.4 \%)$ \\
\hline Total TLW & $2(12.5 \%)$ & $6(37.5 \%)$ & $2(12.5 \%)$ & $8(50 \%)$ & $9(56.3 \%)$ \\
\hline Total & $5(16.7 \%)$ & $15(50 \%)$ & $2(6.7 \%)$ & $17(56.7 \%)$ & $19(63.3 \%)$ \\
\hline
\end{tabular}




\section{Antemortem Tooth Absence}

Antemortem tooth absence affected 64.3 percent $(\mathrm{N}=9)$ of the $\mathrm{LW}$ and 50 percent $(\mathrm{N}=$ 8) of the TLW dogs. Teeth absent (regardless of cause) include the mandibular and maxillary first premolar, mandibular and maxillary second premolar, mandibular third premolar, and maxillary second molar. Of the 17 individuals with absent teeth, 12 can reliably be said to have lost teeth during life rather than due to agenesis. All of the teeth noted as absent rather than lost are first premolars.

\section{Antemortem Tooth Fracture}

Eight fractured teeth were observed in the assemblage, representing three LW (21.4 percent) and two TLW (12.5 percent) individuals. All fractured teeth present are from the maxilla, including the fourth premolar, canine, and incisors. Four of the five dogs have a single fractured tooth while the fifth dog exhibits fractures of all four central incisors.

It does not appear that any of the fractured teeth in the Range assemblage resulted from intentional breakage, as the corresponding teeth in both situations are present and not fractured. Both individuals (Dog F\#431-1 and Dog F\#5385-1) with fractured fourth premolars also exhibit significant deformity (likely due to multiple healed depression fractures on the left frontal) causing malocclusion. The asymmetry of both jaws may have resulted in excess pressure on the right fourth premolar making it more susceptible to fracture. Similarly, it appears that the dog (Dog F\#3765-1) with the fractured central incisors suffered from malocclusion. The beveled fractures and abnormally heavy wear on both the maxillary and mandibular incisors suggests this 
dog had a significant overbite. The dog (Dog F\#441-3) with the fractured canine does not have any additional pathology that would suggest a specific cause of fracture.

\begin{abstract}
Abscess
Two abscesses are present: one is located around the roots of a maxillary first molar and the other at the base of the mandibular second and third premolars. Both occurrences were observed on TLW dogs. The two dogs (Dog F\#2915-1 and Dog F\#5385-1) with abscesses also have significant cranial deformity that resulted in abnormal occlusal wear on the maxillary and mandibular teeth and extensive periodontal disease.
\end{abstract}

\title{
Skeletal Paleopathology
}

Skeletal pathology is observable on 16 dogs (eight LW, eight TLW), representing 30.8 percent of the population (Table 7.5). The majority of these individuals are adults and male.

Table 6

Summary of Skeletal Trauma Observed in the Range Assemblage

\begin{tabular}{|c|c|c|c|c|c|}
\hline & $\begin{array}{c}\text { Vertebral } \\
\text { Trauma }\end{array}$ & $\begin{array}{l}\text { Cranial } \\
\text { Trauma }\end{array}$ & $\begin{array}{c}\text { Rib } \\
\text { Trauma }\end{array}$ & $\begin{array}{c}\text { Appendicular } \\
\text { Trauma }\end{array}$ & $\begin{array}{c}\text { Scapular/Pelvic } \\
\text { Trauma }\end{array}$ \\
\hline Late Woodland & $\begin{array}{c}7(36.8 \\
\%)\end{array}$ & $\begin{array}{c}2(8.0 \\
\%)\end{array}$ & $\begin{array}{c}4(21.1 \\
\%)\end{array}$ & $5(26.3 \%)$ & $3(15.8 \%)$ \\
\hline $\begin{array}{l}\text { Terminal Late } \\
\text { Woodland }\end{array}$ & $\begin{array}{c}4(25.0 \\
\%)\end{array}$ & $\begin{array}{c}5(18.5 \\
\%)\end{array}$ & $\begin{array}{c}2(12.5 \\
\%)\end{array}$ & $3(18.8 \%)$ & $4(25.0 \%)$ \\
\hline Total & $\begin{array}{c}11(31.4 \\
\%)\end{array}$ & $\begin{array}{c}7(13.5 \\
\%)\end{array}$ & $\begin{array}{c}6(17.1 \\
\%)\end{array}$ & $8(22.9 \%)$ & $7(20.0 \%)$ \\
\hline
\end{tabular}




\section{Cranial Trauma}

Approximately 15 percent of the 46 dogs with heads exhibited evidence of cranial trauma or pathology, representing 8.7 percent $(\mathrm{N}=2)$ of the LW and 21.7 percent $(\mathrm{N}=5)$ of the TLW populations (Table 7). The majority of these individuals have fractures of the frontals or rostrum, and two individuals have fractures in both regions. Number of fractures per individual range from one to four, with a single fracture observed on three dogs, two fractures present on two dogs, and four fractures observed on one individual. One LW and all five TLW dogs exhibit large depression fractures.

Smaller fractures are slightly less common, affecting one LW and one TLW individual. Small fractures, especially those present on the rostrum, likely represent bite or puncture marks resulting from fights with other dogs. Larger depression fractures, on the other hand, are likely from a blow, kick, or strike either from a human or another animal. Partial or complete healing of these fractures suggests the initial injuries were not fatal. In three individuals (Dog F\#431-1, Dog F\#2335-1, and Dog F\#5385-1), healed fractures resulted in deformity of the rostrum and malocclusion. In some cases this caused further injury such as tooth fracture, periodontal disease, and abscess.

Interestingly, all of the dogs with cranial trauma are adult males, with the exception of one pup (Dog F\#2335-1) of indeterminate sex. This pattern may simply be due to the skewed proportions of male and female individuals in the assemblage. On the other hand, it may be the result of more aggression in the male portion of the population. 
Table 7

Cranial Trauma Observed in the Range Assemblage

\begin{tabular}{|c|c|c|c|c|c|}
\hline Dog F\# & Age/Sex & Fracture & Infection & Deformity & \\
\hline $431-1$ & Adult/M & $\mathrm{X}$ & -- & $\mathrm{X}$ & \\
\hline $5586-1$ & Adult/M & -- & $X$ & -- & \\
\hline $5328-1$ & Adult/M & $X$ & -- & -- & \\
\hline $5385-1$ & Adult/M & $X$ & $X$ & $X$ & \\
\hline $5047-2$ & Adult/M & $\mathrm{X}$ & -- & -- & \\
\hline $2335-1$ & Pup/Indet. & $X$ & $\mathrm{X}$ & $\mathrm{X}$ & \\
\hline \multirow[t]{4}{*}{ 2915-1 } & Adult/M & $\mathrm{X}$ & -- & -- & \\
\hline & & & & & $\begin{array}{c}\text { Total Dogs } \\
\text { with Cranial } \\
\text { Path/Trauma }\end{array}$ \\
\hline & Total LW & $1(4.3 \%)$ & $1(4.3 \%)$ & $1(4.3 \%)$ & $2(8.7 \%)$ \\
\hline & Total TLW & $5(21.7 \%)$ & $2(8.7 \%)$ & $2(8.7 \%)$ & $5(21.7 \%)$ \\
\hline
\end{tabular}

\section{Vertebral Trauma}

Vertebral pathologies and trauma were observed on seven LW (36.8 percent) and four TLW (25 percent) dogs, accounting for 31.4 percent of the assemblage (Table 8 ). Seven of the dogs are male, with the remainder consisting of a single female and three individuals of indeterminate sex. Additionally, all of the dogs with vertebral trauma are categorized as either a $\mathrm{B} 1$ or B2 burial.

Spinous process anomalies. Six dogs (four LW and two TLW) have spinous process anomalies, with deviation from the midline being most common. Spinous process anomalies are most commonly observed on the lower thoracic, and upper and lower lumbar vertebrae. All of 
these dogs have deviated spinous processes and the majority also have fractures and compression of the spinous processes. One individual (Dog F\#431-1) also exhibits a bifurcated spinous process of the seventh thoracic vertebra. The number of vertebrae with spinous process anomalies ranges from nine to 17 per individual. Vertebral spinous process anomalies are generally interpreted as the effect of pack or load carrying, although other causes like congenital factors may also result in such trauma (e.g., Arnold 1979; Crellin 1994; Darwent and Gilliland 2001; Morey and Aaris-Sorensen 2002; Snyder 1995; Warren 2004).

Osteophytes and ankylosis spondylitis. Osteophytic growth is present on seven of the LW dogs and two of the TLW dogs. Ankylosis spondylitis was observed on two individuals: the second and third lumbar of Dog F\#441-1 are partially fused, and the thirteenth thoracic, and first and second lumbar of Dog F\#5010-1 are completely fused. These types of pathologies typically affect the lower cervical, thoracic and lumbar vertebrae.

Fractures of the transverse processes and centrum. Two dogs (Dog F\#2335-1 and Dog F\#2915-1) have one or more lumbar vertebrae with fractures of the transverse process and one dog (Dog F\#5047-2) has a lumbar with a flared transverse process. Centrum compression fractures are present on one caudal vertebra of Dog F\#2978-1 and the seventh thoracic vertebra of Dog F\#441-1. 
Table 8

Vertebral Trauma Observed in the Range Assemblage

\begin{tabular}{|c|c|c|c|c|c|c|c|}
\hline $\begin{array}{c}\text { Dog } \\
\text { F\# }\end{array}$ & Sex & $\begin{array}{c}\text { Spinous } \\
\text { Process } \\
\text { Anomalies } \\
\end{array}$ & Osteophytes & $\begin{array}{c}\text { Ankylosis } \\
\text { Spondylitis }\end{array}$ & $\begin{array}{l}\text { Fractures } \\
\text { (transverse } \\
\text { processes) }\end{array}$ & $\begin{array}{l}\text { Fractures } \\
\text { (centrum) }\end{array}$ & \\
\hline $431-1$ & M & $X$ & $\mathrm{X}$ & -- & -- & -- & \\
\hline $441-1$ & $\mathrm{~F}$ & $\mathrm{X}$ & $\mathrm{X}$ & $\mathrm{X}$ & -- & $X$ & \\
\hline $\begin{array}{l}441-3 \\
3765-\end{array}$ & M & $\mathrm{X}$ & $X$ & -- & -- & -- & \\
\hline $\begin{array}{c}1 \\
4819-\end{array}$ & M & -- & $X$ & -- & -- & -- & \\
\hline $\begin{array}{c}1 \\
5010-\end{array}$ & M & -- & $\mathrm{X}$ & -- & -- & -- & \\
\hline & Indet. & $\mathrm{X}$ & $\mathrm{X}$ & $X$ & -- & -- & \\
\hline $\begin{array}{c}1 \\
2335-\end{array}$ & M & -- & $\mathrm{X}$ & -- & -- & -- & \\
\hline $\begin{array}{c}1 \\
2915-\end{array}$ & Indet. & -- & -- & -- & $\mathrm{X}$ & -- & \\
\hline $\begin{array}{c}1 \\
2978-\end{array}$ & $\mathrm{M}$ & $X$ & $\mathrm{X}$ & -- & $X$ & -- & \\
\hline $\begin{array}{c}1 \\
5047-\end{array}$ & Indet. & -- & -- & -- & -- & $X$ & \\
\hline 2 & M & $\mathrm{X}$ & $\mathrm{X}$ & -- & -- & -- & \\
\hline & & & & & & & $\begin{array}{c}\text { Total \# of } \\
\text { Dogs w/ } \\
\text { vertebral } \\
\text { trauma }\end{array}$ \\
\hline & tal LW & $4(21.1 \%)$ & $7(36.8 \%)$ & $2(10.5 \%)$ & 0 & $1(5.3 \%)$ & $7(36.8 \%)$ \\
\hline Tot: & $1 \mathrm{TLW}$ & $2(12.5 \%)$ & $2(12.5 \%)$ & 0 & $2(12.5 \%)$ & $1(6.3 \%)$ & $4(25.0 \%)$ \\
\hline & Total & $6(17.1 \%)$ & $9(25.7 \%)$ & $2(5.7 \%)$ & $2(5.7 \%)$ & $2(5.7 \%)$ & $11(31.4 \%)$ \\
\hline
\end{tabular}

\section{Rib Trauma}

Rib fractures were observed on 17 percent $(\mathrm{N}=6)$ of the total dog assemblage. Twice as many LW dogs $(\mathrm{N}=4)$ experienced rib trauma as compared to TLW dogs $(\mathrm{N}=2)$. Five of the six individuals are adults, and only one dog has fractures on both the left and right ribs. All other 
dogs have fractures limited to one side or the side is indeterminate. The number of ribs fractured per individual ranges from one to five, with one, two, and five fractures observed on two individuals each. A single rib (from Dog F\#431-1) exhibits evidence of more than one fracture. Similar to depression fracture, rib trauma is often associated with blows, kicks, or strikes from humans or other animals, although other causes may have resulted in the injuries (e.g., Binois et al. 2013; Groot 2008; Noe-Nygaard 1974; Teegan 2005; Warren 2004).

\section{Scapular and Pelvic Trauma}

Seven dogs (three LW and four TLW) exhibit evidence of scapular or pelvic pathology. Two individuals, one LW and one TLW, have scapular trauma. Dog F\#5047-3 has active infection on the spine of his left scapula. Although the infection is not extensive, the occurrence is surprising given the young age of the individual. The left scapula of Dog F\#441-1 exhibits extensive active infection along the entire length of the spine, likely as the result of a fracture. Three LW and three TLW dogs have pelvic trauma. Dog F\#431-1 exhibits extensive infection on and around the acetabulum of the left pelvis. The extreme degree of pathology is similarly observed on the head of the left femur and eburnation on the interior surface of the acetabulum suggests malarticulation of the joint. The right pelves of Dog F\#441-1 and Dog F\#3765-1 have several patches of active infection. The right ilium of Dog F\#2915-1 exhibits a healing fracture with active infection and small areas of infection and possible fracture are present on the left pelvis. Extensive infection is observed on the left pelvis of Dog F\#5047-2, particularly around the acetabulum. Both the left and right pelves of Dog F\#2335-1 exhibit extensive infection around the acetabula. The infection is particularly significant on the left pelvis, which resulted in deformity of the acetabulum. 


\section{Appendicular Trauma}

Approximately 23 percent of the dogs with postcranial elements exhibit evidence of appendicular trauma, affecting five LW and three TLW dogs. The most common trauma observed is infection, affecting approximately one-quarter of the assemblage (five LW and three TLW dogs). The most common elements exhibiting infection include the femur, tibia, fibula, and humerus. Occurrences per individual range from one to six. The TLW dogs have more elements with areas of infection than the LW dogs. There are several individuals of particular interest. Dog F\#2915-1 has an extensive abscess located just below the ulnar notch on the left ulna. Osteomylitis and osteoperiostitis can result in abscess, but since no other trauma is evident on this element, the underlying cause is unclear. The proximal end of the left femur of Dog F\#431-1 is very deformed due to infection and may be associated with fracture of the neck. Infection and deformity of a similar degree is observable on the acetabulum of the left pelvis.

Multiple individuals have elements that are partially or completely fused including both tibia and fibula of Dog F\#2915-1; the left tibia and fibula, and both radii and ulna of Dog F\#5047-2; the right tibia and fibula of Dog F\#4819-1; and the left radius and ulna of Dog F\#5586-1. In some of these individuals, especially those in which fusion is seen unilaterally, the cause may be associated fractures. Other factors such as age and load-bearing work can also result in skeletal fusion.

Three LW and three TLW individuals have fractured bones, representing 17.1 percent of the assemblage. The most common element fractured is the fibula, although fracture incidence rates on other appendicular elements were very similar. With the exception of one probable fracture observed on a phalanx, all other fractures affected long bones. One case stands out in the 
Range assemblage. In Dog F\#5047-2, both radii and the right ulna were fractured midshaft. The left radius healed with some excessive bony growth remaining and slight curvature of the shaft. The right radius and ulna healed misaligned resulting in excessive bony growth and deformity. In general, trauma observed on the appendicular elements can have a wide variety of causes ranging from environmental and genetic factors to occupational risk and disciplinary abuse. Although frequencies of appendicular fractures seem relatively low, that may be due to the potentially disabling nature of fractures occurring on major elements such as the femur, tibia, and humerus. An animal unable to work may be killed, in which case little or no healing of the fracture would take place. However, the presence of dogs with healed limbs implies some of the dogs did receive some degree of care.

\section{Cut Marks}

Two burial dogs exhibit cut marks. One LW dog (Dog F\#798-1) has cut marks on the ventral surface of the atlas. Cut marks in this location, like those found on the medial surface of the proximal end of the femur, may represent ceremonial or ritual sacrifice. Dog F\#3370-1 is associated with the TLW and exhibits cut marks on the ventral edges of both mandibles. Cut marks in this location likely represent skinning or removal of the pelt (Binford 1981).

\section{Isolated Remains}

Isolates account for 142 remains and represent 3.9 percent of the total canid remains from both the LW $(\mathrm{N}=60)$ and TLW $(\mathrm{N}=82)$ assemblages. The majority of these bones were recovered from refuse pits or midden features. All portions of the body are nearly equally represented with slightly greater quantities of teeth, long bone, and skull fragments. Of these, 
five bones were burned (four LW, one TLW). As previously mentioned, these remains may be either domestic dog or coyote (Canis latrans) and are therefore identified as Canis sp.

Cut marks are present on a total of 12 isolates. During the LW, five elements exhibited evidence of cut marks, including the ventral surface of a mandible, the proximal shaft of a tibia, the proximal shaft of a humerus, and the medial surface of a proximal radius and ulna. Three of these elements also exhibit some degree of burning, as does a proximal ulna that does not have cut marks. During the TLW, cut marks were observed on seven isolates, including the anteriodistal surface of a femur diaphysis, the distal shaft of a femur, an astragulus, the ventral edge of a mandible, a pelvis fragment, the ventral surface of a cervical vertebra, and the lateral edges of a thoracic neural spine. A single TLW element, a complete cuboid, is burned. Cut marks are not observable on this bone. The majority of the cut marks observed on isolated remains likely represent dismemberment or filleting (Binford 1981). 


\section{CHAPTER VIII: DISCUSSION}

\section{Intra-site Comparisons}

\section{Distribution and Location Patterns}

In both the LW and TLW, the majority of the dogs were recovered from pit features, some of which were identified inside larger structure features. The majority of structures containing dog burials are classified as large-sized structures. Of note, three LW dogs were recovered from keyhole structures: the skull of Dog F\#2631-1 was recovered from the floor of the ramp/entryway; the tightly flexed skeleton of Dog F\#2820-1 was recovered from the floor of the ramp/entryway; and the tightly flexed skeleton of Dog F\#4819-1 was found in the corner of the main structure. At the very beginning of the TLW a small number of keyhole structures were still present. Considering the relative scarcity of these structures during this period it is not surprising that none of the TLW dogs were recovered from keyhole structures. Although these

dogs may have been intentionally placed in these structures upon abandonment, the tightly flexed position of Dog F\#2820-1 and Dog F\#4819-1 suggests these individuals may have crawled in and died naturally.

As previously mentioned briefly, keyhole structures are a unique and enigmatic structure present at numerous sites in the Midwest region (e.g., Binford et al. 1970; Dragoo 1955; Fortier 1984, 2016; Fortier \& Jackson 2000; Holt 1996; Kelly et al. 1987; Meinholz \& Kolb 1997; Nolan 1993; Pace and Apfelstadt 1978; Salkin 2000). The keyhole structure is comprised of a main room, extended entryway or ramp, and an end pit. It has been argued that the main rooms, which are similar in size and shape to rectilinear, basin structures, may have served as sleeping 
quarters (Fortier and Jackson 2000). Some have interpreted the ramps, which were probably covered, as representing both an entryway and way to regulate heat in the main room. This function would have made them ideal during the winter, but there is no evidence thus far suggesting they were not utilized year round. Some have suggested this type of structure may have been a special-use facility; as Fortier and Jackson (2000:137) point out, interpretations should take into consideration the distribution and frequency of the structure within specific contexts. At Range, keyhole structures are common and are not separated from other nonkeyhole structures, suggesting they likely do not hold any kind of special status (Fortier et al. 1991; Fortier \& Jackson 2000; Kelly et al. 1987).

A sampling of the placement of burials in relation to structures suggests that generally equal numbers of dogs were buried inside structures and outside of structures. Based on the available data, the position of the burial either inside the structure (i.e., in the corner, center, indeterminate) or outside the structure (i.e., behind, in front, indeterminate) could not be determined for the majority of individuals. Because of this, few meaningful interpretations can be discussed. Crellin and Heffner (2000:162) suggest the placement of dog remains in the center of house structures may represent a sacrificial event for the purpose of spiritually protecting the structure while it is vacant. However, Cantwell (1980) and Strong (1985) suggest dog burials found within structures, even if not in the center, may represent individuals of elevated status.

\section{Burial Types}

Burials with heads are the most common type of burial during both the LW and TLW. This is especially evident during the LW when Burials with heads comprise 68 percent of 
individuals. Over time, the proportion of other types of burials (Burial without head, cranium only, and cranium and mandible) increases.

\section{Age Distributions}

In both the LW and TLW populations, the ratio of adults to juveniles is 3:2. Although necessary as an interpretation construct, detailed discussion of age distributions themselves are not always a reliable reflection of the living population (Lyman 1994). Small-sized bones and bones from younger individuals are more susceptible to destructive forces like post-depositional processes and scavengers (Behrensmeyer 1981; Behrensmeyer and Boaz 1980; Carlson and Pickering 2003; Munson 2000; Munson and Garniewicz 2003, Pickering 2002). Because of this, fewer juvenile individuals may appear archaeologically than actually existed in the living population. This could mask natural mortality due to certain diseases, malnutrition or predation, or human behaviors such as culling.

\section{Sex Distributions}

Males significantly outnumber females in both the LW and TLW populations (total population ratio of 7:1). There are several possible explanations for such skewed proportions. One possibility is differential pathological factors resulting in a natural death. Another explanation is the intentional culling of female dogs for population control. If this were the case, culling would likely occur before a dog reached adulthood. If these dogs received burial treatment, it would be expected that there would be more juvenile females and more adult males. Since sexing juveniles is unreliable if not impossible (without the presence of a baculum to indicate male), it is not possible to know whether this is the case at Range. 
Another possibility is the methods used to determine sex. With most animal populations, there is variation between males and females. Several of the methods used to determine sex in dogs are non-metric observations. Therefore, analysts may interpret observations differently. In the case of this research, dogs were only assigned a sex if the analyst was confident in the interpretation; otherwise, the dog was classified as indeterminate. Almost certainly, some of those "indeterminate" dogs are female, which could potentially balance the ratio of male to female. Due to the small quantity of sexable dogs, few detailed interpretations can be derived from these results.

\section{Dental Pathology}

A significantly higher proportion of LW dogs exhibit periodontal disease as compared with TLW individuals (64.3 percent during the LW compared to 37.5 percent during the TLW). There are a number of possible genetic and environmental causes that may explain this pattern. Carbohydrate-rich foods such as maize induce the formation of plaque, which can initiate periodontal disease in dogs (Harvey 1998). In humans, dental pathologies, particularly periodontal disease, increase temporally as more maize is being consumed (Corey et al. 1993; Hillson 1986; van der Velden et al. 1993). Small amounts of maize were likely consumed at Range during the LW and TLW periods, but possibly not to the extent of causing periodontal disease. Greater consumption of other starchy seeds (e.g., knotweed, goosefoot, maygrass) during the LW period may be an alternative explanation for the observed pattern (Warren 2004; Yarnell 1993). Another possibility is that genetic, environmental, or dietary factors counteracted the plaque build up during the TLW period. Due to the relatively small sample size and limited temporal range of this site, it is difficult to discuss these possibilities in greater detail. Future 
research incorporating earlier and later dog burials, specifically Mississippian dogs, in the region are necessary to identify possible correlations between carbohydrate consumption and periodontal disease.

Antemortem tooth absence is common during both time periods, with slightly higher incidence rates observed during the LW. The majority of the LW and TLW dogs with antemortem tooth absence can be reliably said to have lost the teeth due to pathology and/or trauma during life rather than through agenesis. Given their high co-occurrence rate, it is likely that periodontal disease is the main cause of antemortem tooth loss. The high percentage of first premolars lost during life suggests this tooth may be more vulnerable to loss during life than other teeth. The majority of alveoli of lost first premolars exhibit significant periodontal disease. Harvey (1998) and Page and Schroeder (1981) note that first premolars are highly susceptible to loss due to periodontal disease in modern breeds.

Antemortem tooth loss may also have been due to intentional fracture and/or removal, but this does not appear to be the case with the Range dogs. Bell (1965) and Freuchen (1935) report fracturing and filing of the teeth of modern dogs to prevent fighting, chewing through tethers, and injury to people. Similarly, Wing (1991) suggests that the antemortem absence of the fourth premolar in nearly half of the dogs she analyzed from Puerto Rico demonstrates intentional removal for muzzling. While fracture, whether intentional or accidental, can certainly lead to tooth loss, neither fracture/filing nor complete removal can be proven in this assemblage. Additionally, the teeth primarily targeted in such practices are the carnassials and canines, none of which were lost antemortem. Fracturing of these teeth will be discussed further later.

This relatively small occurrence of absent teeth likely due to agenesis at Range is low compared to other analyses of tooth absence in prehistoric dogs. Allen (1920) noted that a large 
portion of the American aboriginal dogs he examined was missing one or more first premolars, particularly those of the mandible. Colton (1970) observed that approximately one-third of the 100 small Southwestern prehistoric dogs he analyzed lacked one or more mandibular first premolars. He does not note the occurrence of absent first premolars in the maxilla. Other studies have demonstrated similar patterns of premolar absence (e.g., Blick 1988; Crockford 1997). In Poplin's (1976) analysis of modern dogs, he observed high frequencies of premolar absence and suggested that inbreeding and genetics play a major role in rates of agenesis.

Antemortem tooth fractures can be caused by a number of factors, including hunting, chewing on bones or other hard objects, and trauma (i.e., blow, strike, or kick). As previously mentioned, teeth, particularly the canines and carnassials, may be intentionally broken to prevent injury or destruction of material. This does not appear to be the case with the fractured teeth from Range, as the corresponding teeth in each animal are present and intact.

As previously noted, abscesses can be caused by factors such as fracture or periodontal disease. The difference in the number of abscesses present in each Range assemblage is not significant. This may be due to the relatively small sample size or difficulty in identifying abscesses that are just beginning to form.

\section{Skeletal Pathology}

Much of the cranial trauma observed on the Range dogs may be attributed to blows, strikes, and kicks used to discipline the dogs, although other factors may be responsible such as dogs fighting among themselves, accidents, and encounters with large game such as deer, elk, and black bear (Arnold 1979; Bartosiewicz \& Gál 2008; Binois et al. 2013; Crellin 1994; Groot 2008; Kuehn 2014b; MacKinnon 2010; Miklíková 2008; Park 1987; Snyder 1995; Teegen 2005; 
Warren 2004). It is most likely, however, that these injuries are the result of human behavior. Similar actions can also result in fractures of postcranial elements, especially the ribs. Cranial trauma is more prevalent in the TLW dogs (18.5 percent during the TLW compared to 8 percent during the LW), suggesting harsher treatment in comparison to LW dogs. This may indicate that during the TLW, dogs were viewed less as spiritual or ceremonial animals and more as beasts of burden.

Vertebral spinous process anomalies, osteophytes, and ankylosis spondylitis are likely evidence of repetitive physical work, although other factors such as age, disease, and genetics may contribute (Arnold 1979; Crellin 1994; Darwent and Gilliland 2001; Morey and AarisSørensen 2002; Snyder 1995; Warren 2004). Numerous ethnographic accounts note the use of dogs as hauling or pack-carrying animals (e.g., Schwartz 1997:51-55; Warren 2004). The fracture and infection observed on the left scapula of Dog F\#441-1 may also be attributed to such work, as the harnesses used for pulling travois and carrying packs often included a strap around the chest. The relatively high frequency of vertebral trauma (31.4 percent of the total population), particularly spinous process anomalies, as well as multiple occurrences on the majority of the affected dogs, strongly suggests occupational stress is the primary factor responsible in the Range dogs. Higher frequencies of vertebral trauma were observed in the LW dogs (36.8 percent during the LW compared to 25 percent during the TLW), suggesting greater occupational stress during the LW compared with the TLW.

Causes of trauma and pathologies observed on other portions of the skeleton are more difficult to ascertain. Such injuries may be the result of accidents, abusive behavior, work-related trauma, or a combination of factors. Additionally, genetic or environmental factors may exacerbate conditions or make individuals more susceptible to injury. Given the extent of some 
of the trauma observed in the Range assemblage, it is clear that in both the LW and TLW, sick or crippled dogs were cared for well beyond healing of the initial injury.

Cut marks may result from a wide variety of actions. Those observed on the atlas of Dog F\#798-1 are interpreted as evidence of potential ritual sacrifice. Cut marks in similar locations have been found on canid remains associated with ritual activities and ceremonial feasting in cultures of the Great Lakes (Brizinski \& Savage 1983; Oberholtzer 2002; Thomas 1996). Some ritual events and ceremonies resulted in the dismemberment of a dog and internment of specific portions of the body (Schwartz 1997). No other cut marks are present on the remains of this individual so it cannot be assumed that the dog was ceremonially consumed as a part of this event. The cut marks on the mandibles of Dog F\#3370-1 suggest pelt removal. Since only the head and upper cervical vertebrae of this individual were recovered, it is impossible to determine whether or not this dog was butchered for consumption.

The isolated remains with cut marks, however, may represent consumption (either ritual or non-ritual). The location of the majority of the cut marks suggests either dismemberment or filleting activities, and a small portion exhibit some degree of burning. Additionally, the majority of these remains were recovered from features interpreted as middens or refuse pits and were scattered (i.e., very few canid bones recovered from the same feature). Alternatively, the dogs may have been dismembered and/or burned for easy disposal. These remains, as well as those without cut marks or burning, may have been further scattered by scavengers. It should be noted that butchery can be accomplished without leaving marks on the bones; therefore, it is possible some of the remains without cut marks were also consumed. If the remains with cut marks do represent consumption of dogs, little more can be said considering the very small sample size. Also, it should be noted that with some elements (especially when only a portion of the element 
is present), distinguishing between domestic dogs and coyotes (Canis latrans) is very difficult. Therefore, it cannot be ruled out that some of the isolated remains reported here are actually coyote rather than dog. However, it should also be noted that if dogs were as numerous during the LW and TLW as the archaeological record suggests, it is not likely that coyotes would be scavenging near habitation areas.

\section{Inter-site Comparisons}

During the LW and TLW occupations at Range, several patterns are evident based on the pathology and trauma observed on the canid remains. These are compared to the patterns observed in the canid assemblages recovered from a number of contemporaneous sites in the American Bottom region. With the exception of the Janey B. Goode site, where the canid data are not distinguished by time period, this discussion pertains only to canid remains recovered from LW and TLW contexts and, therefore, temporal comparisons will not be discussed here.

\section{There is evidence of potential sacrifice.}

Cut marks similar to those observed on the atlas of Dog F\#798-1 are present on a probable dog atlas from the Olin site (Kuehn 2016:544). These marks, as well as those present on other cervical vertebrae, are associated with the severing of the carotid artery for sacrifice (e.g., Brizinski and Savage 1983; Oberholtzer 2002). Similarly, cut marks located at the proximal end of the femora, approximately $10-15 \mathrm{~mm}$ below the head, can be interpreted as the sacrificial severing of the femoral artery. Cut marks of this nature are observable on both femora of a dog 
from the Fish Lake site (Kuehn 2016) as well as a canid femur of indeterminate temporal association from the East St. Louis site (Kuehn 2018).

Several partially articulated dog forelimbs from the Janey B. Goode site (Kuehn 2014b, 2016) may be interpreted as ceremonial, as discussed briefly before. The lower portions of both forelimbs of Dog F\#6912-1 were recovered from a pit feature. Cut marks are present on the right radius and left ulna. Dog F\#150-1 is represented by the entire right forelimb. No cut marks are observable on these remains. The left forepaw of Dog F\#5609-2 was intermixed with the remains of a complete adult female dog. Neither of these individuals exhibited evidence of butchery. These remains, particularly Dog F\#6912-1 and Dog F\#5609-2, may reflect ceremonial or ritual activity in which forelimbs are intentionally removed and interred (e.g., Byrd et al. 2013; Kerber 1997; Prahl 1967:18; Valera and Costa 2013).

It is also possible that some of the other dog burials represent sacrificed individuals. Major arteries can be severed without leaving any marks on the bone. Other methods, such as strangling, would likely leave no osteological evidence. However, because there is no evidence on any of the other dogs to suggest otherwise, it cannot be assumed that any of these individuals were sacrificially killed.

\section{There is evidence of dismemberment and/or possible consumption.}

Consumption of dog remains has been noted at the John H. Faust \#2 and Fish Lake sites. A minimum of two domestic dogs and one dog/coyote is represented at John H. Faust \#2 (Holley et al. 2001). Because the remains were associated with other dietary refuse, these individuals are thought to represent food rather than burials. No butchery marks were noted on the remains. At Fish Lake, a partial dog skeleton exhibiting cut marks on both the left and right pelves, as well as 
one lumbar vertebra was recovered from a pit feature (Fortier 2014). The pit additionally contains dietary refuse (e.g., deer, turkey, buffalo sucker, etc.), bone with cut marks, modified turtle shell, and a raccoon hind paw that likely represents a ceremonial or ritual item.

The general paucity of cut marks observed on the Janey B. Goode and East St. Louis dog remains suggests that dogs were not typically consumed at the site. However, the lack of cut marks does not necessarily mean dogs were not being consumed (i.e., it is possible to butcher a carcass without leaving cut marks). Similarly, consumed dogs may have been disposed of differently from working dogs that may have held an elevated status in society. At the Janey B. Goode site, only dog remains identified in the field as "dog burials" have been analyzed thus far, so future examination of the remainder of the faunal assemblage may reveal additional canid bones that can be reasonably interpreted as dietary refuse.

\section{Vertebral spinous process anomalies, osteophytes, and ankylosis spondylitis are frequent suggesting dogs were commonly used as hauling or pack animals.}

Of the 55 dogs with postcranial elements at the Janey B. Goode site, 23 are affected by one or more of these pathologies, representing 41.8 percent of the population (Kuehn 2014b) (Table 8.1). The most common of these is spinous process anomalies, which affects 22 dogs. Ankylosis spondylitis is observable in three individuals. Both the spinous process and anomalies and ankylosis spondylitis are most commonly found on the lower thoracic, lumbar, and sacral vertebrae. Osteophytes are similarly most common on these portions of the spine, but were also observed on the scapular glenoid fossa in one individual. All three of these pathologies most frequently affect males, although this may be due to a greater number of males identified in the population. Additionally, the majority of affected individuals are categorized as mature or older 
adult, with the remainder classified as indeterminate adult or young adult. This suggests that age is a factor in the development of such pathologies. Although it appears that the Janey B. Goode dogs were more often subjected to occupational stress and hard work than those at Range, it is likely that sample size is to blame.

At the East St. Louis site, four of the 12 dogs with postcranial elements (33.3 percent of the population) display evidence of vertebral trauma (Kuehn 2018). Ankylosis spondylitis was not observed on any of these remains. Spinous process anomalies and osteophytes are observable on three and three individuals, respectively. Three of the four individuals are identified as adults with the remainder classified as juvenile. All three adults exhibit evidence of spinous process anomalies, again suggesting age may be a contributing factor in the pathology. Osteophytic growth was observable on the juvenile individual, suggesting extensive hard labor early in life. Sex could be determined in two of the four dogs: one male and one female. Due to the small sample size, little more can be interpreted from the remains.

Table 9

Inter-Site Comparison of Vertebral Trauma

\begin{tabular}{rcccc}
\hline & $\begin{array}{c}\text { Spinous } \\
\text { Process } \\
\text { Anomalies }\end{array}$ & Osteophytes & $\begin{array}{c}\text { Ankylosis } \\
\text { Spondylitis }\end{array}$ & $\begin{array}{c}\text { Total \# of Dogs } \\
\text { with Vertebral } \\
\text { Pathology }\end{array}$ \\
\hline Range & $6(17.1 \%)$ & $9(25.7 \%)$ & $2(5.7 \%)$ & $11(31.4 \%)$ \\
Janey B. Goode & $22(40.0 \%)$ & $6(10.9 \%)$ & $3(5.5 \%)$ & $23(41.8 \%)$ \\
ESTL & $3(25.0 \%)$ & $3(25.0 \%)$ & 0 & $4(33.3 \%)$ \\
\hline
\end{tabular}




\section{Cranial trauma and rib fractures are common suggesting harsh treatment.}

At the Janey B. Goode site, cranial and rib trauma is observable on a similar proportion of dogs as compared to the Range assemblage (Table 8.2). A total of 14 dogs, or 20 percent of the population, exhibit evidence of this type of trauma (Kuehn 2014b). Of the ten individuals with cranial trauma, impact or depression fractures are observable on eight. This type of injury is most commonly observed on the frontal or parietal bones, posterior and/or superior to the eye orbit. Similar to these fractures, the inwardly compressed zygomatic arch observable on another individual is likely the result of a blow, kick, or strike, although other causes are possible. One other dog exhibits a circular perforation approximately $3.5 \mathrm{~mm}$ in diameter on the right squamosal. This injury shows some degree of healing and is suggestive of a canine impact mark, possibly resulting from fights with other dogs. Seven dogs exhibit rib fractures.

Cranial and rib trauma is less common at the East St. Louis site, where two dogs are affected, representing 13.3 percent of the population (Kuehn 2018). Two individuals have fractured ribs. A single individual exhibits a large depression fracture above the right orbital. Similarly, a single individual from the Fish Lake site has a depression fracture on the right parietal.

Table 10 Inter-Site Comparison of Cranial and Rib Trauma

\begin{tabular}{rccc}
\hline & $\begin{array}{c}\text { Cranial } \\
\text { Trauma }\end{array}$ & Rib Fractures & $\begin{array}{c}\text { Total \# of Dogs with } \\
\text { Cranial/Rib Trauma }\end{array}$ \\
\hline Range & $7(15.2 \%)$ & $6(17.0 \%)$ & $10(20.0 \%)$ \\
Janey B. Goode & $10(14.3 \%)$ & $7(12.7 \%)$ & $14(20.0 \%)$ \\
ESTL & $1(7.7 \%)$ & $2(16.7 \%)$ & $2(13.3 \%)$ \\
Fish Lake & $1(50.0 \%)$ & 0 & $1(50.0 \%)$ \\
\hline
\end{tabular}




\section{Dental pathology is common and primarily reflects dog diet.}

At the Janey B. Goode site, 26 of the dogs with heads exhibit dental pathology, accounting for 37.1 percent of the population (Kuehn 2014b) (Table 8.3). By far, the most common pathology observed is antemortem tooth absence, which affects 23 individuals. Other dental pathologies observed at Janey B. Goode are periodontal disease, abscess, and fracture, which affect five, four, and two individuals, respectively. In one individual, an abscess is observable in association with a fractured fourth maxillary premolar, suggesting the two pathologies may be related. The maxillary canine of another dog was fractured. At East St. Louis, the only dental pathology noted is periodontal disease, which affects two individuals, or 15.4 percent of the population (Kuehn 2018).

In comparison to other sites, a higher proportion of the Range population exhibits evidence of dental pathologies ( $\mathrm{N}=30$ or 57.7 percent). At Range, 76.5 percent of dogs with antemortem tooth absence also exhibited evidence of periodontal disease. At the Janey B. Goode site, 22.7 percent of the individuals with antemortem tooth absence also had periodontal disease (Kuehn 2014b). This comparison may suggest that the higher rate of antemortem tooth absence observable at Range is caused, in part, by the higher rate of periodontal disease. The contrasting rates of periodontal disease may be due to dietary differences. As mentioned previously, individuals that consume large amounts of carbohydrate-rich foods are more likely to have plaque buildup, leading to periodontal disease. In this regard, higher rates of periodontal disease may be an indicator that the Range dogs' diet was not supplemented by their human companions resulting in poor nutrition. However, such varying dental health may also be the result of differences in preservation and analytical techniques. 
Table 11

Inter-Site Comparison of Dental Pathology

\begin{tabular}{rccccc}
\hline & $\begin{array}{c}\text { Antemortem } \\
\text { Tooth } \\
\text { Absence }\end{array}$ & $\begin{array}{c}\text { Periodontal } \\
\text { Disease }\end{array}$ & Abscess & Fracture & $\begin{array}{c}\text { Total \# of } \\
\text { Dogs with } \\
\text { Dental } \\
\text { Pathology }\end{array}$ \\
\hline Range & $17(56.7 \%)$ & $15(50.0 \%)$ & $2(6.7 \%)$ & $\begin{array}{c}5(16.7 \\
\%)\end{array}$ & $30(57.7 \%)$ \\
Janey B. Goode & $23(32.9 \%)$ & $5(7.1 \%)$ & $4(5.7 \%)$ & $2(2.9 \%)$ & $26(37.1 \%)$ \\
ESTL & 0 & $2(15.4 \%)$ & 0 & 0 & $2(15.4 \%)$ \\
\hline
\end{tabular}




\section{CHAPTER VIIII: CONCLUSION}

The domestic dog has served a wide variety of both physical and spiritual roles in Native American societies for thousands of years. Paleopathological analysis of prehistoric canid remains can aid in our understanding of the daily lives of these dogs. Social zooarchaeology is a necessary theoretical construct in dog paleopathology as it goes beyond typical zooarchaeological studies that emphasize dietary patterns, resource exploitation, environmental reconstruction, tool production, and related topics. In contrast, social zooarchaeology recognizes the complexity of the human-dog relationship.

This research consisted of the reanalysis the canid remains recovered from the Range site as well as previously unanalyzed canid remains. A total of 52 dog burials associated with the LW and TLW were identified in the assemblage. Close examination of the skeletal remains indicates the most common pathologies present are periodontal disease, antemortem tooth absence, cranial trauma, rib fractures, and spinous process anomalies. Periodontal disease and antemortem tooth absence are more frequently observed during the LW, potentially suggesting greater consumption of carbohydrate-rich foods during this period, although other factors, such as genetics, environmental causes, and other pathologies or trauma may be responsible. Spinous process anomalies and rib fractures are also more common during this earlier period. Vertebral trauma, including spinous process anomalies, osteophytosis, and ankylosis are attributed with occupational stress. Rib fractures, as well as cranial trauma, are likely the result of disciplinary action, although other causes such as accidents, dog fights, and confrontations with large game are possible. Cranial trauma is more common during the TLW, suggesting dogs were more harshly treated during this period. 
The slight differences in pathology incidence rates between the two time periods are observable but minimal. Generally, the data suggest that the Range dogs primarily served as beasts of burden and hunting companions (as opposed to food or for sacrificial/ceremonial purposes) and endured harsh treatment. These interpretations compare favorably with patterns observed at other sites in the American Bottom region. The only major difference between the Range dogs and those from other sites is the high rate of dental pathologies, although this may be due to analytical differences and bone preservation.

Future research directions would include in depth paleopathological analyses of the canid remains from other sites in the American Bottom region, as well as reanalysis of material where the initial examination was partial or limited. Paleopathological analysis would minimally include: (1) determination of age and sex, (2) select cranial and postcranial measurements, (4) description of burial context, including placement within the feature, other material present in the feature, and position in relation to other major structures, and (4) detailed documentation (and illustration, when appropriate) of select dental and skeletal pathologies, including location, degree of severity, possible causes or associated pathology/trauma. The select pathologies for particular consideration minimally include: (1) periodontal disease, (2) antemortem tooth absence, (3) tooth abscess, (4) tooth fracture, (5) cranial fractures, (6) rib fractures, (7) spinous process anomalies, (8) osteophytes (particularly on the vertebrae, but should be noted if observed on other elements as well), (9) ankylosis spondylitis, (10) fractures of postcranial elements. These analytical techniques will be elaborated upon in a future publication. Implementation of dog paleopathological analysis at other sites will allow researchers to better understand the changing roles and treatment of dogs throughout prehistory and across various human populations. 


\section{REFERENCES}

Allen, G. M.

1920 Dogs of American Aborigines. Bulletin of the Museum of Comparative Zoology, Harvard University 63:431-517.

Arima, E.

1984 Caribou Eskimo. In Handbook of North American Indians, Vol. 5, edited by D. Dumas, pp. 447-462. Smithsonian Institution, Washington, D.C.

Arnold, Charles D.

1979 Possible Evidence of Domestic Dog in Paleoeskimo Context. Arctic 32(3):263265.

Baker, J., and D. Brothwell

1980 Animal Diseases in Archaeology. Academic Press, New York.

Bartelle, Barney G., René L. Vellanoweth, Elizabeth S. Netherton, Nicholas W. Poister, William E. Kendig, Amira F. Ainis, Ryan J. Glenn, Johanna V. Marty, Lisa Thomas-Barnett, and Steven J. Schwartz

2010 Trauma and Pathology of a Buried Dog from San Nicolas Island, California, U.S.A. Journal of Archaeological Science 37:2721-2734.

Bartosiewicz, László, and Erika Gál

2008 Symptoms of Aggression on Animal Bones From Archaeological Sites. Animal Welfare, Ethology and Housing Systems 4(1):3-25.

Behrensmeyer, A. K.

1981 Vertebrate Paleoecology in a Recent East African Ecosystem. In Communities of the Past, edited by J. Gray, A. J. Boucot, and W. B. N. Berry, pp. 591-615.

Hutchinson Ross Publishing Co., Stroudsburg.

Behrensmeyer, A. K., and D. E. D. Boaz

1980 The Recent Bones of Amboseli National Park, Kenya, in Relation to East African Paleoecology. In Fossils in the Making, edited by A. K. Behrensmeyer and A. P. Hill, pp. 72-92. University of Chicago Press, Chicago.

Benecke, N.

1987 Studies on Early Dog Remains From Northern Europe. Journal of Archaeological Science 14:31-49.

Binford, Lewis R.

1981 Bones: Ancient Men and Modern Myths. Academic Press, Inc., Orlando. 
Binford, Lewis R., Sally R. Binford, Robert Whallon, and Margaret Ann Hardin

1970 Archaeology at Hatchery West. Memoir 24. Society for American Archaeology, Washington D. C.

Binois, Annelise, Christophe Wardius, Pierre Rio, Anne Bridault, and Christophe Petit

2013 A Dog's Life: Multiple Trauma and Potential Abuse in a Medieval Dog from Guimps (Charente, France). International Journal of Paleopathology 3(1):39-47.

Bluhm, Elaine A.

1951 Ceramic Sequence in Central Basin and Hopewell Sites in Central Illinois. American Antiquity 16: 324-329.

Bourdelle, E., and C. Bressou

1953 Anatomie Regionale des Animaux Domestiques, Part IV, pp. 168. Bailliére, Paris.

Brightman, R. A.

1993 Grateful Prey: Rock Cree Human-Animal Relationships. University of California Press, Berkeley.

Brizinski, Morris, and Howard Savage

1983 Dog Sacrifices Among the Algonkian Indians: An Example from the Frank Bay Site. Ontario Archaeology 39:33-40.

Buikstra, Jane E., Lyle W. Konigsberg, and Jill Bullington

1986 Fertility and the Development of Agriculture in the Prehistoric Midwest. American Antiquity 51:528-546.

Byrd, Brian F., Anna Cornellas, Jelmer W. Eerkens, Jeffrey S. Rosenthal, Tim R. Carpenter, Alan Leventhal, and Jennifer A. Leonard

2012 The Role of Canids in Ritual and Domestic Contexts: New Ancient DNA Insights from Complex Hunter-Gatherer Sites in Prehistoric Central California. Journal of Archaeological Science 40:2176-2189.

Cantwell, Anne-Marie

1980 Middle Woodland Dog Ceremonialism in Illinois. The Wisconsin Archeologist 61:480-496.

Carlson, K. J., and T. R. Pickering

2003 Intrinsic Qualities of Primate Bones as Indicators of Skeletal Element Representation in Modern and Fossil Carnivore Feeding Assemblages. Journal of Human Evolution 44:431-450.

Claassen, Cheryl

2008 Archaic Rituals: Rebalancing With Dogs. Paper presented at the annual meeting of the Southeastern Archaeological Conference, Charlotte. 
Corey, L. A., W. E. Nance, P. Hofstede, and H. A. Schenkein

1993 Self-Reported Periodontal Disease in a Virginia Twin Population. Journal of Periodontology 64:1205-1208.

Crellin, David F.

1994 Is There a Dog in the House: The Cultural Significance of Prehistoric Domesticated Dogs in the Mid Fraser River Region of British Columbia. M.A. thesis, Department of Anthropology, Simon Fraser University, Burnaby, B.C.

Crellin, David F., and T. Heffner

2000 The Cultural Significance of Domesticated Dogs in Prehistoric Keatley Creek Society. In The Ancient Past of Keatley Creek 2: Socioeconomy, edited by Brian Hayden, pp. 151-166. Archaeology Press, Simon Fraser University, Burnaby.

Crothers, George

2005 Vertebrate Fauna from the Carlston Annis Site. In Archaeology of the Middle Green River Region, Kentucky, edited by William Marquardt and Patty Jo Watson, p. 295-314. Institute of Archaeology and Paleoenvironmental Studies, Monograph 5, Florida Museum of Natural History, University of Florida, Gainesville.

Dorsey, G.

1905 The Cheyenne. Part 1: Ceremonial Organization. Field Columbian Museum Pub. 5, Anthropology Series 1. Chicago.

Dragoo, Don W.

1955 Excavations at the Johnson Site, Indiana County, Pennsylvania. Pennsylvania Archaeologist 25(2):85-141.

Dumas, D.

1984 Copper Eskimo. In Handbook of North American Indians, Vol. 5, edited by D. Dumas, pp. 397-414. Smithsonian Institution, Washington, D.C.

Emerson, Thomas E.

1984 The Dryoff-Levin Site. In The Go-Kart North Site by A. Fortier and The DryoffLevin Sites by T. Emerson. American Bottom Archaeology FAI-270 Site Reports 9. University of Illinois Press, Urbana.

Emerson, Thomas E., and Douglas K. Jackson 1984 The BBB Motor Site. American Bottom Archaeology FAI-270 Site Reports 6. University of Illinois Press, Urbana.

Emerson, Thomas E., Dale L. McElrath, and Andrew C. Fortier 2000 Late Woodland Societies: Tradition and Transformation Across the Midcontinent. University of Nebraska Press, Lincoln. 
Emerson, Thomas E., George R. Milner, and Douglas K. Jackson

1983 The Florence Street Site. American Bottom Archaeology FAI-270 Site Reports 2. University of Illinois Press, Urbana

Fiedel, Stuart J.

2001 What Happened in the Early Woodland? Archaeology of Eastern North America 29: $101-142$.

Fortier, Andrew C.

1984 Feature Types and Distributions. In The Fish Lake Site (11-Mo-608), edited by Andrew C. Fortier, Richard B. Lacampagne, and Fred A. Finney, pp. 17-83. American Bottom Archaeology FAI-270 Site Reports 8. University of Illinois Press, Urbana.

2001 A Tradition of Discontinuity: American Bottom Early and Middle Woodland Culture History Reexamined. In The Archaeology of Traditions: Agency and History Before and After Columbus, edited by T. R. Pauketat, pp. 174-194. University Press of Florida, Gainsville.

2014 Late Woodland Communities in the American Bottom: The Fish Lake Site, edited by Andrew C. Fortier. Illinois State Archaeological Survey Research Report 28, University of Illinois, Champaign-Urbana.

2015 Radiocarbon Dates. In A Late Woodland Procurement and Ceremonial Complex at the Reilley and Husted Sites in the Northern American Bottom, edited by Andrew C. Fortier, pp. 135-138. Research Reports 32, Illinois State Archaeological Survey, University of Illinois Press.

2016 Keyhole Structures in the American Bottom: Their Distribution, Cultural Contexts and Function. Illinois Archaeology 28:385-404.

Fortier, Andrew C., and Douglas K. Jackson

2000 The Formation of a Late Woodland Heartland in the American Bottom, Illinois cal A.D. 650-900. In Late Woodland Societies: Tradition and Transformation Across the Midcontinent, edited by Thomas E. Emerson, Dale L. McElrath, and Andrew C. Fortier, pp. 123-148. University of Nebraska Press, Lincoln.

Fortier, Andrew C., Thomas E. Emerson, and Dale L. McElrath

2006 Calibrating and Reassessing American Bottom Culture History. Southeastern Archaeology 25(2): 170-211.

Fortier, Andrew C., Richard B. Lacampagne, and Fred A. Finney

1984 The Fish Lake Site (11-Mo-608). American Bottom Archaeology FAI-270 Site Reports Vol. 8. University of Illinois Press, Urbana. 
Fortier, Andrew C., Thomas O. Maher, and Joyce A. Williams

1991 The Sponemann Site: The Formative Emergent Mississippian Sponemann Phase Occupations (11-Ms-517). American Bottom Archaeology FAI-270 Site Reports 23. University of Illinois Press, Urbana.

Fortier, Andrew C., and Dale L. McElrath

2002 Deconstructing the Emergent Mississippian Concept: The Case for the Terminal Late Woodland in the American Bottom. Midcontinental Journal of Archaeology 27:172-215.

Freuchen, $\mathrm{P}$.

1935 Field Notes and Biological Observations. In Report of the Fifth Thule Expedition 1921-24. Vol. 2(4-5): Zoology I-Mammals, Copenhagen, pp. 68-278.

Fritz, Gayle J.

1993 Early and Middle Woodland Period Paleoethnobotany. In Foraging and Farming in the Eastern Woodlands, edited by Margaret Scarry. University Press of Florida, Gainesville.

Galloy, Joseph M.

2003 Excavations at the Janey B. Goode Site (11S1232), St. Clair County, Illinois: Interim Report, Research Design, and Mitigation Plan. Research Reports 92. Illinois State Archaeological Survey, University of Illinois, Champiagn-Urbana.

Gayton, A. H.

1946 Yokuts and Western Mono Ethnography. University of California Anthropological Records 10: 10-230.

Grant, Annie

1984 Survival or Sacrifice? A Critical Appraisal of Animal Burials in Britain in the Iron Age. In Animals and Archaeology: 4. Husbandry in Europe, edited by C. Grigson and J. Clutton-Brock, pp. 221-227. British Archaeological Reports, International Series. Archaeopress, Oxford.

Green, William

1987 Between Hopewell and Mississippian: Late Woodland in the Prairie Peninsula as Viewed from the Western Illinois Uplands. Ph.D. dissertation, University of Wisconsin-Madison. University Microfilms, Ann Arbor.

1993 A Prehistoric Frontier in the Prairie Peninsula: Late Woodland Upland Settlement and Subsistence Patterns. In Highways to the Past: Essays on Illinois Archaeology in Honor of Charles J. Bareis, edited by Thomas E. Emerson, Andrew C. Fortier, and Dale L. McElrath. Illinois Archaeology 5:201-214.

Griffin, James B.

1952 Archaeology of the Eastern United States. University of Chicago Press. 
Groot, Maaike

2008 Understanding Past Human-Animal Relationships through the Analysis of Fractures: A Case Study from a Roman Site in the Netherlands. In Current Research in Animal Palaeopathology: Proceedings of the Second ICAZ Animal Palaeopathology Working Group Conference, edited by Zora Miklíková and Richard Thomas, Chapter 6. BAR International Series 1844. Archaeopress, Oxford, England.

Haag, William G.

1948 An Osteometric Analysis of Some Aboriginal Dogs. Reports in Anthropology 7 (3). Department of Anthropology, University of Kentucky, Lexington.

Harn, Alan D.

1980 Comments on the Spatial Distribution of Late Woodland and Mississippian Ceramics in the General Cahokia Sphere. Rediscovery 1:17-26.

Harvey, C. E.

1998 Periodontal Disease in Dogs. Veterinary Clinics of North America: Small Animal Practice 28:1111-1128.

Hedman, Kristin M.

2006 Late Cahokia Subsistence and Health: Stable Isotope and Dental Evidence.

Southeastern Archaeology 25(2): 258-274.

Hedman, Kristin M., and Thomas E. Emerson

2015 Stable Isotope Evidence for Maize Consumption in Upper Mississippian Populations in Illinois: Subsistence and Social Complexity. Manuscript on file, Illinois State Archaeological Survey, Champaign.

Hillson, S.

1986 Teeth. Cambridge University Press, Cambridge.

Holley, George R.

1989 The Archaeology of the Cahokia Mounds ICT-II: Ceramics. Illinois Cultural Resources Study 11. Illinois Historic Preservation Agency, Springfield.

Holley, George R., Rinita A. Dalan, and Phillip A. Smith

1993 Investigations in the Cahokia Site Grand Plaza. American Antiquity 58:306-319.

Holley George R., Kathryn E. Parker, Elizabeth M. Scott, Harold W. Watters, Jr., Julie N. Harper, Mikels Skele, Alan J. Brown, Donald L. Booth, Joyce A. Williams, and Jennifer E. Ringberg

2001 The Faust South Locality, Scott Joint-Use Archaeological Project, Pt. I-V. Office of Contract Archaeology, Southern Illinois University at Edwardsville. 
Holt, Julie Z.

1996 AG Church Site Features and Community Organization. Illinois Archaeology 8:58-84.

2000 Animal Exploitation and the Middle to Late Woodland Transition: A Comparison of Animal Use at Mound Centers and Hamlets in the Lower and Central Illinois Valleys. Unpublished Ph.D. Dissertation. Department of Anthropology, New York University.

Howard, J. H.

1965 The Ponca Tribe. Bureau of American Ethnology Bulletin 190, Smithsonian Institution, Washington, D.C.

Hudson, Charles

1976 The Southeastern Indians. University of Tennessee Press, Knoxville.

Iseminger, William R.

2010 Cahokia Mounds: America's First City. The History Press, Charleston, South Carolina.

Kelly, John E., Fred A. Finney, Dale L. McElrath, and Steven J. Ozuk

1984 Late Woodland Period. In American Bottom Archaeology, edited by Charles J. Bareis and James W Porter, pp. 104-127. University of Illinois Press, Urbana.

Kelly, John E., Andrew C. Fortier, Steven J. Ozuk, and Joyce A. Williams

1987 The Range Site: Archaic through Late Woodland Occupations. American Bottom Archaeology FAI-270 Site Reports Vol. 16. University of Illinois Press, Urbana.

Kelly, John E., Steven J. Ozuk, and Joyce A. Williams

1990 The Range Site 2: The Emergent Mississippian Dohack and Range Phase

Occupations. American Bottom Archaeology FAI-270 Site Reports Vol. 20.

University of Illinois Press, Urbana.

Kelly, John E., Steven J. Ozuk, and Joyce A. Williams

2007 The Range Site 4: Emergent Mississippian George Reeves and Lindeman Phase Occupations. Illinois Transportation Archaeological Research Reports No. 18. University of Illinois at Urbana-Champaign.

Kelly, Lucretia S.

1987 Patrick Phase Faunal Materials. In The Range Site: Archaic Through Late Woodland Occupations, by John E. Kelly, Andrew C. Fortier, Steven J. Ozuk, and Joyce A. Williams, pp. 350-400. American Bottom Archaeology FAI270 Site Reports Vol. 16. University of Illinois Press, Urbana. 
Kelly, Lucretia S.

1990a Dohack Phase Faunal Analysis. In The Range Site 2 (11-S-47): The Emergent Mississippian Dohack and Range Phase Occupation, by John E. Kelly, Steven J. Ozuk, and Joyce A Williams, pp. 237-265. American Bottom Archaeology FAI-270 Site Reports Vol. 20. University of Illinois Press, Urbana.

1990b Range Phase Faunal Analysis. In The Range Site 2 (11-S-47): The Emergent Mississippian Dohack and Range Phase Occupation, by John E. Kelly, Steven J. Ozuk, and Joyce A Williams, pp. 487-511. American Bottom Archaeology FAI-270 Site Reports Vol. 20. University of Illinois Press, Urbana.

2007a George Reeves Phase Faunal Analysis. In The Range Site 4: Emergent Mississippian George Reeves and Lindeman Phase Occupations, by John E. Kelly, Steven J. Ozuk, and Joyce A. Williams, pp. 175-203. Transportation Archaeological Research Reports No. 18, University of Illinois at UrbanaChampaign.

2007b Lindeman Phase Faunal Analysis. In The Range Site 4: Emergent Mississippian George Reeves and Lindeman Phase Occupations, by John E. Kelly, Steven J. Ozuk, and Joyce A. Williams, pp. 423-451. Transportation Archaeological Research Reports No. 18, University of Illinois at UrbanaChampaign.

Kerber, Jordan E.

1997 Native American Treatment of Dogs in Northeastern North America: Archaeological and Ethnohistorical Perspectives. Archaeology of Eastern North America 25:81-96.

Koldehoff, Brad, and Joseph M. Galloy

2006 Woodland Frontiers in the American Bottom Region. Southeastern Archaeology 25(2): 275-300.

Kuehn, Steven R.

2014a Canis familiaris in Life and Death: Late Prehistoric Dogs in the American Bottom. Manuscript on file, Illinois State Archaeological Survey, University of Illinois at Urbana-Champaign.

2014b Prehistoric Dog Pathology in the American Bottom: Evidence from the Janey B. Goode Site (11S1232), St. Clair County, Illinois. Illinois Archaeology 26: 97-129.

2016 Beyond Diet: Faunal Remains and Ritual During the Late Woodland Through Mississippian Periods in the American Bottom Region. Illinois Archaeology 28:533-566.

2018 East St. Louis (11S706) Faunal Analysis. In East St. Louis Precinct (11S706) Fauna, Flora, and Marine Remains, edited by Steven R. Kuehn. 
Lawrence, B., and C. Reed

1983 The Dogs from Jarmo. In Prehistoric Archaeology Along the Zargos Flanks, edited by L. Braidwood, R. Braidwood, B. Howe, C. Reed, and P. Watson, pp. 485-489. Oriental Institute, University of Chicago.

Lewis, R. Barry

1986 Early Woodland Adaptations to the Illinois Prairie. In Early Woodland Archaeology, edited by Kenneth B. Farnsworth and Thomas E. Emerson. Center for American Archaeology Press, Kampsville, Illinois.

Lewis, T. M., and M. K. Lewis

1961 Eva: An Archaic Site. University of Tennessee Press, Knoxville.

Losey, Robert J., Erin Jessup, Tatiana Nomokonova, Mikhail Sablin

2014 Craniomandibular Trauma and Tooth Loss in Northern Dogs and Wolves: Implications for the Archaeological Study of Dog Husbandry and Domestication. PLOS ONE 9(6): e99746, pp. 1-16.

MacKinnon, Michael

2010 'Sick as a Dog:' Zooarchaeological Evidence for Pet Dog Health and Welfare in the Roman World. World Archaeology 42(2):290-309.

McElrath, Dale L.

1988 Project Background. In Late Woodland Site in the American Bottom Uplands, edited by Charles Bentz, Dale L. McElrath, Fred A. Finney, and Richard B. Lacampagne. American Bottom Archaeology FAI-270 Site Reports Vol. 18, pp. 1-14. University of Illinois Press, Urbana.

McElrath, Dale L., and Andrew C. Fortier

2000 The Early Late Woodland Occupation of the American Bottom. In Late Woodland Societies: Tradition and Transformation Across the Midcontinent, edited by Thomas E. Emerson, Dale L. McElrath, and Andrew C. Fortier, pp. 97-122. University of Nebraska Press.

McMillan, R. B.

1970 Early Canid Burial from the Western Ozark Highland. Science 167:1246-1247.

Meinholz, Norm, and Jennifer L. Kolb

1997 The Statz Site: A Late Woodland Community and Archaic Lithic Workshop in Dane County, Wisconsin. Archaeology Research Series 5, Museum Archaeology Program, State Historical Society of Wisconsin, Madison.

Miller, M.E.

1949 Guide to the Dissection of the Dog. Ithaca, New York. 
Milner, George R.

2004 The Moundbuilders: Ancient Peoples of Eastern North America. Thames \& Hudson Ltd., London.

Milner, George R., Thomas E. Emerson, Mark W. Mehrer, Joyce A. Williams, and Duane Esarey 1984 Mississippian and Oneota Period. In American Bottom Archaeology, ed. Charles J. Bareis and James W. Porter, pp. 158-86. University of Illinois Press, Urbana.

Morey, Darcy F.

1986 Studies on Amerindian Dogs: Taxonomic Analysis of Canid Crania From the Northern Plains. Journal of Archaeological Science 13(2): 119-145.

1992 Size, Shape, and Development in the Evolution of the Domestic Dog. Journal of Archaeological Science 19:181-204.

1994 The Early Evolution of the Domestic Dog. American Scientist 82(4):336-347.

2006 Burying Key Evidence: The Social Bond Between Dogs and People. Journal of Archaeological Science 33:158-175.

Morey, Darcy F., and Kim Aaris-Sorensen

2002 Paleoeskimo Dogs of the Eastern Arctic. Arctic 55 (1): 44-56.

Morey, Darcy F., and M. D. Wiant

1992 Early Holocene Domestic Dog Burials From the North American Midwest.

Current Anthropology 33:224-229.

Morris, James

2011 Investigating Animal Burials: Ritual, Mundane and Beyond. British Archaeological Reports, British Series 535, Oxford.

Muller, Jon

1997 Mississippian Political Economy. Plenum Press, New York.

Munson, P. J.

2000 Age-Correlated Differential Destruction of Bones and its Effect on Archaeological Mortality Profiles of Domestic Sheep and Goats. Journal of Archaeological Science 27:391-407.

Munson, P. J., and R. C. Garniewicz

2003 Age-Mediated Survivorship of Ungulate Mandibles and Teeth in Canid-Ravaged Faunal Assemblages. Journal of Archaeological Science 30:405-416.

Nickel, R., A. Schummer, and E. Seiferle

1960 Lehrbuch der Anatomie der Haustiere, Band II, pp. 82. Berlin and Hamburg. 
Nolan, David

1993 A Late Woodland Keyhole Structures From Adams County, Illinois. Illinois Antiquity 28:10-14.

Oberholtzer, Cath

2002 Fleshing Out the Evidence: From Archaic Dog Burials to Historic Dog Feasts. Ontario Archaeology 73:3-14.

Olsen, S. J.

1974 Early Domestic Dogs in North America and Their Origins. Journal of Field Archaeology 1:343-345.

1985 Origins of the Domestic Dog: The Fossil Record. University of Arizona Press, Tucson.

Pace, Robert E., and Gary A. Apfelstadt

1978 Allison-LaMotte Culture of the Daugherty-Monroe Site, Sullivan County, Indiana. Archaeology Laboratory, Indiana State University, Terre Haute.

Page, R. C., and H. E. Shroeder

1981 Spontaneous Chronic Periodonitis in Adult Dogs: A Clinical and Histopathological Survey. Journal of Periodontology 52:60-73.

1982 Peridontitis in Man and Other Animals: A Comparative Review. Basel, Karger.

Park, Robert W.

1987 Dog Remains from Devon Island, N.W.T.: Archaeological and Osteological

Evidence for Domestic Dog Use in the Thule Culture. Arctic 40(3):184-190.

Pauketat, Timothy R.

1994 The Ascent of Chiefs: Cahokia and Mississippian Politics in Native North America. University of Alabama Press, Tuscaloosa.

1998 Refiguring the Archaeology of Greater Cahokia. Journal of Archaeological Research 6: 45-89.

2012 The Archaeology of the Cosmos: Rethinking Agency and Religion in Ancient America. Routledge, New York.

Peregrine, Peter N., and Melvin Ember (editors) 2001 Encyclopedia of Prehistory: Volume 6: North America. Springer, pp. 248-268.

Pfeil, Dirsko J. F. von, and Charles E. DeCamp

2009 The Epiphyseal Plate: Physiology, Anatomy, and Trauma. Compendium: Continuing Education for Veterinarians. Veterinary Learning Systems, CompendiumVet.com. 
Pickering, T. R.

2002 Baboon Bone Mineral Densities: Implications for the Taphonomy of Primate Skeletons in South African Cave Sites. Journal of Archaeological Science 29:883-896.

Poplin, F.

1976 Existe-t-il une Correlation Entre les Anomalies de Nombre Des Dents Jugales et l'allongement Facial, Chez le Chien? Zentralblatt Fur Veterinarmedizen Reihe C $5: 21-34$.

Prahl, Earl J.

1967 Prehistoric Dogs of Michigan. The Michigan Archaeologist 13 (1): 13-27.

Rasmussen, Knud

1931 The Netsilik Eskimos: Social life and spiritual culture, Vol. 8 (1-2). Ams Press.

Reitz, Elizabeth J., and Elizabeth S. Wing

2008 Zooarchaeology: Cambridge Manuals in Archaeology, $2^{\text {nd }}$ edition. Cambridge University Press.

Ruscillo, Deborah

2006 The Table Test: A Simple Technique for Sexing Canid Humeri. In Recent Advances in Ageing and Sexing Animal Bones, edited by Deborah Ruscillo, pp. 62-67. Oxbow Books, Oxford.

Russell, Nerissa

2012 Social Zooarchaeology: Humans and Animals In Prehistory. Cambridge University Press, Cambridge.

Salkin, Philip H.

2000 The Horicon and Kekoskee Phases: Cultural Complexity in the Late Woodland Stage in Southeastern Wisconsin. In Late Woodland Societies: Tradition and Transformation Across the Midcontinent, edited by Thomas E. Emerson, Dale L. McElrath, and Andrew C. Fortier, pp. 525-542.

Schwartz, Marion

1997 A History of Dogs in the Early Americas. Yale University Press, New Haven.

Scott, J. H.

1957 Muscle Growth and Function in Relation to Skeletal Morphology. American Journal of Physical Anthropology 15:197-234.

Seger, J. H.

1934 Early Days Among the Cheyenne and Arapahoe Indians, edited by S. Vestal. University of Oklahoma Press, Norman. 
Shigehara, Nobuo, Satoru Onodera, and Moriharu Eto

1997 Sex Determination by Discriminant Analysis and Evaluation of Non-Metric Traits in the Dog Skeleton. In Osteometry of Makah and Coast Salish Dogs, by Susan J. Crockford, pp. 113-126. Archaeology Press, Simon Fraser University, Burnaby, B.C.

Siegel, Jane

1976 Animal Palaeopathology: Possibilities and Problems. Journal of Archaeological Science 3: 349-384.

Simon, Mary L.

2017 Reevaluating the Evidence for Middle Woodland Maize From the Holding Site. American Antiquity 82(1):140-150.

Simon, Mary L., Kristin M. Hedman, Thomas E. Emerson, and Kelsey E. Witt 2016 Cahokia and Corn: Multidisciplinary Research on the Timing and Intensity of Maize Consumption in Western Illinois. Manuscript on file Illinois State Archaeological Survey, Champaign.

Simon, Mary L., and Kathryn Parker

2006 Prehistoric Plant Use in the American Bottom: New Thoughts and Interpretations. Southeastern Archaeology 25(2): 170-211.

Snyder, Lynn M.

1995 Assessing the Role of the Domestic Dog as a Native American Food Resource in the Middle Missouri Subarea A.D. 1000-1840. Ph.D. dissertation, University of Tennessee, Knoxville. ProQuest Information and Learning Company, Ann Arbor.

Speck, F. G.

1925 Dogs of the Labrador Indians. Natural History 25:58-64.

Strong, John A.

1985 Late Woodland Dog Ceremonialism on Long Island in Comparative and Temporal Perspective. The Bulletin and Journal of the New York State Archaeological Association 91:32-38.

Teegan, Wolf-Rudiger

2005 Rib and Vertebral Fractures in Medieval Dogs from Haithabu, Starigard and Schleswig. In Diet and Health in Past Animal Populations, edited by J. Davies, M. Fabis, I. Mainland, M. Richards, and R. Thomas, pp. 34-38. Oxbow Books.

Templeton, A. R.

1989 The Meaning of Species and Speciation: A Genetic Perspective. In Speciation and Its Consequences, edited by D. Otte and J. Endler, pp. 3-27. Sinauer Associates, Sunderland. 
The, T. L., and C. O. Trouth

1976 Sexual Dimorphism in the Basilar Part of the Occipital Bone of the Dog (Canis familiaris). Acta Anatomica Basel 95: 565-571.

Thomas, Stephen Cox

1996 The House 7 Multiple Dog Cremation Burial. In The Archaeology of the Dunsmore Site: A Late Iroquoian Community in Southern Simcoe County, edited by David A. Robertson and Ronald F. Williamson, pp. 125-180. Manuscript on file, Ontario Ministry of Culture, Toronto.

Valera, A. C., and C. Costa

2013 Animal Limbs in Funerary Contexts in Southern Portugal and the Question of Segmentation. Anthropozoologica 48(2):263-275.

Van der Velden, U., F. Abbas, S. Armand, J. de Graaf, M. F. Timmerman, G. A. van der Weijen, A. J. van Winkelhoff, and E. G. Winkel

1993 The Effect of Sibling Relationship on the Periodontal Condition. Journal of Clinical Periodontology 20:683-690.

Von den Driesch, Angela

1976 A Guide to the Measurement of Animal Bones From Archaeological Sites.

Bulletin 1, Peabody Museum of Archaeology and Ethnology, Harvard University.

Walker, Renee B., Darcy F. Morey, and John H. Relethford

2005 Early and Mid-Holocene Dogs in Southeastern North America: Examples from Dust Cave. Southeastern Archaeology 24(1):83-92.

Warren, Diane M.

2004 Skeletal Biology and Paleopathology of Domestic Dogs from Prehistoric Alabama, Illinois, Kentucky, and Tennessee. Unpublished Ph.D. dissertation, Indiana University, Bloomington. ProQuest Information and Learning Company, Ann Arbor.

Wayne, R. K.

1993 Molecular Evolution of the Dog Family. Trends in Genetics 9:218-224.

Webb, William S.

1950 Carlston Annis Mound, Site 5, Butler County, Kentucky. Reports in Anthropology 7(4), University of Kentucky, Lexington.

1974 Indian Knoll. University of Tennessee Press, Knoxville.

White, William P., Sissel Johannessen, Paula G. Cross, and Lucretia S. Kelly

1984 Environmental Setting. In American Bottom Archaeology, edited by Charles J.

Bareis and James W. Porter, pp. 15-33. University of Illinois Press, Urbana. 
Wing, Elizabeth S.

1991 Dog Remains From the Sorcé Site on Vieques Island, Puerto Rico. In Beamers, Bobwhites, and Blue-Points, edited by J.R. Purdue, W.E. Klippel, and B.W. Styles. Illinois State Museum Scientific Papers Vol. 23, University of Tennessee Report 52, Springfield, pp.379-386.

Yarnell, R. A.

1993 The Importance of Native Crops During the Late Archaic and Woodland Periods. In Foraging and Farming in the Eastern Woodlands, edited by C. M. Scarry, pp. 13-26. University Press of Florida, Gainesville. 


\begin{tabular}{|c|c|c|c|c|}
\hline ELEMENT & LEFT & RIGHT & $\begin{array}{c}\text { AGE OF FUSION } \\
\text { (Pfeil \& DeCamp } \\
\text { 2009) }\end{array}$ & $\begin{array}{c}\text { AGE OF } \\
\text { INDIVIDUAL }\end{array}$ \\
\hline DENTITION (MAX) & & & SEE CHART & \\
\hline DENTITION (MAND) & & & SEE CHART & \\
\hline SCP TUBEROSITY & & & 12 wk-5 mo & \\
\hline PX HUM & & & $10 \mathrm{mo}-12 \mathrm{mo}$ & \\
\hline DS HUM & & & $5 \mathrm{mo}-8 \mathrm{mo}$ & \\
\hline PX ULNA & & & $5 \mathrm{mo}-8 \mathrm{mo}$ & \\
\hline DS ULNA & & & $6 \mathrm{mo}-11 \mathrm{mo}$ & \\
\hline PX RAD & & & $5 \mathrm{mo}-9 \mathrm{mo}$ & \\
\hline ACC CARPAL & & & 10 wk-5 mo & \\
\hline MC BONES & & & $5 \mathrm{mo}-7 \mathrm{mo}$ & \\
\hline PHA (FORELIMB) & & & $4 \mathrm{mo}-7 \mathrm{mo}$ & \\
\hline \multicolumn{5}{|l|}{ GREATER TROCHANTER } \\
\hline (FEM) & & & $6 \mathrm{mo}-11 \mathrm{mo}$ & \\
\hline PX FEM & & & $6 \mathrm{mo}-12 \mathrm{mo}$ & \\
\hline LESSER TROCHANTER (FEM) & & & $9 \mathrm{mo}-12 \mathrm{mo}$ & \\
\hline DS FEM & & & $6 \mathrm{mo}-11 \mathrm{mo}$ & \\
\hline PX TIB & & & $6 \mathrm{mo}-12 \mathrm{mo}$ & \\
\hline TIB TUBERCLE & & & $10 \mathrm{mo}-12 \mathrm{mo}$ & \\
\hline DS TIB & & & $5 \mathrm{mo}-11 \mathrm{mo}$ & \\
\hline MEDIAL MALLEOLUS (TIB) & & & $4 \mathrm{mo}-5 \mathrm{mo}$ & \\
\hline PX FIB & & & $6 \mathrm{mo}-11 \mathrm{mo}$ & \\
\hline DS FIB & & & $5 \mathrm{mo}-11 \mathrm{mo}$ & \\
\hline CAL & & & 11 wk-8 mo & \\
\hline MT BONES & & & $5 \mathrm{mo}-8 \mathrm{mo}$ & \\
\hline PHA (HINDLIMB) & & & $4 \mathrm{mo}-8 \mathrm{mo}$ & \\
\hline DENTAL & LEFT & RIGHT & $\begin{array}{l}\text { TOOTH ERUPTION } \\
\text { (Arnall 1961, Table 2) }\end{array}$ & $\begin{array}{c}\text { AGE OF } \\
\text { INDIVIDUAL }\end{array}$ \\
\hline \multicolumn{5}{|l|}{ DECIDUOUS } \\
\hline I1 & & & $4-6 \mathrm{wk}$ & \\
\hline $\mathbf{I 2}$ & & & $4-6 w k$ & \\
\hline $\mathbf{I 3}$ & & & $4-6 w k$ & \\
\hline $\mathbf{C}$ & & & $3-5 w k$ & \\
\hline P1 & & & $1-2 \mathrm{mo}$ & \\
\hline P2 & & & $1-2 \mathrm{mo}$ & \\
\hline P3 & & & $1-2 \mathrm{mo}$ & \\
\hline \multicolumn{5}{|l|}{ PERMANENT } \\
\hline I1 & & & $2-5 \mathrm{mo}$ & \\
\hline I2 & & & $2-5 \mathrm{mo}$ & \\
\hline I3 & & & 3-5 mo & \\
\hline $\mathbf{C}$ & & & 5-7 mo & \\
\hline P1 & & & 4-6 mo & \\
\hline $\mathbf{P 2}$ & & & 5-6 mo & \\
\hline $\mathbf{P 3}$ & & & 5-6 mo & \\
\hline P4 & & & 4-6 mo & \\
\hline M1 & & & 4-6 mo & \\
\hline M2 & & & 5-7 mo & \\
\hline M3 & & & 6-7 mo & \\
\hline
\end{tabular}


APPENDIX B: CANID MEASUREMENTS (HAAG 1948)

\begin{tabular}{|c|c|c|c|}
\hline \multicolumn{4}{|c|}{ Dog F\#431-1 } \\
\hline Haag \# & Code & Description & Measurement (mm) \\
\hline 1 & $\mathrm{~A}-\mathrm{C}$ & occipital length & -- \\
\hline 2 & $A-G$ & basal length & -- \\
\hline 3 & A-H & condylo-basal length & -- \\
\hline 4 & $A-F$ & palatial length & 89.0 \\
\hline 5 & K-K' & palate width at M1 & 58.0 \\
\hline 6 & J-J' & canine width & 34.5 \\
\hline 7 & M-M' & mastoid width & 60.3 \\
\hline 8 & $\mathrm{~N}-\mathrm{N}^{\prime}$ & occipital condyle width & 29.9 \\
\hline 9 & L-L' & zygomatic arch width & -- \\
\hline 10 & $\mathrm{O}-\mathrm{P}$ & nasal length & 58.0 \\
\hline 11 & $\mathrm{P}-\mathrm{C}$ & occiput to nasion & -- \\
\hline 12 & A-E & orbit to alveolus & 77.8 \\
\hline 13 & R-R' & supraorbital width & -- \\
\hline 14 & Q-Q' & interorbital width & 44.5 \\
\hline 15 & B-D & cranial height & -- \\
\hline 16 & ${\mathrm{~S}-\mathrm{S}^{\prime}}^{\prime}$ & least cranial width & -- \\
\hline 17 & $X-X^{\prime}$ & maximum cranial width & -- \\
\hline 18 & A-D & meatus to alveolus I1 & -- \\
\hline 19 & I1-M2 & alveolus I1 to M2 (max) & 89.0 \\
\hline 20 & $\mathrm{C}-\mathrm{M} 2$ & alveolus canine to $\mathrm{M} 2(\max )$ & 73.8 \\
\hline 21 & P1-M2 & alveolus $\mathrm{P} 1$ to $\mathrm{M} 2(\max )$ & 60.4 \\
\hline 22 & $\mathrm{P} 2-\mathrm{M} 2$ & alveolus P2 to M2 (max) & 52.4 \\
\hline 23 & M1-M2 & alveolus M1 to M2 (max) & 18.0 \\
\hline 24 & P4 & carnassial P4 length (max) & 17.0 \\
\hline 25 & I1-M3 & alveolus I1 to M3 (mand) & 87.0 \\
\hline 26 & C-M3 & alveolus canine to M3 (mand) & 83.0 \\
\hline 27 & P1-M3 & alveolus P1 to M3 (mand) & 67.3 \\
\hline 28 & P2-M3 & alveolus P2 to M3 (mand) & 63.3 \\
\hline 29 & P3-M3 & alveolus P3 to M3 (mand) & 52.7 \\
\hline 30 & P4-M3 & alveolus P4 to M3 (mand) & 42.7 \\
\hline 31 & M1-M3 & alveolus M1 to M3 (mand) & 32.0 \\
\hline 32 & M1 & length carnassial M1 (mand) & 18.0 \\
\hline 33 & $\mathrm{I} 1-\mathrm{Z}$ & condylo-symphysis length (mand) & $\sim 125.0$ \\
\hline 34 & $\mathrm{Y}-\mathrm{Y} 1$ & bicondular width (mand) & 76.4 \\
\hline 35 & $\mathrm{~A}-\mathrm{B}^{*}$ & Humerus & 137.5 \\
\hline 36 & M-M'* & diameter of humerus head & 37.0 \\
\hline 37 & $\mathrm{~N}-\mathrm{N}^{\prime *}$ & transverse diameter humerus head & 23.5 \\
\hline 38 & $\mathrm{C}-\mathrm{D}^{*}$ & Radius & 144.0 \\
\hline 39 & E-G* & Ulna & 170.0 \\
\hline 40 & F-G* & ulnar notch & 145.0 \\
\hline 41 & $\mathrm{~K}-\mathrm{L}^{*}$ & Femur & 154.0 \\
\hline 42 & H-J* & Tibia & 156.0 \\
\hline 43 & $\mathrm{n} / \mathrm{a}$ & baculum length & -- \\
\hline 44 & $\mathrm{n} / \mathrm{a}$ & baculum width & 10.0 \\
\hline
\end{tabular}




\begin{tabular}{|c|c|c|c|}
\hline $\begin{array}{l}\text { Dog F\#4 } \\
\text { Haag \# }\end{array}$ & Description & Code & Measurement (mm) \\
\hline 1 & occipital length & $\mathrm{A}-\mathrm{C}$ & 153.0 \\
\hline 2 & basal length & $A-G$ & 133.0 \\
\hline 3 & condylo-basal length & $\mathrm{A}-\mathrm{H}$ & 147.0 \\
\hline 4 & palatial length & A-F & 79.0 \\
\hline 5 & palate width at M1 & K-K' & 54.0 \\
\hline 6 & canine width & $\mathrm{J}-\mathrm{J}^{\prime}$ & 33.0 \\
\hline 7 & mastoid width & M-M' & 59.0 \\
\hline 8 & occipital condyle width & $\mathrm{N}-\mathrm{N}^{\prime}$ & 36.0 \\
\hline 9 & zygomatic arch width & L-L' & 87.0 \\
\hline 10 & nasal length & $\mathrm{O}-\mathrm{P}$ & 49.0 \\
\hline 11 & occiput to nasion & $\mathrm{P}-\mathrm{C}$ & 85.0 \\
\hline 12 & orbit to alveolus & A-E & 68.5 \\
\hline 13 & supraorbital width & R-R' & 43.0 \\
\hline 14 & interorbital width & $Q^{-} Q^{\prime}$ & 31.5 \\
\hline 15 & cranial height & B-D & 56.0 \\
\hline 16 & least cranial width & S-S' & 36.0 \\
\hline 17 & maximum cranial width & $X-X^{\prime}$ & 54.0 \\
\hline 18 & meatus to alveolus I1 & A-D & 125.0 \\
\hline 19 & alveolus I1 to M2 (max) & I1-M2 & 84.0 \\
\hline 20 & alveolus canine to $\mathrm{M} 2(\max )$ & $\mathrm{C}-\mathrm{M} 2$ & 67.0 \\
\hline 21 & alveolus $\mathrm{P} 1$ to $\mathrm{M} 2(\max )$ & P1-M2 & 57.5 \\
\hline 22 & alveolus $\mathrm{P} 2$ to $\mathrm{M} 2(\max )$ & $\mathrm{P} 2-\mathrm{M} 2$ & 50.5 \\
\hline 23 & alveolus M1 to M2 (max) & M1-M2 & 17.5 \\
\hline 24 & carnassial P4 length (max) & P4 & 17.0 \\
\hline 25 & alveolus I1 to M3 (mand) & I1-M3 & 80.0 \\
\hline 26 & alveolus canine to M3 (mand) & C-M3 & 76.5 \\
\hline 27 & alveolus P1 to M3 (mand) & P1-M3 & 62.0 \\
\hline 28 & alveolus P2 to M3 (mand) & P2-M3 & 57.5 \\
\hline 29 & alveolus P3 to M3 (mand) & P3-M3 & 48.5 \\
\hline 30 & alveolus P4 to M3 (mand) & P4-M3 & 39.5 \\
\hline 31 & alveolus M1 to M3 (mand) & M1-M3 & 30.0 \\
\hline 32 & $\begin{array}{l}\text { length carnassial M1 (mand) } \\
\text { condylo-symphysis length }\end{array}$ & M1 & 18.5 \\
\hline 33 & (mand) & $\mathrm{I} 1-\mathrm{Z}$ & 110.0 \\
\hline 34 & bicondular width (mand) & $\mathrm{Y}-\mathrm{Y} 1$ & 66.0 \\
\hline 35 & Humerus & A-B* & 120.0 \\
\hline 36 & $\begin{array}{l}\text { diameter of humerus head } \\
\text { transverse diameter humerus }\end{array}$ & $\mathrm{M}-\mathrm{M}^{\prime *}$ & 32.0 \\
\hline 37 & head & $\mathrm{N}-\mathrm{N}^{\prime *}$ & 24.5 \\
\hline 38 & Radius & $\mathrm{C}-\mathrm{D}^{*}$ & 123.5 \\
\hline 39 & Ulna & E-G* & 147.0 \\
\hline 40 & ulnar notch & $\mathrm{F}-\mathrm{G}^{*}$ & 126.0 \\
\hline 41 & Femur & $\mathrm{K}-\mathrm{L} *$ & 137.0 \\
\hline 42 & Tibia & H-J* & 135.0 \\
\hline 43 & baculum length & $\mathrm{n} / \mathrm{a}$ & -- \\
\hline 44 & baculum width & $\mathrm{n} / \mathrm{a}$ & -- \\
\hline
\end{tabular}




\begin{tabular}{|c|c|c|c|}
\hline $\begin{array}{r}\text { Dog F\#441 } \\
\text { Haag \# }\end{array}$ & Description & Code & Measurement (mm) \\
\hline 1 & occipital length & $\mathrm{A}-\mathrm{C}$ & 175.0 \\
\hline 2 & basal length & $A-G$ & 153.0 \\
\hline 3 & condylo-basal length & $\mathrm{A}-\mathrm{H}$ & 164.5 \\
\hline 4 & palatial length & $A-F$ & 87.0 \\
\hline 5 & palate width at M1 & K-K' & 57.5 \\
\hline 6 & canine width & $\mathrm{J}-\mathrm{J}^{\prime}$ & 33.5 \\
\hline 7 & mastoid width & M-M' & 62.5 \\
\hline 8 & occipital condyle width & $\mathrm{N}-\mathrm{N}^{\prime}$ & 35.0 \\
\hline 9 & zygomatic arch width & L-L' & 95.0 \\
\hline 10 & nasal length & $\mathrm{O}-\mathrm{P}$ & 70.0 \\
\hline 11 & occiput to nasion & $\mathrm{P}-\mathrm{C}$ & 94.5 \\
\hline 12 & orbit to alveolus & A-E & 80.5 \\
\hline 13 & supraorbital width & R-R' & 48.5 \\
\hline 14 & interorbital width & Q-Q' & 35.0 \\
\hline 15 & cranial height & B-D & $\sim 62.0$ \\
\hline 16 & least cranial width & S-S' & 35.0 \\
\hline 17 & maximum cranial width & $X-X^{\prime}$ & 63.0 \\
\hline 18 & meatus to alveolus I1 & A-D & 138.5 \\
\hline 19 & alveolus I1 to M2 (max) & I1-M2 & 92.0 \\
\hline 20 & alveolus canine to M2 (max) & $\mathrm{C}-\mathrm{M} 2$ & 77.0 \\
\hline 21 & alveolus $\mathrm{P} 1$ to $\mathrm{M} 2(\max )$ & P1-M2 & 63.0 \\
\hline 22 & alveolus $\mathrm{P} 2$ to $\mathrm{M} 2(\max )$ & $\mathrm{P} 2-\mathrm{M} 2$ & 55.0 \\
\hline 23 & alveolus M1 to M2 (max) & M1-M2 & 21.0 \\
\hline 24 & carnassial P4 length (max) & P4 & 16.0 \\
\hline 25 & alveolus I1 to M3 (mand) & I1-M3 & 85.0 \\
\hline 26 & alveolus canine to M3 (mand) & $\mathrm{C}-\mathrm{M} 3$ & 82.0 \\
\hline 27 & alveolus P1 to M3 (mand) & P1-M3 & 68.0 \\
\hline 28 & alveolus P2 to M3 (mand) & P2-M3 & 62.0 \\
\hline 29 & alveolus P3 to M3 (mand) & P3-M3 & -- \\
\hline 30 & alveolus P4 to M3 (mand) & P4-M3 & 43.0 \\
\hline 31 & alveolus M1 to M3 (mand) & M1-M3 & 31.0 \\
\hline 32 & length carnassial M1 (mand) & M1 & 18.0 \\
\hline 33 & condylo-symphysis length (mand) & $\mathrm{I} 1-\mathrm{Z}$ & 120.0 \\
\hline 34 & bicondular width (mand) & $\mathrm{Y}-\mathrm{Y} 1$ & 73.5 \\
\hline 35 & humerus & A-B* & 131.5 \\
\hline 36 & diameter of humerus head & $\mathrm{M}-\mathrm{M}^{\prime *}$ & 35.5 \\
\hline 37 & transverse diameter humerus head & $\mathrm{N}-\mathrm{N}^{\prime *}$ & 22.3 \\
\hline 38 & radius & $\mathrm{C}-\mathrm{D}^{*}$ & 130.0 \\
\hline 39 & ulna & E-G* & 157.0 \\
\hline 40 & ulnar notch & F-G* & 134.5 \\
\hline 41 & femur & $\mathrm{K}-\mathrm{L} *$ & 146.0 \\
\hline 42 & tibia & H-J* & 143.0 \\
\hline 43 & baculum length & $\mathrm{n} / \mathrm{a}$ & -- \\
\hline 44 & baculum width & $\mathrm{n} / \mathrm{a}$ & -- \\
\hline
\end{tabular}




\begin{tabular}{|c|c|c|c|}
\hline \multicolumn{2}{|c|}{ Dog F\#2368-1 } & Code & Measurement (mm) \\
\hline 1 & occipital length & $\mathrm{A}-\mathrm{C}$ & -- \\
\hline 2 & basal length & A-G & -- \\
\hline 3 & condylo-basal length & A-H & -- \\
\hline 4 & palatial length & $A-F$ & -- \\
\hline 5 & palate width at M1 & K-K' & -- \\
\hline 6 & canine width & J-J' & -- \\
\hline 7 & mastoid width & M-M' & -- \\
\hline 8 & occipital condyle width & N-N' & -- \\
\hline 9 & zygomatic arch width & L-L' & -- \\
\hline 10 & nasal length & O-P & -- \\
\hline 11 & occiput to nasion & $\mathrm{P}-\mathrm{C}$ & -- \\
\hline 12 & orbit to alveolus & A-E & -- \\
\hline 13 & supraorbital width & R-R' & -- \\
\hline 14 & interorbital width & $\mathrm{Q}^{-Q^{\prime}}$ & -- \\
\hline 15 & cranial height & B-D & -- \\
\hline 16 & least cranial width & S-S' & -- \\
\hline 17 & maximum cranial width & $\mathrm{X}-\mathrm{X}^{\prime}$ & -- \\
\hline 18 & meatus to alveolus I1 & A-D & -- \\
\hline 19 & alveolus I1 to M2 (max) & I1-M2 & -- \\
\hline 20 & alveolus canine to $\mathrm{M} 2(\max )$ & $\mathrm{C}-\mathrm{M} 2$ & -- \\
\hline 21 & alveolus P1 to M2 (max) & P1-M2 & -- \\
\hline 22 & alveolus $\mathrm{P} 2$ to $\mathrm{M} 2(\max )$ & P2-M2 & -- \\
\hline 23 & alveolus M1 to M2 (max) & M1-M2 & -- \\
\hline 24 & carnassial P4 length (max) & P4 & -- \\
\hline 25 & alveolus I1 to M3 (mand) & I1-M3 & -- \\
\hline 26 & alveolus canine to M3 (mand) & C-M3 & -- \\
\hline 27 & alveolus P1 to M3 (mand) & P1-M3 & -- \\
\hline 28 & alveolus P2 to M3 (mand) & P2-M3 & -- \\
\hline 29 & alveolus P3 to M3 (mand) & P3-M3 & -- \\
\hline 30 & alveolus P4 to M3 (mand) & P4-M3 & -- \\
\hline 31 & alveolus M1 to M3 (mand) & M1-M3 & -- \\
\hline 32 & $\begin{array}{l}\text { length carnassial M1 (mand) } \\
\text { condylo-symphysis length }\end{array}$ & M1 & -- \\
\hline 33 & (mand) & $\mathrm{I} 1-\mathrm{Z}$ & -- \\
\hline 34 & bicondular width (mand) & Y-Y1 & -- \\
\hline 35 & humerus & A-B* & 112.0 \\
\hline 36 & $\begin{array}{l}\text { diameter of humerus head } \\
\text { transverse diameter humerus }\end{array}$ & M-M'* & 30.0 \\
\hline 37 & head & $\mathrm{N}-\mathrm{N}^{\prime} *$ & 19.0 \\
\hline 38 & radius & C-D* & 115.0 \\
\hline 39 & ulna & E-G* & 138.0 \\
\hline 40 & ulnar notch & $\mathrm{F}-\mathrm{G}^{*}$ & 123.0 \\
\hline 41 & femur & $\mathrm{K}-\mathrm{L}^{*}$ & -- \\
\hline 42 & tibia & H-J* & -- \\
\hline 43 & baculum length & $\mathrm{n} / \mathrm{a}$ & -- \\
\hline 44 & baculum width & $\mathrm{n} / \mathrm{a}$ & -- \\
\hline
\end{tabular}




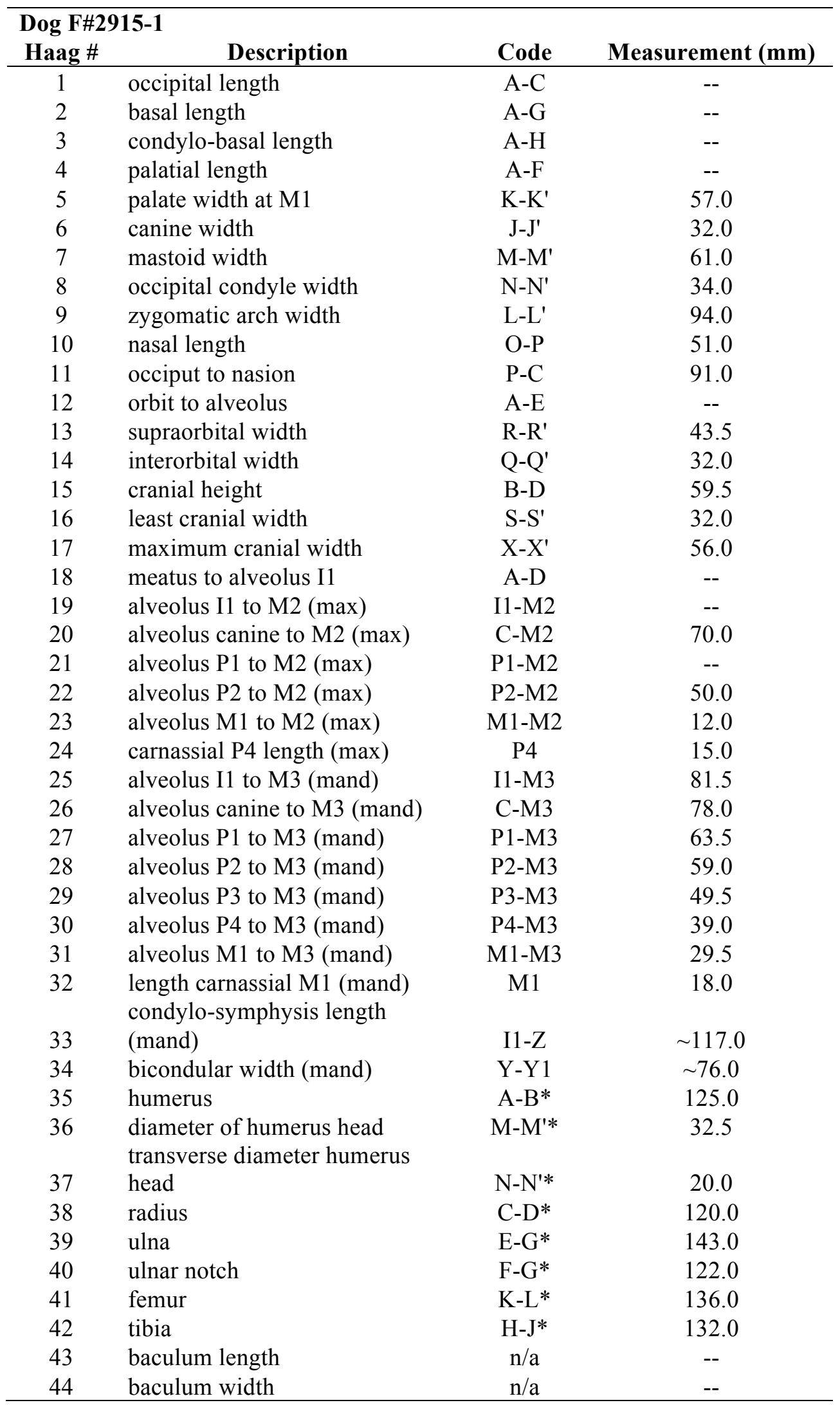




\begin{tabular}{|c|c|c|c|}
\hline Dog F\#3093-1 & Description & Code & Measurement (mm) \\
\hline 1 & occipital length & $\mathrm{A}-\mathrm{C}$ & -- \\
\hline 2 & basal length & $A-G$ & -- \\
\hline 3 & condylo-basal length & A-H & -- \\
\hline 4 & palatial length & A-F & -- \\
\hline 5 & palate width at M1 & $\mathrm{K}-\mathrm{K}^{\prime}$ & -- \\
\hline 6 & canine width & J-J' & -- \\
\hline 7 & mastoid width & M-M' & 61.0 \\
\hline 8 & occipital condyle width & N-N' & 34.0 \\
\hline 9 & zygomatic arch width & L-L' & -- \\
\hline 10 & nasal length & O-P & -- \\
\hline 11 & occiput to nasion & $\mathrm{P}-\mathrm{C}$ & -- \\
\hline 12 & orbit to alveolus & A-E & -- \\
\hline 13 & supraorbital width & R-R' & -- \\
\hline 14 & interorbital width & Q-Q' & -- \\
\hline 15 & cranial height & B-D & -- \\
\hline 16 & least cranial width & S-S' & 37.0 \\
\hline 17 & maximum cranial width & $X-X^{\prime}$ & 59.0 \\
\hline 18 & meatus to alveolus I1 & A-D & -- \\
\hline 19 & alveolus I1 to M2 (max) & I1-M2 & -- \\
\hline 20 & alveolus canine to $\mathrm{M} 2(\max )$ & $\mathrm{C}-\mathrm{M} 2$ & -- \\
\hline 21 & alveolus P1 to M2 (max) & P1-M2 & -- \\
\hline 22 & alveolus P2 to M2 (max) & P2-M2 & -- \\
\hline 23 & alveolus M1 to M2 (max) & M1-M2 & -- \\
\hline 24 & carnassial P4 length (max) & P4 & -- \\
\hline 25 & alveolus I1 to M3 (mand) & I1-M3 & -- \\
\hline 26 & alveolus canine to M3 (mand) & $\mathrm{C}-\mathrm{M} 3$ & -- \\
\hline 27 & alveolus P1 to M3 (mand) & P1-M3 & -- \\
\hline 28 & alveolus P2 to M3 (mand) & P2-M3 & -- \\
\hline 29 & alveolus P3 to M3 (mand) & P3-M3 & -- \\
\hline 30 & alveolus P4 to M3 (mand) & P4-M3 & -- \\
\hline 31 & alveolus M1 to M3 (mand) & M1-M3 & -- \\
\hline 32 & $\begin{array}{l}\text { length carnassial M1 (mand) } \\
\text { condylo-symphysis length }\end{array}$ & M1 & -- \\
\hline 33 & (mand) & $\mathrm{I} 1-\mathrm{Z}$ & -- \\
\hline 34 & bicondular width (mand) & $\mathrm{Y}-\mathrm{Y} 1$ & -- \\
\hline 35 & humerus & A-B* & -- \\
\hline 36 & $\begin{array}{l}\text { diameter of humerus head } \\
\text { transverse diameter humerus }\end{array}$ & M-M'* & -- \\
\hline 37 & head & $\mathrm{N}-\mathrm{N}^{\prime *}$ & -- \\
\hline 38 & radius & C-D* & -- \\
\hline 39 & ulna & E-G* & -- \\
\hline 40 & ulnar notch & F-G* & -- \\
\hline 41 & femur & $\mathrm{K}-\mathrm{L} *$ & -- \\
\hline 42 & tibia & H-J* & -- \\
\hline 43 & baculum length & $\mathrm{n} / \mathrm{a}$ & -- \\
\hline 44 & baculum width & $\mathrm{n} / \mathrm{a}$ & -- \\
\hline
\end{tabular}




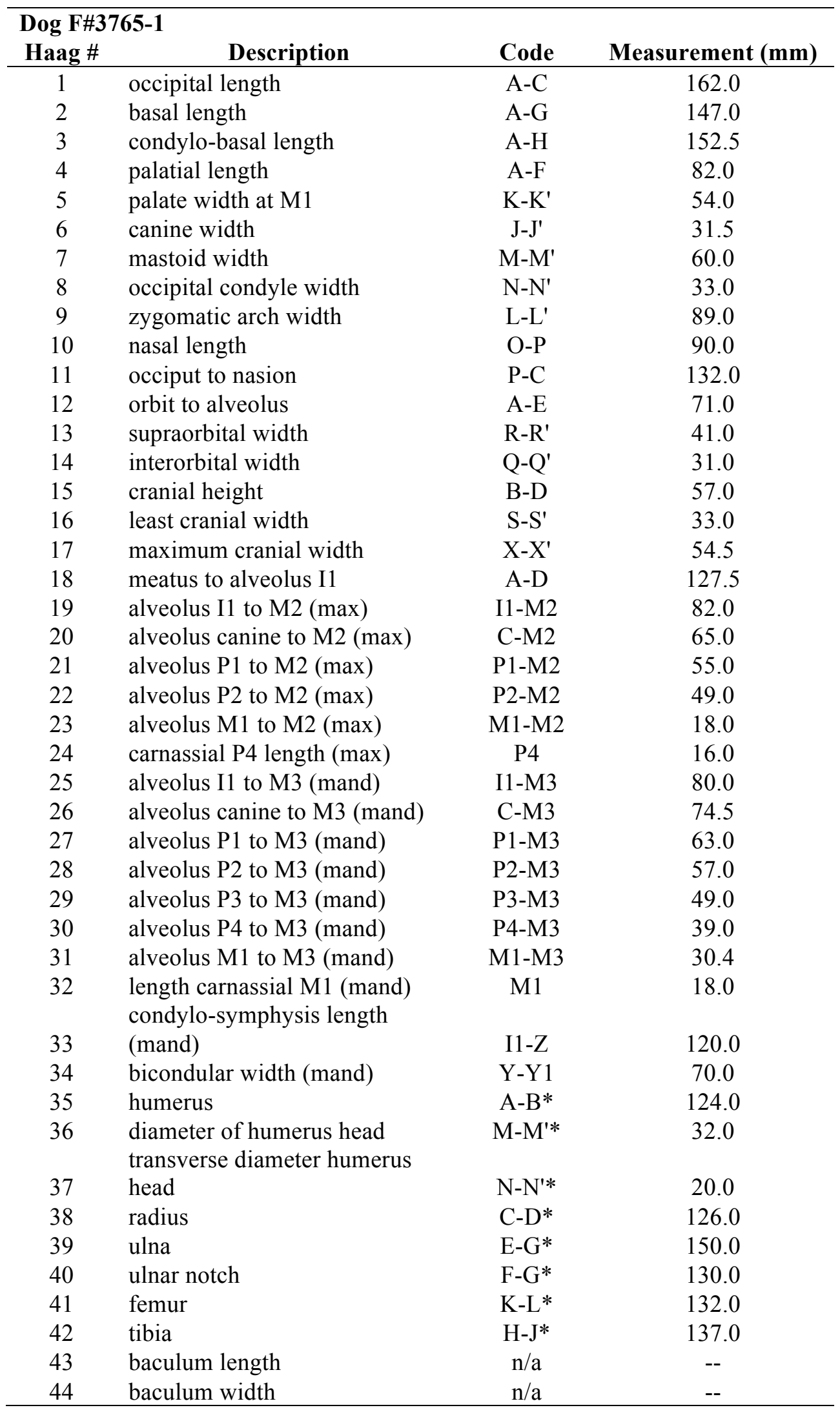




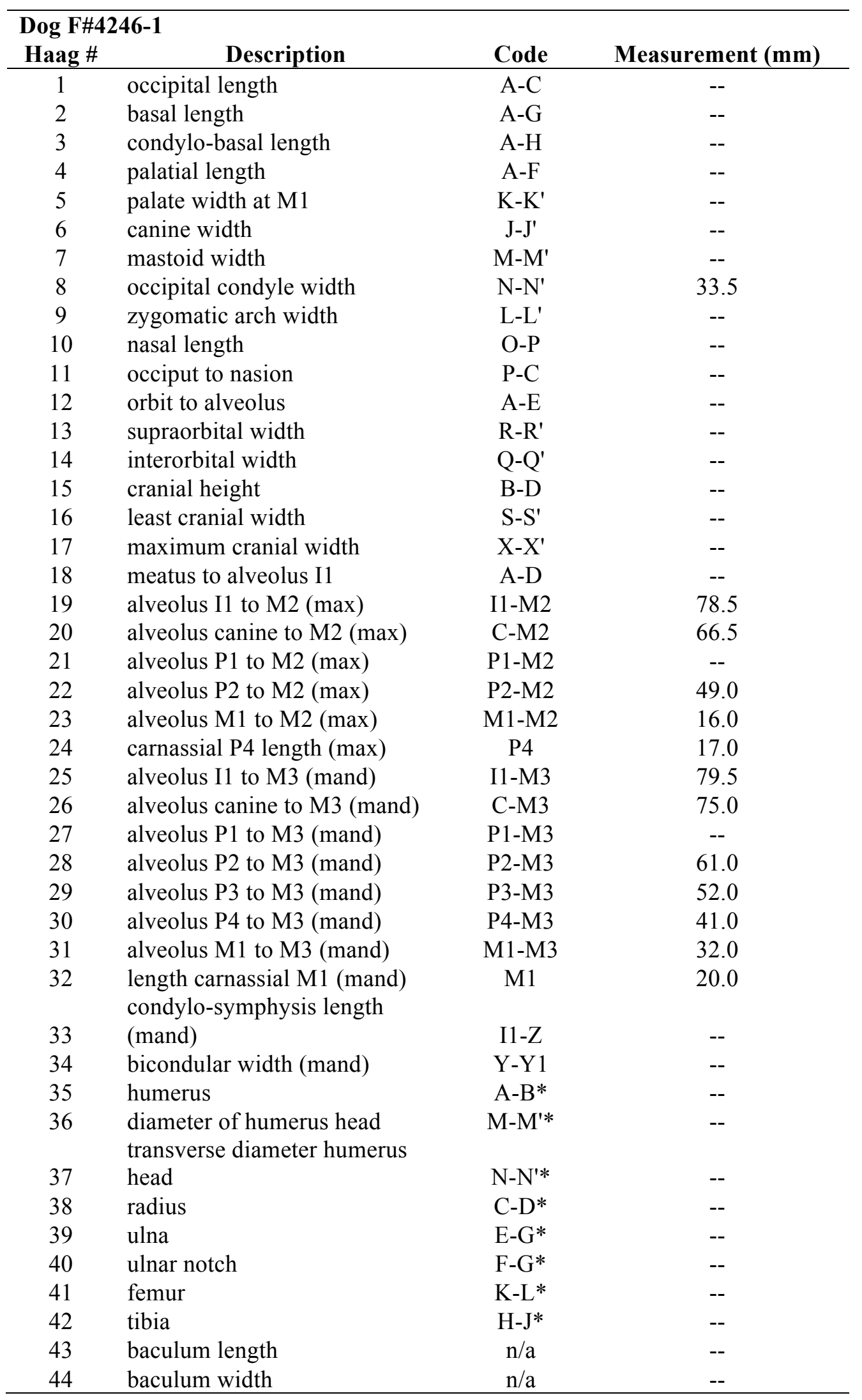




\begin{tabular}{|c|c|c|c|}
\hline $\begin{array}{l}\text { Dog F\#4 } \\
\text { Haag \# }\end{array}$ & Description & Code & Measurement (mm) \\
\hline 1 & occipital length & $\mathrm{A}-\mathrm{C}$ & -- \\
\hline 2 & basal length & $A-G$ & -- \\
\hline 3 & condylo-basal length & A-H & -- \\
\hline 4 & palatial length & $A-F$ & -- \\
\hline 5 & palate width at M1 & $\mathrm{K}-\mathrm{K}^{\prime}$ & -- \\
\hline 6 & canine width & J-J' & -- \\
\hline 7 & mastoid width & M-M' & -- \\
\hline 8 & occipital condyle width & $\mathrm{N}-\mathrm{N}^{\prime}$ & -- \\
\hline 9 & zygomatic arch width & L-L' & -- \\
\hline 10 & nasal length & $\mathrm{O}-\mathrm{P}$ & -- \\
\hline 11 & occiput to nasion & $\mathrm{P}-\mathrm{C}$ & -- \\
\hline 12 & orbit to alveolus & $A-E$ & -- \\
\hline 13 & supraorbital width & R-R' & -- \\
\hline 14 & interorbital width & $Q^{-} Q^{\prime}$ & -- \\
\hline 15 & cranial height & B-D & -- \\
\hline 16 & least cranial width & S-S' & -- \\
\hline 17 & maximum cranial width & $X-X^{\prime}$ & -- \\
\hline 18 & meatus to alveolus I1 & A-D & -- \\
\hline 19 & alveolus I1 to M2 (max) & I1-M2 & -- \\
\hline 20 & alveolus canine to $\mathrm{M} 2(\max )$ & $\mathrm{C}-\mathrm{M} 2$ & 70.5 \\
\hline 21 & alveolus P1 to M2 (max) & P1-M2 & -- \\
\hline 22 & alveolus P2 to M2 (max) & P2-M2 & 51.2 \\
\hline 23 & alveolus M1 to M2 (max) & M1-M2 & 17.0 \\
\hline 24 & carnassial P4 length (max) & P4 & 16.5 \\
\hline 25 & alveolus I1 to M3 (mand) & I1-M3 & -- \\
\hline 26 & alveolus canine to M3 (mand) & C-M3 & 77.0 \\
\hline 27 & alveolus P1 to M3 (mand) & P1-M3 & -- \\
\hline 28 & alveolus P2 to M3 (mand) & P2-M3 & 60.4 \\
\hline 29 & alveolus P3 to M3 (mand) & P3-M3 & 51.0 \\
\hline 30 & alveolus P4 to M3 (mand) & P4-M3 & 41.0 \\
\hline 31 & alveolus M1 to M3 (mand) & M1-M3 & 31.5 \\
\hline 32 & $\begin{array}{l}\text { length carnassial M1 (mand) } \\
\text { condylo-symphysis length }\end{array}$ & M1 & 19.0 \\
\hline 33 & (mand) & $\mathrm{I} 1-\mathrm{Z}$ & -- \\
\hline 34 & bicondular width (mand) & $Y-Y 1$ & -- \\
\hline 35 & humerus & A-B* & 126.0 \\
\hline 36 & $\begin{array}{l}\text { diameter of humerus head } \\
\text { transverse diameter humerus }\end{array}$ & $\mathrm{M}-\mathrm{M}^{\prime *}$ & 34.0 \\
\hline 37 & head & $\mathrm{N}-\mathrm{N}^{\prime} *$ & 24.0 \\
\hline 38 & radius & C-D* & 129.0 \\
\hline 39 & ulna & E-G* & -- \\
\hline 40 & ulnar notch & F-G* & -- \\
\hline 41 & femur & $\mathrm{K}-\mathrm{L}^{*}$ & $\sim 140.0$ \\
\hline 42 & tibia & H-J* & 141.0 \\
\hline 43 & baculum length & $\mathrm{n} / \mathrm{a}$ & -- \\
\hline 44 & baculum width & $\mathrm{n} / \mathrm{a}$ & -- \\
\hline
\end{tabular}




\begin{tabular}{|c|c|c|c|}
\hline Dog F\#5010-1 & Description & Code & Measurement (mm) \\
\hline 1 & occipital length & $\mathrm{A}-\mathrm{C}$ & -- \\
\hline 2 & basal length & $A-G$ & -- \\
\hline 3 & condylo-basal length & $\mathrm{A}-\mathrm{H}$ & -- \\
\hline 4 & palatial length & A-F & -- \\
\hline 5 & palate width at M1 & K-K' & -- \\
\hline 6 & canine width & $\mathrm{J}-\mathrm{J}^{\prime}$ & -- \\
\hline 7 & mastoid width & M-M' & -- \\
\hline 8 & occipital condyle width & N-N' & -- \\
\hline 9 & zygomatic arch width & L-L' & -- \\
\hline 10 & nasal length & $\mathrm{O}-\mathrm{P}$ & -- \\
\hline 11 & occiput to nasion & $\mathrm{P}-\mathrm{C}$ & -- \\
\hline 12 & orbit to alveolus & A-E & -- \\
\hline 13 & supraorbital width & $\mathrm{R}^{-\mathrm{R}^{\prime}}$ & -- \\
\hline 14 & interorbital width & $Q^{-} Q^{\prime}$ & -- \\
\hline 15 & cranial height & B-D & -- \\
\hline 16 & least cranial width & S-S' & -- \\
\hline 17 & maximum cranial width & $X-X^{\prime}$ & -- \\
\hline 18 & meatus to alveolus I1 & A-D & -- \\
\hline 19 & alveolus I1 to M2 (max) & I1-M2 & -- \\
\hline 20 & alveolus canine to M2 (max) & $\mathrm{C}-\mathrm{M} 2$ & -- \\
\hline 21 & alveolus P1 to M2 (max) & $\mathrm{P} 1-\mathrm{M} 2$ & -- \\
\hline 22 & alveolus P2 to M2 (max) & P2-M2 & -- \\
\hline 23 & alveolus M1 to M2 (max) & M1-M2 & -- \\
\hline 24 & carnassial P4 length (max) & P4 & -- \\
\hline 25 & alveolus I1 to M3 (mand) & I1-M3 & -- \\
\hline 26 & alveolus canine to M3 (mand) & $\mathrm{C}-\mathrm{M} 3$ & -- \\
\hline 27 & alveolus P1 to M3 (mand) & P1-M3 & -- \\
\hline 28 & alveolus P2 to M3 (mand) & P2-M3 & -- \\
\hline 29 & alveolus P3 to M3 (mand) & P3-M3 & -- \\
\hline 30 & alveolus P4 to M3 (mand) & P4-M3 & -- \\
\hline 31 & alveolus M1 to M3 (mand) & M1-M3 & -- \\
\hline 32 & $\begin{array}{l}\text { length carnassial M1 (mand) } \\
\text { condylo-symphysis length }\end{array}$ & M1 & -- \\
\hline 33 & (mand) & $\mathrm{I} 1-\mathrm{Z}$ & -- \\
\hline 34 & bicondular width (mand) & $\mathrm{Y}-\mathrm{Y} 1$ & -- \\
\hline 35 & humerus & A-B* & -- \\
\hline 36 & $\begin{array}{l}\text { diameter of humerus head } \\
\text { transverse diameter humerus }\end{array}$ & $\mathrm{M}-\mathrm{M}^{\prime *}$ & -- \\
\hline 37 & head & $\mathrm{N}-\mathrm{N}^{\prime} *$ & -- \\
\hline 38 & radius & C-D* & -- \\
\hline 39 & ulna & E-G* & -- \\
\hline 40 & ulnar notch & $\mathrm{F}-\mathrm{G}^{*}$ & -- \\
\hline 41 & femur & $\mathrm{K}-\mathrm{L}^{*}$ & 140.0 \\
\hline 42 & tibia & H-J* & -- \\
\hline 43 & baculum length & $\mathrm{n} / \mathrm{a}$ & -- \\
\hline 44 & baculum width & $\mathrm{n} / \mathrm{a}$ & -- \\
\hline
\end{tabular}




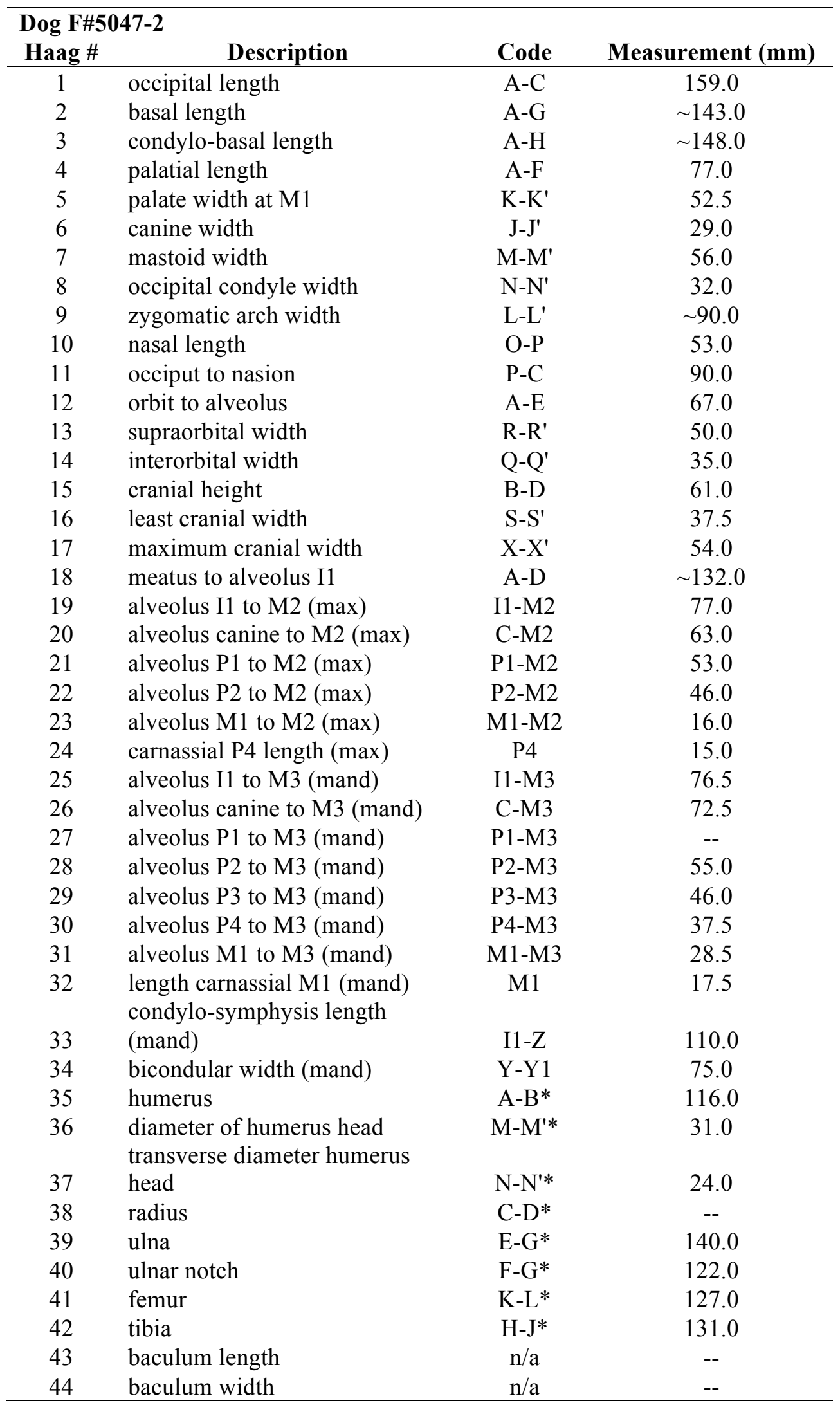




\begin{tabular}{|c|c|c|c|}
\hline $\begin{array}{l}\text { Dog F\#5 } \\
\text { Haag \# }\end{array}$ & Description & Code & Measurement (mm) \\
\hline 1 & occipital length & $\mathrm{A}-\mathrm{C}$ & 149.0 \\
\hline 2 & basal length & $A-G$ & 131.0 \\
\hline 3 & condylo-basal length & $\mathrm{A}-\mathrm{H}$ & 136.0 \\
\hline 4 & palatial length & A-F & 75.0 \\
\hline 5 & palate width at M1 & K-K' & 54.5 \\
\hline 6 & canine width & $\mathrm{J}-\mathrm{J}^{\prime}$ & 30.0 \\
\hline 7 & mastoid width & M-M' & 55.0 \\
\hline 8 & occipital condyle width & $\mathrm{N}-\mathrm{N}^{\prime}$ & 28.0 \\
\hline 9 & zygomatic arch width & L-L' & -- \\
\hline 10 & nasal length & $\mathrm{O}-\mathrm{P}$ & 43.0 \\
\hline 11 & occiput to nasion & $\mathrm{P}-\mathrm{C}$ & 85.0 \\
\hline 12 & orbit to alveolus & A-E & $\sim 65.0$ \\
\hline 13 & supraorbital width & R-R' & 45.0 \\
\hline 14 & interorbital width & $Q^{-} Q^{\prime}$ & 75.0 \\
\hline 15 & cranial height & B-D & 57.0 \\
\hline 16 & least cranial width & S-S' & 37.5 \\
\hline 17 & maximum cranial width & $X-X^{\prime}$ & 54.0 \\
\hline 18 & meatus to alveolus I1 & A-D & 120.0 \\
\hline 19 & alveolus I1 to M2 (max) & I1-M2 & 80.0 \\
\hline 20 & alveolus canine to $\mathrm{M} 2(\max )$ & $\mathrm{C}-\mathrm{M} 2$ & 65.0 \\
\hline 21 & alveolus P1 to M2 (max) & P1-M2 & 56.0 \\
\hline 22 & alveolus P2 to M2 (max) & P2-M2 & 50.0 \\
\hline 23 & alveolus M1 to M2 (max) & M1-M2 & 17.0 \\
\hline 24 & carnassial P4 length (max) & P4 & 15.5 \\
\hline 25 & alveolus I1 to M3 (mand) & I1-M3 & -- \\
\hline 26 & alveolus canine to M3 (mand) & $\mathrm{C}-\mathrm{M} 3$ & -- \\
\hline 27 & alveolus P1 to M3 (mand) & P1-M3 & -- \\
\hline 28 & alveolus P2 to M3 (mand) & P2-M3 & -- \\
\hline 29 & alveolus P3 to M3 (mand) & P3-M3 & -- \\
\hline 30 & alveolus P4 to M3 (mand) & P4-M3 & -- \\
\hline 31 & alveolus M1 to M3 (mand) & M1-M3 & -- \\
\hline 32 & $\begin{array}{l}\text { length carnassial M1 (mand) } \\
\text { condylo-symphysis length }\end{array}$ & M1 & -- \\
\hline 33 & (mand) & $\mathrm{I} 1-\mathrm{Z}$ & -- \\
\hline 34 & bicondular width (mand) & $\mathrm{Y}-\mathrm{Y} 1$ & -- \\
\hline 35 & humerus & A-B* & -- \\
\hline 36 & $\begin{array}{l}\text { diameter of humerus head } \\
\text { transverse diameter humerus }\end{array}$ & $\mathrm{M}-\mathrm{M}^{\prime *}$ & -- \\
\hline 37 & head & $\mathrm{N}-\mathrm{N}^{\prime *}$ & -- \\
\hline 38 & radius & $\mathrm{C}-\mathrm{D}^{*}$ & -- \\
\hline 39 & ulna & E-G* & -- \\
\hline 40 & ulnar notch & F-G* & -- \\
\hline 41 & femur & $\mathrm{K}-\mathrm{L}^{*}$ & -- \\
\hline 42 & tibia & H-J* & -- \\
\hline 43 & baculum length & $\mathrm{n} / \mathrm{a}$ & -- \\
\hline 44 & baculum width & $\mathrm{n} / \mathrm{a}$ & -- \\
\hline
\end{tabular}




\begin{tabular}{|c|c|c|c|}
\hline \multicolumn{3}{|c|}{ Dog F\#5263-1 } & \multirow[b]{2}{*}{ Measurement $(\mathrm{mm})$} \\
\hline Haag \# & Description & Code & \\
\hline 1 & occipital length & $\mathrm{A}-\mathrm{C}$ & -- \\
\hline 2 & basal length & $A-G$ & -- \\
\hline 3 & condylo-basal length & A-H & -- \\
\hline 4 & palatial length & A-F & -- \\
\hline 5 & palate width at M1 & K-K' & 52.0 \\
\hline 6 & canine width & $\mathrm{J}-\mathrm{J}^{\prime}$ & -- \\
\hline 7 & mastoid width & M-M' & 59.0 \\
\hline 8 & occipital condyle width & $\mathrm{N}-\mathrm{N}^{\prime}$ & 31.5 \\
\hline 9 & zygomatic arch width & L-L' & -- \\
\hline 10 & nasal length & $\mathrm{O}-\mathrm{P}$ & -- \\
\hline 11 & occiput to nasion & $\mathrm{P}-\mathrm{C}$ & 89.0 \\
\hline 12 & orbit to alveolus & A-E & -- \\
\hline 13 & supraorbital width & R-R' & 42.5 \\
\hline 14 & interorbital width & Q-Q' & 30.3 \\
\hline 15 & cranial height & B-D & 59.5 \\
\hline 16 & least cranial width & S-S' & 34.5 \\
\hline 17 & maximum cranial width & $X-X^{\prime}$ & 53.0 \\
\hline 18 & meatus to alveolus I1 & A-D & -- \\
\hline 19 & alveolus I1 to M2 (max) & I1-M2 & -- \\
\hline 20 & alveolus canine to $\mathrm{M} 2(\max )$ & C-M2 & 65.0 \\
\hline 21 & alveolus P1 to M2 (max) & P1-M2 & -- \\
\hline 22 & alveolus P2 to M2 (max) & P2-M2 & 49.5 \\
\hline 23 & alveolus M1 to M2 (max) & M1-M2 & 18.0 \\
\hline 24 & carnassial P4 length (max) & P4 & 17.0 \\
\hline 25 & alveolus I1 to M3 (mand) & I1-M3 & -- \\
\hline 26 & alveolus canine to M3 (mand) & C-M3 & -- \\
\hline 27 & alveolus P1 to M3 (mand) & P1-M3 & -- \\
\hline 28 & alveolus P2 to M3 (mand) & P2-M3 & -- \\
\hline 29 & alveolus P3 to M3 (mand) & P3-M3 & -- \\
\hline 30 & alveolus P4 to M3 (mand) & P4-M3 & -- \\
\hline 31 & alveolus M1 to M3 (mand) & M1-M3 & -- \\
\hline 32 & $\begin{array}{l}\text { length carnassial M1 (mand) } \\
\text { condylo-symphysis length }\end{array}$ & M1 & -- \\
\hline 33 & (mand) & $\mathrm{I} 1-\mathrm{Z}$ & -- \\
\hline 34 & bicondular width (mand) & $\mathrm{Y}-\mathrm{Y} 1$ & -- \\
\hline 35 & humerus & A-B* & -- \\
\hline 36 & $\begin{array}{l}\text { diameter of humerus head } \\
\text { transverse diameter humerus }\end{array}$ & M-M'* & -- \\
\hline 37 & head & $\mathrm{N}-\mathrm{N}^{\prime *}$ & -- \\
\hline 38 & radius & C-D* & -- \\
\hline 39 & ulna & E-G* & -- \\
\hline 40 & ulnar notch & F-G* & -- \\
\hline 41 & femur & $\mathrm{K}-\mathrm{L}^{*}$ & -- \\
\hline 42 & tibia & H-J* & -- \\
\hline 43 & baculum length & $\mathrm{n} / \mathrm{a}$ & -- \\
\hline 44 & baculum width & $\mathrm{n} / \mathrm{a}$ & -- \\
\hline
\end{tabular}




\begin{tabular}{|c|c|c|c|}
\hline $\begin{array}{l}\text { Dog F\#5 } \\
\text { Haag \# }\end{array}$ & Description & Code & Measurement (mm) \\
\hline 1 & occipital length & $\mathrm{A}-\mathrm{C}$ & -- \\
\hline 2 & basal length & $A-G$ & -- \\
\hline 3 & condylo-basal length & $\mathrm{A}-\mathrm{H}$ & -- \\
\hline 4 & palatial length & $A-F$ & 85.0 \\
\hline 5 & palate width at M1 & K-K' & 56.0 \\
\hline 6 & canine width & $\mathrm{J}-\mathrm{J}^{\prime}$ & 34.0 \\
\hline 7 & mastoid width & M-M' & -- \\
\hline 8 & occipital condyle width & $\mathrm{N}-\mathrm{N}^{\prime}$ & -- \\
\hline 9 & zygomatic arch width & L-L' & -- \\
\hline 10 & nasal length & $\mathrm{O}-\mathrm{P}$ & -- \\
\hline 11 & occiput to nasion & $\mathrm{P}-\mathrm{C}$ & -- \\
\hline 12 & orbit to alveolus & $A-E$ & -- \\
\hline 13 & supraorbital width & $\mathrm{R}^{-\mathrm{R}^{\prime}}$ & -- \\
\hline 14 & interorbital width & $Q^{-} Q^{\prime}$ & -- \\
\hline 15 & cranial height & B-D & -- \\
\hline 16 & least cranial width & S-S' & -- \\
\hline 17 & maximum cranial width & $X-X^{\prime}$ & -- \\
\hline 18 & meatus to alveolus I1 & A-D & -- \\
\hline 19 & alveolus I1 to M2 (max) & I1-M2 & 86.5 \\
\hline 20 & alveolus canine to M2 (max) & $\mathrm{C}-\mathrm{M} 2$ & 70.5 \\
\hline 21 & alveolus P1 to M2 (max) & $\mathrm{P} 1-\mathrm{M} 2$ & 59.0 \\
\hline 22 & alveolus P2 to M2 (max) & P2-M2 & 2.0 \\
\hline 23 & alveolus M1 to M2 (max) & M1-M2 & 18.5 \\
\hline 24 & carnassial P4 length (max) & P4 & 17.0 \\
\hline 25 & alveolus I1 to M3 (mand) & I1-M3 & $\sim 82.0$ \\
\hline 26 & alveolus canine to M3 (mand) & C-M3 & 80.0 \\
\hline 27 & alveolus P1 to M3 (mand) & P1-M3 & 65.0 \\
\hline 28 & alveolus P2 to M3 (mand) & P2-M3 & 58.0 \\
\hline 29 & alveolus P3 to M3 (mand) & P3-M3 & 51.0 \\
\hline 30 & alveolus P4 to M3 (mand) & P4-M3 & 42.0 \\
\hline 31 & alveolus M1 to M3 (mand) & M1-M3 & 32.0 \\
\hline 32 & $\begin{array}{l}\text { length carnassial M1 (mand) } \\
\text { condylo-symphysis length }\end{array}$ & M1 & 20.0 \\
\hline 33 & (mand) & $\mathrm{I} 1-\mathrm{Z}$ & -- \\
\hline 34 & bicondular width (mand) & $\mathrm{Y}-\mathrm{Y} 1$ & -- \\
\hline 35 & humerus & A-B* & -- \\
\hline 36 & $\begin{array}{l}\text { diameter of humerus head } \\
\text { transverse diameter humerus }\end{array}$ & $\mathrm{M}-\mathrm{M}^{\prime *}$ & -- \\
\hline 37 & head & $\mathrm{N}-\mathrm{N}^{\prime} *$ & -- \\
\hline 38 & radius & $\mathrm{C}-\mathrm{D} *$ & -- \\
\hline 39 & ulna & E-G* & -- \\
\hline 40 & ulnar notch & F-G* & -- \\
\hline 41 & femur & $\mathrm{K}-\mathrm{L}^{*}$ & -- \\
\hline 42 & tibia & H-J* & -- \\
\hline 43 & baculum length & $\mathrm{n} / \mathrm{a}$ & -- \\
\hline 44 & baculum width & $\mathrm{n} / \mathrm{a}$ & -- \\
\hline
\end{tabular}




\begin{tabular}{|c|c|c|c|}
\hline $\begin{array}{l}\text { Dog F\#5 } \\
\text { Haag \# }\end{array}$ & Description & Code & Measurement (mm) \\
\hline 1 & occipital length & $\mathrm{A}-\mathrm{C}$ & -- \\
\hline 2 & basal length & $A-G$ & -- \\
\hline 3 & condylo-basal length & A-H & -- \\
\hline 4 & palatial length & $A-F$ & -- \\
\hline 5 & palate width at M1 & K-K' & 58.5 \\
\hline 6 & canine width & J-J' & -- \\
\hline 7 & mastoid width & M-M' & -- \\
\hline 8 & occipital condyle width & $\mathrm{N}-\mathrm{N}^{\prime}$ & 32.0 \\
\hline 9 & zygomatic arch width & L-L' & -- \\
\hline 10 & nasal length & $\mathrm{O}-\mathrm{P}$ & -- \\
\hline 11 & occiput to nasion & $\mathrm{P}-\mathrm{C}$ & 91.0 \\
\hline 12 & orbit to alveolus & $A-E$ & -- \\
\hline 13 & supraorbital width & R-R' & -- \\
\hline 14 & interorbital width & $Q^{-} Q^{\prime}$ & 45.0 \\
\hline 15 & cranial height & B-D & 63.0 \\
\hline 16 & least cranial width & S-S' & 37.0 \\
\hline 17 & maximum cranial width & $X-X^{\prime}$ & 50.0 \\
\hline 18 & meatus to alveolus I1 & A-D & -- \\
\hline 19 & alveolus I1 to M2 (max) & I1-M2 & -- \\
\hline 20 & alveolus canine to $\mathrm{M} 2(\max )$ & $\mathrm{C}-\mathrm{M} 2$ & -- \\
\hline 21 & alveolus P1 to M2 (max) & P1-M2 & -- \\
\hline 22 & alveolus P2 to M2 (max) & P2-M2 & -- \\
\hline 23 & alveolus M1 to M2 (max) & M1-M2 & -- \\
\hline 24 & carnassial P4 length (max) & P4 & -- \\
\hline 25 & alveolus I1 to M3 (mand) & I1-M3 & -- \\
\hline 26 & alveolus canine to M3 (mand) & C-M3 & -- \\
\hline 27 & alveolus P1 to M3 (mand) & P1-M3 & -- \\
\hline 28 & alveolus P2 to M3 (mand) & P2-M3 & -- \\
\hline 29 & alveolus P3 to M3 (mand) & P3-M3 & -- \\
\hline 30 & alveolus P4 to M3 (mand) & P4-M3 & -- \\
\hline 31 & alveolus M1 to M3 (mand) & M1-M3 & -- \\
\hline 32 & $\begin{array}{l}\text { length carnassial M1 (mand) } \\
\text { condylo-symphysis length }\end{array}$ & M1 & -- \\
\hline 33 & (mand) & $\mathrm{I} 1-\mathrm{Z}$ & -- \\
\hline 34 & bicondular width (mand) & $Y-Y 1$ & -- \\
\hline 35 & humerus & A-B* & -- \\
\hline 36 & $\begin{array}{l}\text { diameter of humerus head } \\
\text { transverse diameter humerus }\end{array}$ & $\mathrm{M}-\mathrm{M}^{\prime *}$ & -- \\
\hline 37 & head & $\mathrm{N}-\mathrm{N}^{\prime} *$ & -- \\
\hline 38 & radius & C-D* & -- \\
\hline 39 & ulna & E-G* & -- \\
\hline 40 & ulnar notch & F-G* & -- \\
\hline 41 & femur & $\mathrm{K}-\mathrm{L}^{*}$ & -- \\
\hline 42 & tibia & H-J* & -- \\
\hline 43 & baculum length & $\mathrm{n} / \mathrm{a}$ & -- \\
\hline 44 & baculum width & $\mathrm{n} / \mathrm{a}$ & -- \\
\hline
\end{tabular}




\begin{tabular}{|c|c|c|c|}
\hline \multicolumn{2}{|c|}{ Dog F\#5586-1 } & Code & Measurement (mm) \\
\hline 1 & occipital length & $\mathrm{A}-\mathrm{C}$ & -- \\
\hline 2 & basal length & $A-G$ & -- \\
\hline 3 & condylo-basal length & A-H & -- \\
\hline 4 & palatial length & A-F & -- \\
\hline 5 & palate width at M1 & K-K' & -- \\
\hline 6 & canine width & $\mathrm{J}-\mathrm{J}^{\prime}$ & -- \\
\hline 7 & mastoid width & M-M' & -- \\
\hline 8 & occipital condyle width & $\mathrm{N}-\mathrm{N}^{\prime}$ & -- \\
\hline 9 & zygomatic arch width & L-L' & -- \\
\hline 10 & nasal length & $\mathrm{O}-\mathrm{P}$ & -- \\
\hline 11 & occiput to nasion & $\mathrm{P}-\mathrm{C}$ & -- \\
\hline 12 & orbit to alveolus & A-E & -- \\
\hline 13 & supraorbital width & R-R' & -- \\
\hline 14 & interorbital width & $Q^{-} Q^{\prime}$ & -- \\
\hline 15 & cranial height & B-D & -- \\
\hline 16 & least cranial width & S-S' & -- \\
\hline 17 & maximum cranial width & $X-X^{\prime}$ & -- \\
\hline 18 & meatus to alveolus I1 & A-D & -- \\
\hline 19 & alveolus I1 to M2 (max) & I1-M2 & -- \\
\hline 20 & alveolus canine to $\mathrm{M} 2(\max )$ & $\mathrm{C}-\mathrm{M} 2$ & -- \\
\hline 21 & alveolus P1 to M2 (max) & P1-M2 & -- \\
\hline 22 & alveolus P2 to M2 (max) & P2-M2 & -- \\
\hline 23 & alveolus M1 to M2 (max) & M1-M2 & -- \\
\hline 24 & carnassial P4 length (max) & P4 & -- \\
\hline 25 & alveolus I1 to M3 (mand) & I1-M3 & -- \\
\hline 26 & alveolus canine to M3 (mand) & $\mathrm{C}-\mathrm{M} 3$ & -- \\
\hline 27 & alveolus P1 to M3 (mand) & P1-M3 & -- \\
\hline 28 & alveolus P2 to M3 (mand) & P2-M3 & -- \\
\hline 29 & alveolus P3 to M3 (mand) & P3-M3 & -- \\
\hline 30 & alveolus P4 to M3 (mand) & P4-M3 & -- \\
\hline 31 & alveolus M1 to M3 (mand) & M1-M3 & -- \\
\hline 32 & $\begin{array}{l}\text { length carnassial M1 (mand) } \\
\text { condylo-symphysis length }\end{array}$ & M1 & -- \\
\hline 33 & (mand) & $\mathrm{I} 1-\mathrm{Z}$ & -- \\
\hline 34 & bicondular width (mand) & $\mathrm{Y}-\mathrm{Y} 1$ & -- \\
\hline 35 & humerus & A-B* & -- \\
\hline 36 & $\begin{array}{l}\text { diameter of humerus head } \\
\text { transverse diameter humerus }\end{array}$ & $\mathrm{M}-\mathrm{M}^{\prime *}$ & -- \\
\hline 37 & head & $\mathrm{N}-\mathrm{N}^{\prime} *$ & -- \\
\hline 38 & radius & $\mathrm{C}-\mathrm{D}^{*}$ & 136.0 \\
\hline 39 & ulna & E-G* & -- \\
\hline 40 & ulnar notch & F-G* & -- \\
\hline 41 & femur & $\mathrm{K}-\mathrm{L} *$ & 147.0 \\
\hline 42 & tibia & H-J* & 145.0 \\
\hline 43 & baculum length & $\mathrm{n} / \mathrm{a}$ & $\sim 72.0$ \\
\hline 44 & baculum width & $\mathrm{n} / \mathrm{a}$ & -- \\
\hline
\end{tabular}

